\title{
Regulation of cardiac long-chain fatty acid and glucose utilization : studies with cardiomyocytes from genetically manipulated mice
}

Citation for published version (APA):

Habets, D. D. J. (2008). Regulation of cardiac long-chain fatty acid and glucose utilization : studies with cardiomyocytes from genetically manipulated mice. [Doctoral Thesis, Maastricht University]. Datawyse / Universitaire Pers Maastricht. https://doi.org/10.26481/dis.20081208dh

Document status and date:

Published: 01/01/2008

DOI:

10.26481/dis.20081208dh

Document Version:

Publisher's PDF, also known as Version of record

Please check the document version of this publication:

- A submitted manuscript is the version of the article upon submission and before peer-review. There can be important differences between the submitted version and the official published version of record.

People interested in the research are advised to contact the author for the final version of the publication, or visit the DOI to the publisher's website.

- The final author version and the galley proof are versions of the publication after peer review.

- The final published version features the final layout of the paper including the volume, issue and page numbers.

Link to publication

\footnotetext{
General rights rights.

- You may freely distribute the URL identifying the publication in the public portal. please follow below link for the End User Agreement:

www.umlib.nl/taverne-license

Take down policy

If you believe that this document breaches copyright please contact us at:

repository@maastrichtuniversity.nl

providing details and we will investigate your claim.
}

Copyright and moral rights for the publications made accessible in the public portal are retained by the authors and/or other copyright owners and it is a condition of accessing publications that users recognise and abide by the legal requirements associated with these

- Users may download and print one copy of any publication from the public portal for the purpose of private study or research.

- You may not further distribute the material or use it for any profit-making activity or commercial gain

If the publication is distributed under the terms of Article 25fa of the Dutch Copyright Act, indicated by the "Taverne" license above, 


\section{Regulation of cardiac long-chain fatty acid
and glucose utilization:
studies with cardiomyocytes from genetically manipulated mice Regulation of cardiac long-chain fatty acid
and glucose utilization:
studies with cardiomyocytes from genetically manipulated mice Regulation of cardiac long-chain fatty acid
and glucose utilization:
studies with cardiomyocytes from genetically manipulated mice Regulation of cardiac long-chain fatty acid
and glucose utilization:
studies with cardiomyocytes from genetically manipulated mice}

C

更


This studies presented in this thesis were performed at the Department of Molecular Genetics, Cardiovascular Research Institute Maastricht (CARIM), Maastricht University, the Netherlands

(C) copyright Daphna D.J. Habets, Maastricht 2008

ISBN: $\quad 978-90-5278-775-6$

Cover design: Daphna D.J. Habets

Printed by: Datawyse / Universitaire Pers Maastricht 


\title{
Regulation of cardiac long-chain fatty acid and glucose utilization:
}

studies with cardiomyocytes from genetically manipulated mice

\author{
Proefschrift
}

\begin{abstract}
ter verkrijging van de graad doctor aan de Universiteit Maastricht, op gezag van de Rector Magnificus, Prof. mr. G.P.M.F. Mols, volgens het besluit van het College van Decanen, in het openbaar te verdedigen op maandag 8 december 2008 om 16.00 uur
\end{abstract}

$$
\text { door }
$$

Daphna Diane Joost Habets

geboren op 25 mei 1981 te Maastricht

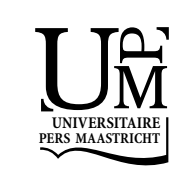




\section{Promotores:}

Prof. dr. J.FC. Glatz

Prof. dr. A. Bonen

University of Guelph, Canada

\section{Co-promotor:}

Dr. J.J.F.P. Luiken

\section{Beoordelingscommissie:}

Prof. dr. F.C.S. Ramaekers

Voorzitter

Prof. dr. L. Bertrand

Univesité catholique de Louvain, Brussels

Prof. dr. B. Kiens

University of Copenhagen, Denmark

Dr. P. Schrauwen

Prof. dr. C. Stehouwer

The studies presented in this thesis were supported by a grant of the Netherlands Organization for Scientific Research (ZonMw), project 912-04-075.

Financial support by the Netherlands Heart foundation and the Diabetes Foundation for publication of this thesis were gratefully acknowledged. Printing of this thesis was also financially supported by the J.E. Jurriaanse Stichting and AB Diets, Woerden. 


\section{Contents}

\section{Chapter 1}

Introduction

\section{Chapter 2}

Oligomycin as tool to mimic contraction signaling to metabolism in cardiomyocytes

\section{Chapter 3}

AMPK-mediated increase in myocardial long-chain fatty acid uptake critically depends on sarcolemmal CD36

\section{Chapter 4}

Crucial role for LKB1 to AMPK $\alpha 2$ axis in the regulation of CD36-mediated long-chain fatty acid uptake into cardiomyocytes: comparison with GLUT4mediated glucose uptake

\section{Chapter 5}

AICAR stimulates long-chain fatty acid uptake and oxidation in mouse heart independent of CD36

\section{Chapter 6}

Munc18c is not rate-limiting for glucose and long-chain fatty acid uptake in the heart

\section{Chapter 7}

General discussion

Summary / Samenvatting 



\author{
Introduction
}

\title{
CHAPTER 1 \\ CHAPTER 1 \\ 1
}

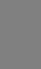

$-$

$\ln$

\author{
Introduction
}

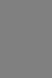

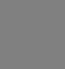

(1)

(1)

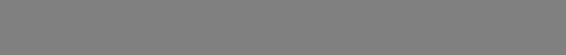

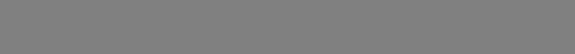

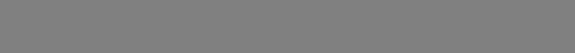

-

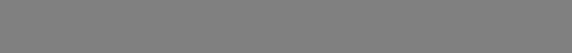

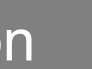

(2) 


\section{Introduction}

The heart is an adaptive organ for pumping blood, responding to changing needs by modifying contractile strength and beating rate. The cardiomyocyte is the principal cell of the heart; it coordinates and performs contraction and has the capability to sense a large number of hormonal, neural, electrical and mechanical inputs. In addition, cardiomyocytes are also target for an extraordinary number of metabolic changes, because of the critical need to regulate ATP concentrations.

The human heart uses between 3.5 and $5 \mathrm{~kg}$ of ATP every day to keep pumping [1]. Although constant ATP provision is required for cardiac contraction and all associated essential processes, such as calcium uptake by the sarcoplasmic reticulum, most of the ATP produced by the heart is dissipated. Minimal amounts of ATP are used for: active transport by the sodium-potassium pump, the actual generation of the action potential, and the conduction of the cardiac impulse. Even lower amounts of ATP are needed to phosphorylate proteins or to form cyclic AMP, for the futile cycles of glycogen and triacylglycerol turnover, for mitochondrial calcium uptake and release, and protein synthesis. Thus, the actual energy liberated by ATP hydrolysis is largely converted to heat, and approximately $25 \%$ of the ATP is actually converted into mechanical work [1].

To produce ATP, the heart requires a continuous supply of both oxygen and specific fuels to meet increases in energy need (e.g., increased workload). Glucose and lactate are the predominant carbohydrates utilized, and long-chain fatty acids (LCFA) are the key lipids oxidized [2, 3]. However, both at rest and during increased workload, LCFA (60-70\%) oxidation is the principal route for ATP synthesis with glucose (20-30\%) being used to a lesser extent [3-5]. While in the healthy heart there is a distinctive and very finely tuned balance between the utilization of these metabolic substrates, in chronic cardiac disease this balance is altered. In some diseases (e.g., cardiac hypertrophy and failure) [6-8] glucose utilization is markedly increased, while in other pathologies (e.g., diabetic cardiomyopathy) [9-11] LCFA utilization is greatly favoured. Recent studies support the concept that changes in cardiac metabolism may play a causal role in the development of cardiac diseases. Optimizing myocardial energy metabolism and thereby manipulating the balance of energy utilization could be of therapeutic benefit [12]. Therefore, understanding the regulation of cardiac metabolism in the healthy heart could be promising to help identify therapeutic targets to rectify a disruption of the cardiac substrate balance occurring in chronic cardiac diseases.

This thesis describes new insights in the mechanism of cellular substrate uptake and its regulation by signal transduction pathways, and discusses their significance for myocardial energy homeostasis. This introduction aims to present the reader with background information to comprehend the studies performed in this thesis. 


\section{Substrate uptake and their transporters}

It is known that both LCFA and glucose are mainly supplied from extracellular sources to the heart (and also to skeletal muscle), because the heart possesses a limited storage capacity for LCFA and glucose [13]. Hence, sarcolemmal transport might be an important step in the metabolism of substrate uptake [12], and could provide another key point regulatory side next to the regulation of mitochondrial oxidation according to the Randle cycle [14]. The uptake of both LCFA and glucose appears to be dependent on a substrate gradient across the plasma membrane, which in turn, is dependent on the metabolic rate of the respective tissue. The heart, having a relatively high metabolic rate, has a steep inwardly direct gradient for LCFA and glucose. Upon their uptake, both substrates are rapidly covalently linked to highenergy moieties, resulting in their trapping and maintenance of the substrate gradient. Before uptake these substrates need to pass the selectively permeable lipid bilayer of cardiomyocytes. Because of its hydrophilic nature, glucose is unable to pass the lipid bilayer of the plasma membrane by passive diffusion. Therefore, glucose transport across the plasma membrane is largely a protein-mediated process $[15,16]$. The molecular process of LCFA transport is more controversial due to the biophysical properties of LCFA. The hydrophobic properties of LCFA do not rule out the possibility of passive diffusion [17, 18], however, evidence for proteinmediated LCFA transport across the plasma membrane is accumulating [19, 20]. In the earlier days, this evidence was provided by the saturation kinetics of LCFA uptake, sensitivity to inhibitors of protein-mediated transport, and sensitivity to competitive inhibition [20,21]. More recently, evidence for protein-mediated LCFA transport has been provided from experimental work in transfected cell lines, and from studies with genetically manipulated animals [22, 23]. The integrated view is that both mechanisms contribute to LCFA uptake, but at least in the heart, the bulk of LCFA uptake is regulated by protein-mediated transport. In addition, distinct LCFA binding and LCFA transport proteins have been identified and were found to be crucial for cardiac LCFA uptake [20,21]. The potential physiological importance of protein-mediated transmembrane transport is that it would represent a site of control, allowing changes in the presence and/or activity of these membrane proteins to regulate not only glucose uptake, as has been discovered in the early eighties, but similarly also regulate cellular LCFA uptake [12].

\section{Protein-mediated long-chain fatty acid uptake}

The membrane-associated proteins involved in cardiac LCFA uptake are putative fatty acid translocase/CD36 (CD36), plasma membrane fatty acid-binding protein (FABPpm), and the isoforms of the fatty acid-transport protein family (FATP1, FATP4 and FATP6) [20]. These proteins function in trapping of LCFA from 
extracellular donors, whereafter LCFA cross the cell membrane either in un-ionized form by a flip-flop mechanism through the lipid bilayer (passive diffusion) or through a channel formed from (homo- or heterotrimeric) complexes of these membrane-associated proteins (facilitated diffusion). However, the membrane topology of the various membrane proteins is still unclear so that the exact nature whereby each of these proteins acts on LCFA uptake is not yet known [24-26] (Fig. $1.1)$.

\section{LCFA}

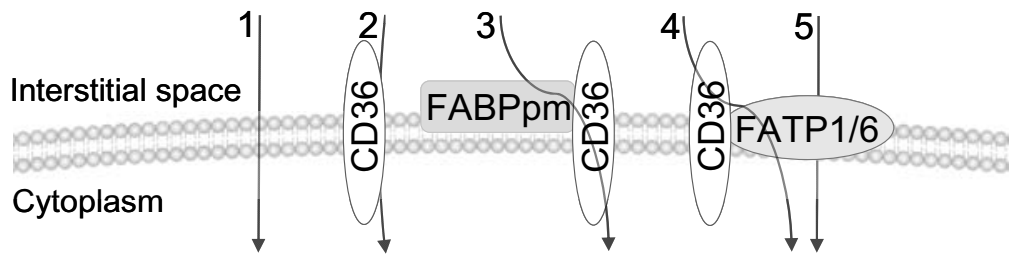

Figure 1.1 Schematic representation of the mechanism of LCFA uptake into cardiomyocytes The proposed mechanisms for transmembrane transport of long-chain fatty acids (LCFA) are illustrated by numbers 1-5. Because of their hydrophobic nature LCFA could cross the membrane by passive diffusion (1). However, the majority of LCFA uptake is dependent on the presence of fatty acid translocase/CD36 (CD36). It is not yet clear whether CD36 binds LCFA at the cell surface alone (2), or that it operates in conjunction with the plasma membrane fatty acid-binding protein (FABPpm) (3) to increase the transport of LCFA across the sarcolemma. CD36 might also serve in trapping LCFA close to the plasma membrane to supply fatty acid-transport protein 1 and/or 6 (FATP 1 and FATP6) (4) with LCFA which in turn transfer this substrate directly across the plasma membrane, or FATP1/6 itself (5) is sufficient to increase LCFA influx.

\section{CD36}

An 88 -kDa adipocyte membrane protein was identified by covalent labeling with $\mathrm{N}$ sulfosuccinimidyl esters of LCFA, which irreversibly inhibited LCFA transport by $75 \%$ [30, 31]. Subsequently, Abumrad et al. [32] cloned fatty acid translocase (FAT), the sequence of which was $85 \%$ homologous with that of glycoprotein IV (CD36). This $88-\mathrm{kDa}$ integral membrane protein known as FAT/CD36 or CD36 [32], is a heavily glycosylated integral membrane protein with two transmembrane domains, two short cytoplasmic tails and an extracellular domain. This structure makes it likely that CD36 operates mainly through trapping of LCFA to the plasma membrane. Consequently, accumulation of LCFA close to the cell surface will create a local diffusional gradient across the plasma membrane, or alternatively facilitates the flip-flop of LCFA across the bilayer [33-35]. 
CD36, when expressed in cells normally lacking this protein, can bind LCFA with high affinity which resulted in increased rates of LCFA uptake [36, 37]. Specific inhibition of CD36 with sulfo- $N$-succinimidyl esters of LCFA, e.g., sulfo- $N$ succinimidyl oleate (SSO) or sulfo- $N$-succinimidyl palmitate (SSP), provided pharmacological evidence for the notion that CD36 is responsible for the majority of LCFA uptake [30, 38, 39]. Many other studies have documented that CD36 is a key LCFA transporter in metabolically important tissues. CD36 is mainly expressed in tissues that prefer LCFA utilization, e.g., heart, red skeletal muscle, and adipocytes. In CD36 null mice the basal uptake rates of fatty analogs were significantly reduced in heart (50-80\%), skeletal muscle (40-75\%), and adipose tissue (60-70\%) [40]. Reduced LCFA uptake in CD36 null mice also lowered the rates of LCFA oxidation and LCFA incorporation into intramyocellular triacylglycerols in muscle and heart [40-42]. Muscle-specific overexpression of CD36 has shown that LCFA oxidation was increased in this tissue, but only during muscle contraction, not at rest [43].

\section{FABPpm}

Plasma membrane-associated fatty acid-binding protein (FABPpm) was identified in the heart by Stremmel [44]. Analysis of its amino acid sequences showed FABPpm to be identical to mitochondrial aspartate aminotransferase (mAspAt) [45]. Apparently, FABPpm/mAspAt is a protein with distinct functions at different subcellular sites. FABPpm is a $43-\mathrm{kDa}$ peripheral membrane protein anchored with its hydrophobic tail to the outer leaflet of the plasma membrane [45]. Since FABPpm is a peripheral membrane protein, this protein is not expected to operate as a classical channel for LCFA, but rather it could be involved in the trapping of LCFA close to the cell surface. This LCFA trapping could be sufficient for facilitation of LCFA transport, because of the generation of locally steep outwardto-inward LCFA gradients. Additionally, FABPpm could cooperate with (an) other protein(s) to facilitate the transport of LCFA across the plasma membrane.

Similar to CD36, FABPpm can bind LCFA with high affinity, and a higher expression of FABPpm results in increased LCFA uptake rates [46, 47]. In addition, LCFA uptake rates were inhibited by antibodies directed against FABPpm [48]. It remains to be established whether FABPpm alone is effective for increasing LCFA transport rates or that FABPpm may function in conjunction with other LCFA transporters, particularly CD36, as these proteins co-immunoprecipitate [27]. Based on kinetic evidence, it has been suggested that both FABPpm and CD36 function as two components of one LCFA transport system, in which FABPpm serves as a receptor for LCFA, and then interacts with $\mathrm{CD} 36$, which, on its turn, mediates the transmembrane passage of LCFA [20, 27, 48, 49]. 


\section{FATP1-6}

A family of fatty acid-transport proteins (FATPs) has been implicated in facilitating LCFA as well [50]. FATPs are integral membrane proteins with several transmembrane domains [51]. It has been shown that these LCFA transporters additionally possess long-chain acyl-CoA synthase activity, which could be beneficial for so called vectorial LCFA uptake. Thus, the extra enzymatic activity would cause rapid trapping of the substrate without decline of the outward-toinward LCFA gradient [52]. Six members of the FATP family (FATP1-6) have been identified and are expressed in a tissue-specific manner [28, 53, 54]. FATP1 and FATP4 are expressed in adipose tissue, heart and skeletal muscle while FATP6 appears to be exclusively expressed in the heart. Since FATP1 and FATP6 are associated with the sarcolemma and colocalize with CD36, the proposed models either envision that CD36 and FATPs act together [28, 29], possibly by transferring LCFA from CD36 to FATPs at the plasma membrane, or alternatively FATPs transfer LCFA directly across the plasma membrane [55].

Genetically manipulated mice with cardiac-specific overexpression of FATP1 demonstrated a fourfold increase in LCFA uptake [10]. This was associated with a twofold increase in cardiomyocyte lipid accumulation and LCFA metabolism, as well as cardiac dysfunction with pathophysiological findings similar to those in diabetic cardiomyopathy [10]. FATP6 is principally expressed in the heart where it is the predominant FATP family member [28]. Stably expressing human FATP6 in a cell line enhanced uptake of LCFA and indicates that the FATP6 isoform is more important than FATP1 for LCFA uptake [28]. However, there is some debate as to the whether FATP6 has a transport role in the heart [56].

\section{Glucose transporter-mediated glucose uptake}

A family of specific glucose transporter (GLUT1-12) proteins has been identified and these transporters were found to show a tissue specific distribution. In the heart, skeletal muscle and adipose tissue two glucose transport proteins are present, namely GLUT1 and GLUT4, of which GLUT4 is most abundant. GLUT1 is mainly present at the sarcolemma, and is largely responsible for basal glucose uptake [57, 58]. However, GLUT4 is located in intracellular storage compartments from where it can be recruited to the plasma membrane upon insulin stimulation and elevated contractile activity. At the cell surface, GLUT4 functions in achieving altered rates of glucose uptake [15, 59].

GLUT4 is critical for postprandial glucose disposal, and results from several knockout and transgenic mouse models support the hypothesis that GLUT4 plays a key role in whole-body glucose homeostasis. For example, in the diabetic $\mathrm{db} / \mathrm{db}$ mouse model, overexpression of the human GLUT4 gene protected these animals from insulin resistance and diabetes [60]. Interestingly, the global GLUT4 
homozygous knockout mouse showed a less severe phenotype with respect to glucose homeostasis than heterozygous GLUT4 $^{+/-}$animals, most likely due to compensatory mechanisms in the homozygous condition [61, 62]. In addition, the GLUT4 knockout animals showed many severe defects, including decreased life spans and growth retardation, as well as cardiac and adipose tissue abnormalities, further complicating interpretations regarding glucose homeostasis. The heterozygous GLUT4 ${ }^{+-}$mice, however, are insulin resistant and predisposed to developing diabetes [61, 62]. Interestingly, in the hearts of $\mathrm{db} / \mathrm{db}$ mice and of GLUT4 knockout mice, defects in glucose homeostasis lead to an enhanced LCFA oxidation [63-65]. This shows that the heart possesses an enormous metabolic flexibility, namely that the heart is able to switch to another substrate depending on its availability.

\section{Regulation of substrate uptake by signaling pathways}

As was first identified for GLUT4, also LCFA transporters have been found to be present in intracellular compartments as well as at the sarcolemma. The sarcolemmal pool forms the functional pool of these transporters, whereas the intracellular pools are used as the storage depot. Regulation of substrate transport can occur via the translocation of transporter proteins from these intracellular depots to the sarcolemma. At the cell surface, these transporters function in achieving altered rates of LCFA and glucose uptake [12, 20].

In the heart, the two main physiological stimuli to enhance substrate uptake are insulin and contraction. Insulin and contraction induce transporter translocation concomitant with substrate uptake acutely, i.e., within minutes [66, 67]. Although both stimuli enhance the abundance of sarcolemmal LCFA and glucose transporters simultaneously, their signaling pathways appear to be distinct. Several key players, mainly protein kinase B (PKB)/Akt and AMP-activated protein kinase (AMPK) are potential candidates to be involved in the insulin and contraction signaling pathways, respectively. These signaling events ultimately result in the activation of the so-called trafficking machinery which is responsible for migration of cargo from one compartment to the other, and vice versa. Regulation of this transport needs to be unidirectional and extremely specific to ensure that vesicles containing cargo (e.g., CD36 and/or GLUT4) destined for the plasma membrane do not fuse randomly with membranes from other organelles [68]. The studies in this thesis focus on the signaling and trafficking mechanisms involved in stimulation of substrate uptake by (i) insulin, and by (ii) contraction. For this, these pathways will be discussed in more detail in the next paragraphs. 


\section{Insulin signaling pathway}

Insulin is known as a regulatory hormone for whole-body and cellular glucose homeostasis. Circulating insulin stimulates glucose uptake in the heart and skeletal muscle by the recruitment of intracellularly stored GLUT4 to the sarcolemma [67]. It has been established that insulin is also capable of increasing LCFA uptake in these muscle tissues [67]. This effect of insulin was attributable to the translocation of CD36 from storage compartments to the sarcolemma (Table 1.1), in a similar manner as has been observed for GLUT4. Since the eighties, the insulin-derived signaling pathways have been subject to intensive investigations, and includes insulin binding to, and activation of its receptor followed by docking of insulin receptor substrates and activation of the regulatory subunit p85 of phosphatidylinositol-3-kinase (PI3K) $[69,70]$ as depicted in Fig. 1.2. Blocking PI3K with its inhibitors (wortmannin and LY-294002) prevented both the insulininduced GLUT4-mediated glucose uptake and CD36-mediated LCFA uptake in cardiomyocytes [67]. This suggests that glucose and LCFA uptake are similarly regulated by PI3K activity. Downstream, PI3K catalyses the formation of phosphatidylinositol-3,4,5-triphosphate $\left(\mathrm{PI}(3,4,5) \mathrm{P}_{3}\right)$, which, in turn, leads to the activation of atypical protein kinase $\mathrm{C}(\mathrm{aPKC})-\lambda / \zeta$ and of PKB/Akt. Thereafter, $\mathrm{PKB} / \mathrm{Akt}$ and the PKCs contribute in parallel to insulin-induced GLUT4 translocation [71-74]. Whether similar downstream targets of PI3K are required for CD36-mediated LCFA uptake by insulin remains largely unidentified [67], but $\mathrm{PKB} / \mathrm{Akt}$ is likely involved [75]. The direct downstream target of PKB/Akt in insulin-stimulated GLUT4 translocation has been identified in a screen for putative substrates possessing the PKB/Akt regulatory motif [76]. Of these, the RabGTPase-activating protein (GAP) Akt substrate of $160-\mathrm{kDa}$ (AS160) participates in GLUT4 translocation to the plasma membrane [77, 78], presumably through its recently identified targets Rab2, Rab8, Rab10 and/or Rab 14 [79]. Hence, AS160 is an interesting player in insulin-induced GLUT4 translocation, in that it connects signaling pathways to trafficking pathways. Additionally, a PI3K-independent pathway involving c-Cbl associated protein (CAP), Cbl and the GTPase TC10 could regulate GLUT4 translocation [80], as observed in adipocytes [81]. The importance of this pathway in heart and muscle is still a matter of debate.

Insulin-regulated GLUT4 trafficking can be divided into two discrete steps: 1) movement of GLUT4-containing vesicles close to the plasma membrane; and 2) docking and fusion of these vesicles with the plasma membrane. The first step likely involves an interaction of GLUT4 storage vesicles with the cytoskeleton. Several recent studies have shown a role for microtubule-associated motor proteins $[82,83]$ as well as an actin-associated myosin in GLUT4 trafficking to the plasma membrane [84]. The nature of the insulin-regulated association of GLUT4 storage vesicles with these structures remains to be defined. The second step includes the 


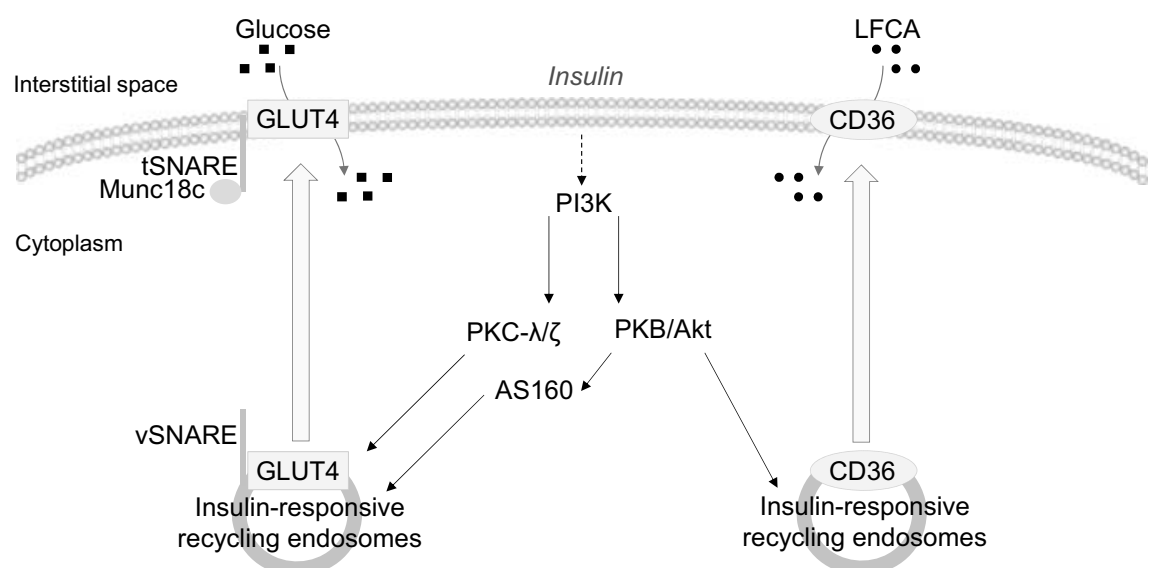

Figure 1.2 The Insulin signaling pathway involved in substrate uptake into cardiomyocytes Insulin-stimulated activation of phosphatidylinositol-3-kinase (PI3K) and subsequently protein kinase B (PKB)/Akt as well as the atypical protein kinase $\mathrm{C}(\mathrm{PKC})-\lambda$ and $-\zeta$, are required for glucose transporter 4 (GLUT4) mobilization from recycling endosomes to the sarcolemma. A recently identified downstream target of PKB/Akt is AS160. Phosphorylated AS160 results in a reposition of Munc18c on target soluble $N$-ethylmaleimide-sensitive factor attachment protein receptors (tSNARE) proteins leading to a more active conformation, allowing vesicle SNARE (vSNARE) protein binding and subsequent docking and fusion of GLUT4. Also insulin-dependent translocation of fatty acid translocase/CD36 (CD36) is dependent on activation of PKB/Akt, however, downstream events are unknown. Increased abundance of GLUT4 and CD36 at sarcolemma elevates the glucose and longchain fatty acid (LCFA) uptake rates into cardiomyocytes, respectively.

fusion and docking of GLUT4 containing vesicles with the plasma membrane. Several vesicle soluble $N$-ethylmaleimide-sensitive factor attachment protein receptors (vSNARE), including vesicle-associated membrane protein 2 (VAMP2), which is located on the GLUT4 storage vesicles, play an important role in exocytosis of these vesicles $[85,86]$. VAMP2 helps to guide the vesicles to the plasma membrane docking site, which consists of the target SNAREs (tSNARE) syntaxin 4 and 23-kDA synaptosomal-associated protein (SNAP23) [87]. SNAREs can form a core complex, a major regulatory feature in the formation of this is the ability of syntaxin to flip between two different conformations [88]. Several syntaxin-binding proteins have been identified as possible regulators of this conformational switch. Some of these are members of the Sec1p/Munc18 (SM) family of proteins [89]. The structure of the Munc18/syntaxin complex demonstrates that the SM protein cradles syntaxin in its inactive closed conformation in the absence of insulin, thus rendering docking and fusion as a major rate-determining step in GLUT4's presentation at the cell surface. Insulin, 
through activation of Akt, results in the phosphorylation of AS160, which disables its GAP activity and results in GTP loading of its cognate Rab protein [76, 78]. The GTP-loaded Rab may subsequently bind to Munc18c resulting in a reposition of Munc18c on syntaxin4 [90]. Syntaxin4 can then flip into a more active conformation, allowing GLUT4 storage vesicles to dock and fuse with the plasma membrane [91]. Taken altogether, increasing numbers of trafficking proteins are being implicated in insulin-induced GLUT4 translocation. However, the search for CD36 trafficking proteins has not yet started. In this respect it would be interesting to examine whether GLUT4 trafficking and CD36 trafficking after insulinstimulation depends on the same trafficking machinery. In case different trafficking proteins might be involved in CD36 translocation compared to GLUT4 translocation, these proteins might present novel targets to modulate cardiac substrate preference.

\section{Contraction signaling pathway}

The continuous contractile function of the heart muscle requires that cardiomyocytes produce large amounts of ATP. This high ATP demand is met primarily by the utilization of LCFA and glucose. AMPK has been established as a key player involved in cardiac energy homeostasis. Generally, AMPK activation results in activation of catabolic pathways (such as LCFA and glucose oxidation) and de-activation of anabolic pathways (such as LCFA and glucose storage) [92]. In the heart, AMPK is assumed to be involved in the translocation of CD36 and GLUT4 based on an association of AMPK activation by contraction and a corresponding increase in LCFA and glucose uptake, respectively [66]. Because of these metabolic consequences of AMPK, up- and downstream targets of AMPK are also likely candidates that may regulate substrate transport in the heart (Fig. 1.3). AMPK is a heterotrimeric protein consisting of a catalytic $\alpha$ subunit and two regulatory subunits $\beta$ and $\gamma$. Different isoforms of each subunit have been identified. Both AMPK $\alpha 1$ and AMPK $\alpha 2$ are expressed in the heart, of which $\alpha 2$ is the predominant subunit [93]. Activation of the AMPK complex occurs mainly via AMP by three independent mechanisms: (i) promotion of phosphorylation of Thr172 within the $\alpha$ subunit by upstream kinases, (ii) allosteric activation of the phosphorylated enzyme, and (iii) inhibition of dephosphorylation of Thr172 by protein phosphatases [94]. Indeed under conditions that favour a rapid increase in intracellular AMP, such as during increased contractile activity [95] or during a period of ischemia [96, 97], AMPK becomes activated in the heart.

Upstream kinases [LKB1 and calmodulin-dependent protein kinase kinase $\alpha$ and $\beta$ $(\mathrm{CaMKK})][92,98]$ and downstream targets of AMPK [acetyl-CoA carboxylase (ACC) and AS160] [99, 100] have been suggested to be involved in regulating substrate uptake and oxidation. In vivo, the upstream kinases LKB1 and CaMKK $\beta$ 


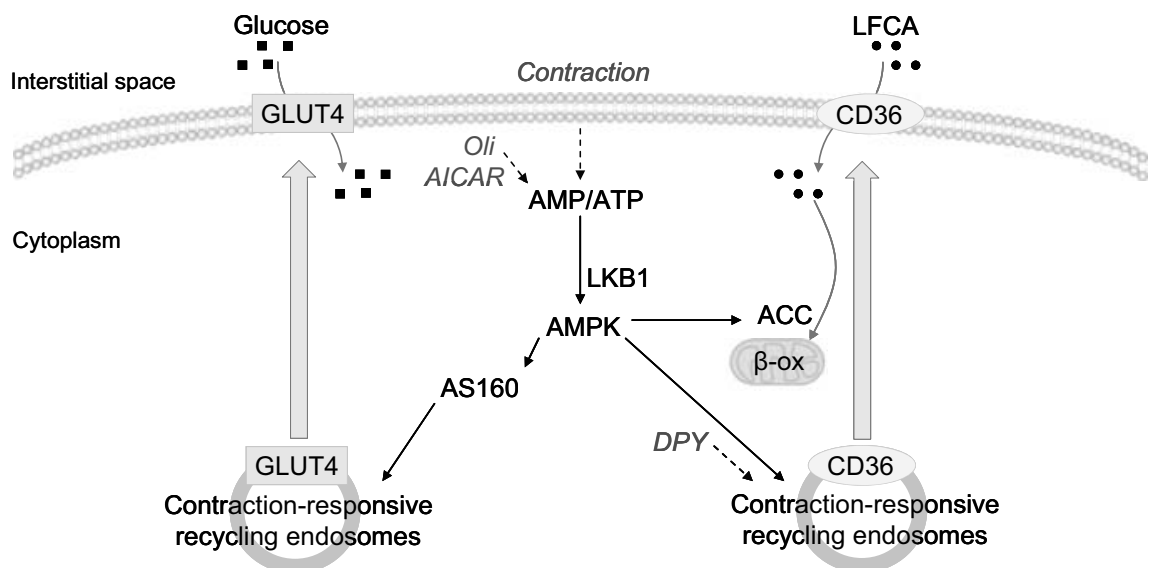

Figure 1.3 The contraction signaling pathway involved in substrate uptake into cardiomyocytes Increased contractile activity results in a temporary increase in the AMP/ATP ratio, which induces a conformational change within AMP-activated protein kinase (AMPK) to make it accessible for phosphorylation by LKB1. Downstream of AMPK, AS160 is involved in glucose transporter 4 (GLUT4)-mediated glucose uptake, the role of AS160 in fatty acid translocase/CD36 (CD36)-mediated long-chain fatty acids (LCFA) uptake is not yet known. AMPK also activates another downstream target, acetyl-CoA carboxylase (ACC), which results in a de-inhibition of LCFA influx into the mitochondria and subsequent elevate LCFA oxidation ( $\beta$-ox). Treatment of cardiomyocytes with oligomycin (Oli) or 5-aminoimidazole-4-carboxamide ribonucleoside (AICAR) results in activation of AMPK and mimics the metabolic effects of contraction. Separately, dipyridamole (DPY) activates an unknown protein kinase downstream of AMPK specifically leading to elevated CD36-mediated LCFA uptake rate.

each are regulated differently. In muscle tissue, $\mathrm{CaMKK} \beta$ is activated by an increase in intracellular $\mathrm{Ca}^{2+}$ [98]. In contrast, LKB1 is constitutively active [101], but it can only activate AMPK during conditions at which intracellular AMP is elevated. Namely, AMP-binding to AMPK induces a conformational change within the AMPK complex so that Thr172 becomes accessible to phosphorylation by LKB1 [102]. Whether CaMKK $\beta$ regulates contraction-stimulated glucose uptake in muscle via AMPK activation remains controversial [102, 103]. However, in LKB1 knockout mice, contraction-stimulated glucose uptake by muscle was reduced [104], as was LCFA oxidation [105]. With respect to regulation of LCFA oxidation, AMPK-mediated phosphorylation of ACC at Ser79 is a crucial event. Ser79 phosphorylation is inhibitory to this enzyme, which leads to a reduction of intracellular malonyl-CoA and the de-inhibition of carnitine palmitoyltransferase-I, thereby increasing mitochondrial LCFA oxidation [106]. An interesting novel target of AMPK is the Rab GTPase-activating protein AS160, which is involved in 
contraction-stimulated glucose uptake into skeletal muscle [100] in an AMPK $\alpha 2$ dependent manner [107, 108]. Collectively, these studies have implicated upstream AMPK kinases and downstream targets of AMPK in the regulation of glucose uptake into skeletal muscle. It has been established that AMPK is involved in cardiac substrate uptake, however, no studies have yet been undertaken to investigate whether the upstream kinases, LKB1 and CaMKK, and downstream target, AS160, are involved in the regulation of cardiac substrate uptake. It has been suggested that in insulin-induced GLUT4 translocation AS160 is involved in the activation of the trafficking machinery. Therefore, it could be speculated that AS160 is also involved in the contraction-induced trafficking of GLUT4 and presumably CD36, however, this process is completely unknown. Again, AS160 could provide the link between signaling and trafficking in contraction-induced substrate uptake, as has been shown for insulin-induced substrate uptake (see previous section). Whether the contraction-dedicated trafficking machinery involved in GLUT4 translocation or CD36 translocation encompasses the same trafficking protein types/isoforms involved insulin-induced GLUT4 or CD36 translocation, needs further investigation.

Pharmacological agents are commonly used to activate AMPK, including 5aminoimidazole-4-carboxamide ribonucleoside (AICAR) $[109,110]$ and the $\mathrm{F}_{1} \mathrm{~F}_{0^{-}}$ ATPase inhibitor oligomycin [66, 111]. At appropriate concentrations these agents stimulate LCFA and glucose uptake into cardiomyocytes, by inducing the translocation of LCFA (Table 1.1) and glucose transporters to the sarcolemma suggesting that indeed AMPK is activated by these pharmacological agents [66, 112-114]. Importantly, the effects of AICAR and oligomycin on LCFA and glucose uptake in cardiomyocytes are not additive to that of contraction, suggesting that the signaling pathways activated by these agents converge with the contraction signaling pathway to induce CD36 and GLUT4 translocation [66]. Another contraction-mimetic agent is dipyridamole, because, just like oligomycin and AICAR, it stimulates LCFA uptake into cardiomyocytes in a non-additive manner to contraction [115]. In contrast to oligomycin and AICAR, dipyridamole does not activate AMPK nor does it stimulate glucose uptake, suggesting that this compound acts on a component in the contraction pathway to CD36 translocation downstream of AMPK [115]. This indicates a hypothetical branch point in signaling to separately regulate CD36 and GLUT4 translocation. 
Table 1.1 Effects of physiological and pharmacological stimuli on LCFA transporter abundance at the sarcolemma

\begin{tabular}{lcclcc}
\hline Stimulus & \multicolumn{5}{c}{ LCFA transporter } \\
\cline { 2 - 6 } & CD36 & FABPpm & FATP1 & FATP4 & FATP6 \\
\hline Insulin & + & - & - & n.k. & n.k. \\
Contraction & + & n.k. & n.k. & n.k. & n.k. \\
AICAR & + & + & - & n.k. & n.k. \\
Oligomycin & + & n.k. & n.k. & n.k. & n.k. \\
\hline
\end{tabular}

The main regulatory mechanism of long-chain fatty acid (LCFA) uptake is the abundance of LCFA transporters at the sarcolemma at the expense of intracellular storage compartments. Fatty acid translocase/CD36 (CD36) relocates towards the sarcolemma, as seen upon insulin treatment and during contraction, 5-aminoimidazole-4-carboxamide ribonucleoside (AICAR) treatment, and oligomycin treatment. The plasma membrane fatty acid-binding protein (FABPpm) translocates by AICAR but not by insulin stimulation. For fatty acid-transport protein 1, 4 and 6 (FATP1, FATP4 and FATP6) this mechanism has not yet been determined, not known (n.k).

\section{Aim of this thesis}

The heart is capable of utilizing a variety of metabolic substrates and is able to rapidly adapt its substrate utilization in the face of changes in substrate need and supply. For example, during exercise the metabolic state is characterized by elevated circulation of lipids, from lipolysis in adipose tissue [5, 116, 117], which competes with glucose at the heart [4]. However, in diabetes and obesity elevated circulating LCFA and triacylglycerols can lead to cardiac lipid accumulation and excessive LCFA metabolism. Recent studies suggest that the alterations in cardiac LCFA metabolism that occur in diabetes and obesity may play a causal role in the development of cardiomyopathies [118, 119]. In contrast, the development of pathologic cardiac hypertrophy and cardiac failure is characterized by a gradual decrease in LCFA utilization, partly compensated for by increased glucose utilization [2, 7, 120] (Fig. 1.4). These observations led to the notion that a disruption of the cardiac substrate balance and cardiac pathology appear invariably linked [12]. The pathways involved in LCFA and glucose metabolism are subject to a complex regulation that is not completely understood. Hence, it is of crucial importance to gain insight in the mechanism of LCFA and glucose metabolism in the healthy heart. Understanding these pathways could be of importance in finding targets to rectify cardiac substrate balance in situation in which altered metabolism contributes to the severity of cardiac abnormalities. The studies described in this thesis, therefore, explore the role of transporter proteins and signal transduction pathways in the regulation of LCFA and glucose uptake in the heart. 


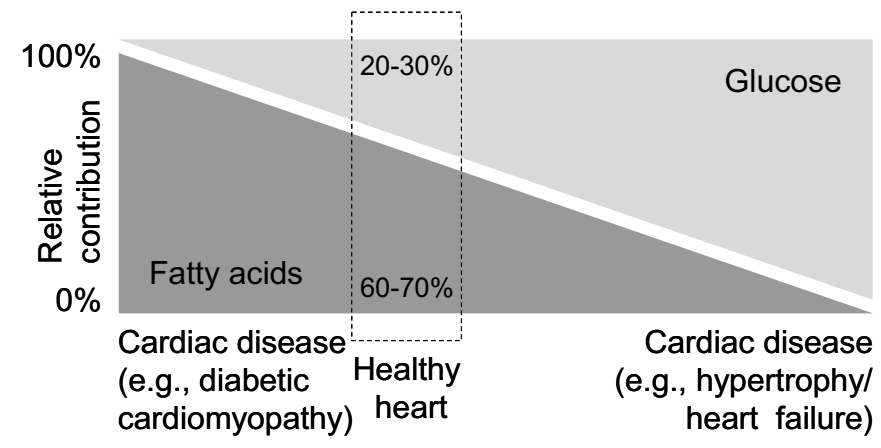

Figure 1.4 Cardiac long-chain fatty acid and glucose utilization in health and disease Schematic presentation of the concept of balance of fuels for the heart, illustrating that an optimal cardiac function appears related to a certain set point of the balance between the relative contribution of long-chain fatty acids and glucose to total energy production, and that a shift from this set point, either towards increased utilization of long-chain fatty acid or glucose, is associated with cardiac disease, e.g., diabetic cardiomyopathy or hypertrophy and heart failure, respectively.

\section{Experimental model: isolated mouse cardiomyocytes in suspension}

Cardiomyocytes, the predominant muscle cell of the heart, have served as a wellestablished model for studying cardiac substrate metabolism [121]. We used freshly isolated cardiomyocytes to perform the measurements presented in the studies of this thesis. The standard procedure for the isolation of cardiomyocytes is a retrograde Langendorff perfusion with collagenase, where after cells are kept in suspension. Single-cell suspensions are easily accessible by pharmacologically active compounds and different interventions are possible within cardiomyocytes from one heart. At the same time the extracellular environment is well-controlled and vascular factors and the endothelial barrier are eliminated. Moreover, the transport of substrates across the sarcolemma can be studied independently of the influence of other types of cells and transport barriers. Although cardiomyocytes contract constantly in vivo, in suspension the trigger for controlled contractions is not present resulting in a decline in metabolic rate. The availability of an experimental system that induces contractions at $200 \mathrm{~V}$ with a frequency of $4 \mathrm{~Hz}$ in cardiomyocytes in suspension makes it possible to investigate the signaling processes and metabolic effects that are induced by contraction. Moreover, in cardiomyocytes the contraction signaling pathway can be pharmacologically activated, for instance by oligomycin, AICAR and dipyridamole. 
Isolated cardiomyocytes were used to measure metabolic parameters, e.g., LCFA and glucose uptake and oxidation. Until now the regulation of metabolism in isolated cardiomyocytes has been mainly studied by using pharmacological inhibitors. The disadvantages of pharmacological approaches are the possible sideeffect, of which only some are known. Given the current focus on mouse genetics, isolated cardiomyocytes from mouse hearts offer significant advantages. However, isolation of cardiac myocytes from mouse heart proved to be quite difficult, notably in comparison to rat cardiomyocytes. This especially applies for metabolic studies demanding relatively high input of cellular material, and may explain the low number of publications on metabolism in isolated cardiomyocytes from genetically manipulated mice. However, in case that the technical problems in the isolation procedure due to the small size of the heart can be overcome, and the cardiomyocyte yield is sufficient to conduct metabolic experiments, there are considerable benefits related to this cardiac model system. Namely, genetically manipulated mice with altered expression of relevant signaling and trafficking genes with putative roles in stimulus-induced translocation of LCFA transporters (most notably CD36) will provide direct evidence for their role in the substrate preference of the heart under healthy and pathological conditions. This thesis describes several studies in which genetically manipulated mouse models were investigated to further unravel the molecular mechanism underlying the regulation of cardiac energy metabolism.

\section{Outline of thesis}

The routinely used model system in this thesis to study the regulation of cardiac substrate uptake is isolated mouse cardiomyocytes. Chapters 2-7 describe several relevant physiological factors and pharmacological agents to stimulate cardiac substrate uptake, and the signaling cascades involved in these events. Specifically: In chapter 2 different approaches are described and compared to study the metabolic effects induced by contraction signaling in cardiomyocytes.

Chapter 3 describes the role of CD36 in LCFA uptake in response to metabolic challenges by using isolated cardiomyocytes from CD36 knockout mice. Moreover, CD36 knockout cardiomyocytes were used to deliver the ultimate evidence concerning the presumed specificity for the CD36 inhibitor SSO.

In order to unravel the contraction transduction pathway involved in the translocation of CD36 and GLUT4 concomitant with LCFA and glucose uptake, respectively, different genetically manipulated mouse models were investigated, e.g., AMPK $\alpha 2$ kinase-dead, AMPK $\alpha 2$ knockout and LKB1 knockout mice. Chapter 4 reports the regulation of CD36-mediated LCFA and GLUT4-mediated glucose uptake by the LKB1 - AMPK axis. 
AICAR can be used for AMPK activation although this agent exerts several unspecific effects. The role of CD36 in AICAR-induced LCFA uptake was studied in cardiomyocytes from CD36 knockout mice as described in chapter 5. Furthermore, the AICAR-induced change in abundance of FABPpm, FATP1 and FATP6 at the sarcolemma was determined.

Chapter 6 presents the role of Munc18c in cardiac substrate uptake. Mun18c is known to be involved in insulin-stimulated GLUT4 translocation in skeletal muscle, but, its role in the heart is not yet known. Insulin and oligomycin-stimulated glucose and LCFA uptake rates were determined in cardiomyocytes from Munc $18 \mathrm{c}^{-/+}$mice. In Chapter 7 the main results of the studies presented in this thesis are summarized, new insights will be discussed, and placed in a broader perspective. 


\section{References}

1 Opie LH and Lopaschuk GD 2004 Fuels: Aerobic and Anaerobic Metabolism. Heart Physiology from Cell to Circulation Fourth edition: p 306 - 354

2 Stanley WC, Recchia FA and Lopaschuk GD 2005 Myocardial substrate metabolism in the normal and failing heart. Physiol Rev 85: 1093-1129

3 Belke DD, Larsen TS, Lopaschuk GD and Severson DL 1999 Glucose and fatty acid metabolism in the isolated working mouse heart. Am J Physiol 277: R1210-1217

4 Goodwin GW and Taegtmeyer H 2000 Improved energy homeostasis of the heart in the metabolic state of exercise. Am J Physiol Heart Circ Physiol 279: H1490-1501

5 Gertz EW, Wisneski JA, Stanley WC and Neese RA 1988 Myocardial substrate utilization during exercise in humans. Dual carbon-labeled carbohydrate isotope experiments. J Clin Invest 82: 2017-2025

6 Kagaya Y, Kanno Y, Takeyama D, Ishide N, Maruyama Y, Takahashi T, Ido T and Takishima T 1990 Effects of long-term pressure overload on regional myocardial glucose and free fatty acid uptake in rats. A quantitative autoradiographic study. Circulation 81: 1353-1361

7 Allard MF 2004 Energy substrate metabolism in cardiac hypertrophy. Curr Hypertens Rep 6: 430-435

8 Heather LC, Cole MA, Lygate CA, Evans RD, Stuckey DJ, Murray AJ, Neubauer S and Clarke K 2006 Fatty acid transporter levels and palmitate oxidation rate correlate with ejection fraction in the infarcted rat heart. Cardiovasc Res 72: 430-437

9 An D and Rodrigues B 2006 Role of changes in cardiac metabolism in development of diabetic cardiomyopathy. Am J Physiol Heart Circ Physiol 291: H1489-1506

10 Chiu HC, Kovacs A, Blanton RM, Han X, Courtois M, Weinheimer CJ, Yamada KA, Brunet S, Xu H, Nerbonne JM, Welch MJ, Fettig NM, Sharp TL, Sambandam N, Olson KM, Ory DS and Schaffer JE 2005 Transgenic expression of fatty acid transport protein 1 in the heart causes lipotoxic cardiomyopathy. Circulation research $96: 225-233$

11 Christoffersen C, Bollano E, Lindegaard ML, Bartels ED, Goetze JP, Andersen CB and Nielsen LB 2003 Cardiac lipid accumulation associated with diastolic dysfunction in obese mice. Endocrinology 144: $3483-3490$

12 Glatz JF, Bonen A, Ouwens DM and Luiken JJ 2006 Regulation of sarcolemmal transport of substrates in the healthy and diseased heart. Cardiovasc Drugs Ther 20: 471-476

13 van der Vusse GJ, Glatz JF, Stam HC and Reneman RS 1992 Fatty acid homeostasis in the normoxic and ischemic heart. Physiol Rev 72: 881-940

14 Randle PJ, Garland PB, Hales CN and Newsholme EA 1963 The glucose fatty-acid cycle. Its role in insulin sensitivity and the metabolic disturbances of diabetes mellitus. Lancet 1: 785-789

15 Abel ED 2004 Glucose transport in the heart. Front Biosci 9: 201-215

16 Zorzano A, Fandos C and Palacin M 2000 Role of plasma membrane transporters in muscle metabolism. The Biochemical journal 349 Pt 3: 667-688

17 Kleinfeld AM 2000 Lipid phase fatty acid flip-flop, is it fast enough for cellular transport? J Membr Biol 175: 79-86

18 Hamilton JA and Kamp F 1999 How are free fatty acids transported in membranes? Is it by proteins or by free diffusion through the lipids? Diabetes 48: 2255-2269

19 Abumrad N, Harmon C and Ibrahimi A 1998 Membrane transport of long-chain fatty acids: evidence for a facilitated process. J Lipid Res 39: 2309-2318

20 Bonen A, Chabowski A, Luiken JJ and Glatz JF 2007 Is membrane transport of FFA mediated by lipid, protein, or both? Mechanisms and regulation of protein-mediated cellular fatty acid uptake: molecular, biochemical, and physiological evidence. Physiology 22: 15-29

21 Luiken JJ, van Nieuwenhoven FA, America G, van der Vusse GJ and Glatz JF 1997 Uptake and metabolism of palmitate by isolated cardiac myocytes from adult rats: involvement of sarcolemmal proteins. J Lipid Res 38: 745-758

22 Hartil K and Charron MJ 2005 Genetic modification of the heart: transgenic modification of cardiac lipid and carbohydrate utilization. J Mol Cell Cardiol 39: 581-593

23 Hajri T and Abumrad NA 2002 Fatty acid transport across membranes: relevance to nutrition and metabolic pathology. Annu Rev Nutr 22: 383-415 
24 Schaffer JE 2002 Fatty acid transport: the roads taken. Am J Physiol Endocrinol Metab 282: E239-246

25 Pohl J, Ring A, Ehehalt R, Herrmann T and Stremmel W 2004 New concepts of cellular fatty acid uptake: role of fatty acid transport proteins and of caveolae. Proc Nutr Soc 63: 259-262

26 Luiken JJ, Coort SL, Koonen DP, van der Horst DJ, Bonen A, Zorzano A and Glatz JF 2004 Regulation of cardiac long-chain fatty acid and glucose uptake by translocation of substrate transporters. Pflugers Arch 448: 1-15

27 Chabowski A, Gorski J, Luiken JJ, Glatz JF and Bonen A 2007 Evidence for concerted action of FAT/CD36 and FABPpm to increase fatty acid transport across the plasma membrane. Prostaglandins Leukot Essent Fatty Acids 77: 345-353

28 Gimeno RE, Ortegon AM, Patel S, Punreddy S, Ge P, Sun Y, Lodish HF and Stahl A 2003 Characterization of a heart-specific fatty acid transport protein. The Journal of biological chemistry 278: 16039-16044

29 Pohl J, Fitscher BA, Ring A, Ihl-Vahl R, Strasser RH and Stremmel W 2000 Fatty acid transporters in plasma membranes of cardiomyocytes in patients with dilated cardiomyopathy. Eur J Med Res 5: 438442

30 Harmon CM and Abumrad NA 1993 Binding of sulfosuccinimidyl fatty acids to adipocyte membrane proteins: isolation and amino-terminal sequence of an $88-\mathrm{kD}$ protein implicated in transport of longchain fatty acids. J Membr Biol 133: 43-49

31 Harmon CM, Luce P, Beth AH and Abumrad NA 1991 Labeling of adipocyte membranes by sulfo-Nsuccinimidyl derivatives of long-chain fatty acids: inhibition of fatty acid transport. J Membr Biol 121: 261-268

32 Abumrad NA, el-Maghrabi MR, Amri EZ, Lopez E and Grimaldi PA 1993 Cloning of a rat adipocyte membrane protein implicated in binding or transport of long-chain fatty acids that is induced during preadipocyte differentiation. Homology with human CD36. The Journal of biological chemistry 268: $17665-17668$

33 Stremmel W, Pohl L, Ring A and Herrmann T 2001 A new concept of cellular uptake and intracellular trafficking of long-chain fatty acids. Lipids 36: 981-989

34 Abumrad N, Coburn C and Ibrahimi A 1999 Membrane proteins implicated in long-chain fatty acid uptake by mammalian cells: CD36, FATP and FABPm. Biochim Biophys Acta 1441: 4-13

35 Glatz JF and Storch J 2001 Unravelling the significance of cellular fatty acid-binding proteins. Curr Opin Lipidol 12: 267-274

36 Bastie CC, Hajri T, Drover VA, Grimaldi PA and Abumrad NA 2004 CD36 in myocytes channels fatty acids to a lipase-accessible triglyceride pool that is related to cell lipid and insulin responsiveness. Diabetes 53: 2209-2216

37 Ibrahimi A, Sfeir Z, Magharaie H, Amri EZ, Grimaldi P and Abumrad NA 1996 Expression of the CD36 homolog (FAT) in fibroblast cells: effects on fatty acid transport. Proc Natl Acad Sci U S A 93: 26462651

38 Coort SL, Willems J, Coumans WA, van der Vusse GJ, Bonen A, Glatz JF and Luiken JJ 2002 Sulfo-Nsuccinimidyl esters of long chain fatty acids specifically inhibit fatty acid translocase (FAT/CD36)mediated cellular fatty acid uptake. Mol Cell Biochem 239: 213-219

39 Kusaka Y, Tanaka T, Okamoto F, Terasaki F, Matsunaga Y, Miyazaki H and Kawamura K 1995 Effect of sulfo-N-succinimidyl palmitate on the rat heart: myocardial long-chain fatty acid uptake and cardiac hypertrophy. J Mol Cell Cardiol 27: 1605-1612

40 Coburn CT, Knapp FF, Jr., Febbraio M, Beets AL, Silverstein RL and Abumrad NA 2000 Defective uptake and utilization of long chain fatty acids in muscle and adipose tissues of CD36 knockout mice. The Journal of biological chemistry 275: 32523-32529

41 Bonen A, Han XX, Habets DD, Febbraio M, Glatz JF and Luiken JJ 2007 A null mutation in skeletal muscle FAT/CD36 reveals its essential role in insulin- and AICAR-stimulated fatty acid metabolism. Am J Physiol Endocrinol Metab 292: E1740-1749

42 Kuang M, Febbraio M, Wagg C, Lopaschuk GD and Dyck JR 2004 Fatty acid translocase/CD36 deficiency does not energetically or functionally compromise hearts before or after ischemia. Circulation 109: 1550-1557 
43 Ibrahimi A, Bonen A, Blinn WD, Hajri T, Li X, Zhong K, Cameron R and Abumrad NA 1999 Musclespecific overexpression of FAT/CD36 enhances fatty acid oxidation by contracting muscle, reduces plasma triglycerides and fatty acids, and increases plasma glucose and insulin. The Journal of biological chemistry 274: 26761-26766

44 Stremmel W 1988 Fatty acid uptake by isolated rat heart myocytes represents a carrier-mediated transport process. J Clin Invest 81: 844-852

45 Stump DD, Zhou SL and Berk PD 1993 Comparison of plasma membrane FABP and mitochondrial isoform of aspartate aminotransferase from rat liver. Am J Physiol 265: G894-902

46 Clarke DC, Miskovic D, Han XX, Calles-Escandon J, Glatz JF, Luiken JJ, Heikkila JJ and Bonen A 2004 Overexpression of membrane-associated fatty acid binding protein (FABPpm) in vivo increases fatty acid sarcolemmal transport and metabolism. Physiol Genomics 17: 31-37

47 Isola LM, Zhou SL, Kiang CL, Stump DD, Bradbury MW and Berk PD 19953 T3 fibroblasts transfected with a cDNA for mitochondrial aspartate aminotransferase express plasma membrane fatty acid-binding protein and saturable fatty acid uptake. Proc Natl Acad Sci U S A 92: 9866-9870

48 Turcotte LP, Swenberger JR, Tucker MZ, Yee AJ, Trump G, Luiken JJ and Bonen A 2000 Muscle palmitate uptake and binding are saturable and inhibited by antibodies to FABP(PM). Mol Cell Biochem 210: 53-63

49 Luiken JJ, Turcotte LP and Bonen A 1999 Protein-mediated palmitate uptake and expression of fatty acid transport proteins in heart giant vesicles. J Lipid Res 40: 1007-1016

50 Stahl A, Gimeno RE, Tartaglia LA and Lodish HF 2001 Fatty acid transport proteins: a current view of a growing family. Trends Endocrinol Metab 12: 266-273

51 Lewis SE, Listenberger LL, Ory DS and Schaffer JE 2001 Membrane topology of the murine fatty acid transport protein 1. The Journal of biological chemistry 276: 37042-37050

52 Zou Z, Tong F, Faergeman NJ, Borsting C, Black PN and DiRusso CC 2003 Vectorial acylation in Saccharomyces cerevisiae. Fatlp and fatty acyl-CoA synthetase are interacting components of a fatty acid import complex. The Journal of biological chemistry 278: 16414-16422

53 Hirsch D, Stahl A and Lodish HF 1998 A family of fatty acid transporters conserved from mycobacterium to man. Proc Natl Acad Sci U S A 95: 8625-8629

54 Schaffer JE and Lodish HF 1994 Expression cloning and characterization of a novel adipocyte long chain fatty acid transport protein. Cell 79: 427-436

55 Doege $\mathrm{H}$ and Stahl A 2006 Protein-mediated fatty acid uptake: novel insights from in vivo models. Physiology (Bethesda) 21: 259-268

56 Lavrentyev EN, He D and Cook GA 2004 Expression of genes participating in regulation of fatty acid and glucose utilization and energy metabolism in developing rat hearts. Am J Physiol Heart Circ Physiol 287: H2035-2042

57 Kraegen EW, Sowden JA, Halstead MB, Clark PW, Rodnick KJ, Chisholm DJ and James DE 1993 Glucose transporters and in vivo glucose uptake in skeletal and cardiac muscle: fasting, insulin stimulation and immunoisolation studies of GLUT1 and GLUT4. The Biochemical journal 295: 287-293

58 Fischer Y, Thomas J, Sevilla L, Munoz P, Becker C, Holman G, Kozka IJ, Palacin M, Testar X, Kammermeier H and Zorzano A 1997 Insulin-induced recruitment of glucose transporter 4 (GLUT4) and GLUT1 in isolated rat cardiac myocytes. Evidence of the existence of different intracellular GLUT4 vesicle populations. The Journal of biological chemistry 272: 7085-7092

59 Watson RT and Pessin JE 2001 Intracellular organization of insulin signaling and GLUT4 translocation. Recent Prog Horm Res 56: 175-193

60 Brozinick JT, Jr., McCoid SC, Reynolds TH, Nardone NA, Hargrove DM, Stevenson RW, Cushman SW and Gibbs EM 2001 GLUT4 overexpression in $\mathrm{db} / \mathrm{db}$ mice dose-dependently ameliorates diabetes but is not a lifelong cure. Diabetes 50: 593-600

61 Katz EB, Stenbit AE, Hatton K, DePinho R and Charron MJ 1995 Cardiac and adipose tissue abnormalities but not diabetes in mice deficient in GLUT4. Nature 377: 151-155

62 Stenbit AE, Tsao TS, Li J, Burcelin R, Geenen DL, Factor SM, Houseknecht K, Katz EB and Charron MJ 1997 GLUT4 heterozygous knockout mice develop muscle insulin resistance and diabetes. Nat Med 3: 1096-1101 
63 Belke DD, Larsen TS, Gibbs EM and Severson DL 2000 Altered metabolism causes cardiac dysfunction in perfused hearts from diabetic $(\mathrm{db} / \mathrm{db})$ mice. Am J Physiol Endocrinol Metab 279: E1104-1113

64 Buchanan J, Mazumder PK, Hu P, Chakrabarti G, Roberts MW, Yun UJ, Cooksey RC, Litwin SE and Abel ED 2005 Reduced cardiac efficiency and altered substrate metabolism precedes the onset of hyperglycemia and contractile dysfunction in two mouse models of insulin resistance and obesity. Endocrinology 146: 5341-5349

65 Huggins CE, Domenighetti AA, Ritchie ME, Khalil N, Favaloro JM, Proietto J, Smyth GK, Pepe S and Delbridge LM 2008 Functional and metabolic remodelling in GLUT4-deficient hearts confers hyperresponsiveness to substrate intervention. J Mol Cell Cardiol 44: 270-280

66 Luiken JJ, Coort SL, Willems J, Coumans WA, Bonen A, van der Vusse GJ and Glatz JF 2003 Contraction-induced fatty acid translocase/CD36 translocation in rat cardiac myocytes is mediated through AMP-activated protein kinase signaling. Diabetes 52: 1627-1634

67 Luiken JJ, Koonen DP, Willems J, Zorzano A, Becker C, Fischer Y, Tandon NN, Van Der Vusse GJ, Bonen A and Glatz JF 2002 Insulin stimulates long-chain fatty acid utilization by rat cardiac myocytes through cellular redistribution of FAT/CD36. Diabetes 51: 3113-3119

68 Cushman SW, Goodyear LJ, Pilch PF, Ralston E, Galbo H, Ploug T, Kristiansen S and Klip A 1998 Molecular mechanisms involved in GLUT4 translocation in muscle during insulin and contraction stimulation. Adv Exp Med Biol 441: 63-71

69 Bertrand L, Horman S, Beauloye C and Vanoverschelde JL 2008 Insulin signalling in the heart. Cardiovasc Res 79: 238-248

70 Thong FS, Dugani CB and Klip A 2005 Turning signals on and off: GLUT4 traffic in the insulinsignaling highway. Physiology 20: 271-284

71 Vollenweider P, Menard B and Nicod P 2002 Insulin resistance, defective insulin receptor substrate 2associated phosphatidylinositol-3' kinase activation, and impaired atypical protein kinase C (zeta/lambda) activation in myotubes from obese patients with impaired glucose tolerance. Diabetes 51: 1052-1059

72 Ishiki M and Klip A 2005 Minireview: recent developments in the regulation of glucose transporter-4 traffic: new signals, locations, and partners. Endocrinology 146: 5071-5078

73 Farese RV, Sajan MP and Standaert ML 2005 Atypical protein kinase C in insulin action and insulin resistance. Biochemical Society transactions 33: 350-353

74 Welsh GI, Hers I, Berwick DC, Dell G, Wherlock M, Birkin R, Leney S and Tavare JM 2005 Role of protein kinase B in insulin-regulated glucose uptake. Biochemical Society transactions 33: 346-349

75 Chabowski A, Coort SL, Calles-Escandon J, Tandon NN, Glatz JF, Luiken JJ and Bonen A 2004 Insulin stimulates fatty acid transport by regulating expression of FAT/CD36 but not FABPpm. Am J Physiol Endocrinol Metab 287: E781-789

76 Kane S, Sano H, Liu SC, Asara JM, Lane WS, Garner CC and Lienhard GE 2002 A method to identify serine kinase substrates. Akt phosphorylates a novel adipocyte protein with a Rab GTPase-activating protein (GAP) domain. The Journal of biological chemistry 277: 22115-22118

77 Thong FS, Bilan PJ and Klip A 2007 The Rab GTPase-activating protein AS160 integrates Akt, protein kinase C, and AMP-activated protein kinase signals regulating GLUT4 traffic. Diabetes 56: 414-423

78 Sano H, Kane S, Sano E, Miinea CP, Asara JM, Lane WS, Garner CW and Lienhard GE 2003 Insulinstimulated phosphorylation of a Rab GTPase-activating protein regulates GLUT4 translocation. The Journal of biological chemistry 278: 14599-14602

79 Miinea CP, Sano H, Kane S, Sano E, Fukuda M, Peranen J, Lane WS and Lienhard GE 2005 AS160, the Akt substrate regulating GLUT4 translocation, has a functional Rab GTPase-activating protein domain. The Biochemical journal 391: 87-93

80 Saltiel AR and Pessin JE 2002 Insulin signaling pathways in time and space. Trends in cell biology 12 $65-71$

81 JeBailey L, Rudich A, Huang X, Di Ciano-Oliveira C, Kapus A and Klip A 2004 Skeletal muscle cells and adipocytes differ in their reliance on TC10 and Rac for insulin-induced actin remodeling. Molecular endocrinology (Baltimore) 18: 359-372

82 Emoto M, Langille SE and Czech MP 2001 A role for kinesin in insulin-stimulated GLUT4 glucose transporter translocation in 3T3-L1 adipocytes. The Journal of biological chemistry 276: 10677-10682 
83 Semiz S, Park JG, Nicoloro SM, Furcinitti P, Zhang C, Chawla A, Leszyk J and Czech MP 2003 Conventional kinesin KIF5B mediates insulin-stimulated GLUT4 movements on microtubules. The EMBO journal 22: 2387-2399

84 Bose A, Robida S, Furcinitti PS, Chawla A, Fogarty K, Corvera S and Czech MP 2004 Unconventional myosin Myolc promotes membrane fusion in a regulated exocytic pathway. Molecular and cellular biology 24: 5447-5458

85 Chen YA and Scheller RH 2001 SNARE-mediated membrane fusion. Nature reviews 2: 98-106

86 Rizo J and Sudhof TC 2002 Snares and Munc18 in synaptic vesicle fusion. Nat Rev Neurosci 3: 641-653

87 Bryant NJ, Govers R and James DE 2002 Regulated transport of the glucose transporter GLUT4. Nature reviews 3: 267-277

88 Dulubova I, Sugita S, Hill S, Hosaka M, Fernandez I, Sudhof TC and Rizo J 1999 A conformational switch in syntaxin during exocytosis: role of munc18. The EMBO journal 18: 4372-4382

89 Toonen RF and Verhage M 2003 Vesicle trafficking: pleasure and pain from SM genes. Trends in cell biology 13: 177-186

90 Smithers NP, Hodgkinson CP, Cuttle M and Sale GJ 2008 Insulin-triggered repositioning of munc18c on syntaxin-4 in GLUT4 signalling. The Biochemical journal 410: 255-260

91 Oh E, Spurlin BA, Pessin JE and Thurmond DC 2005 Munc18c heterozygous knockout mice display increased susceptibility for severe glucose intolerance. Diabetes 54: 638-647

92 Hardie DG, Hawley SA and Scott JW 2006 AMP-activated protein kinase--development of the energy sensor concept. J Physiol 574: 7-15

93 Stapleton D, Mitchelhill KI, Gao G, Widmer J, Michell BJ, Teh T, House CM, Fernandez CS, Cox T, Witters LA and Kemp BE 1996 Mammalian AMP-activated protein kinase subfamily. J Biol Chem 271: 611-614

94 Hardie DG, Salt IP, Hawley SA and Davies SP 1999 AMP-activated protein kinase: an ultrasensitive system for monitoring cellular energy charge. The Biochemical journal 338: 717-722

95 Winder WW and Hardie DG 1996 Inactivation of acetyl-CoA carboxylase and activation of AMPactivated protein kinase in muscle during exercise. Am J Physiol 270: E299-304

96 Kudo N, Gillespie JG, Kung L, Witters LA, Schulz R, Clanachan AS and Lopaschuk GD 1996 Characterization of 5'AMP-activated protein kinase activity in the heart and its role in inhibiting acetylCoA carboxylase during reperfusion following ischemia. Biochim Biophys Acta 1301: 67-75

97 Zarrinpashneh E, Carjaval K, Beauloye C, Ginion A, Mateo P, Pouleur AC, Horman S, Vaulont S, Hoerter J, Viollet B, Hue L, Vanoverschelde JL and Bertrand L 2006 Role of the alpha2-isoform of AMP-activated protein kinase in the metabolic response of the heart to no-flow ischemia. Am J Physiol Heart Circ Physiol 291: H2875-2883

98 Hawley SA, Pan DA, Mustard KJ, Ross L, Bain J, Edelman AM, Frenguelli BG and Hardie DG 2005 Calmodulin-dependent protein kinase kinase-beta is an alternative upstream kinase for AMP-activated protein kinase. Cell Metab 2: 9-19

99 Dyck JR, Kudo N, Barr AJ, Davies SP, Hardie DG and Lopaschuk GD 1999 Phosphorylation control of cardiac acetyl-CoA carboxylase by cAMP-dependent protein kinase and 5'-AMP activated protein kinase. Eur J Biochem 262: 184-190

100 Kramer HF, Witczak CA, Taylor EB, Fujii N, Hirshman MF and Goodyear LJ 2006 AS160 regulates insulin- and contraction-stimulated glucose uptake in mouse skeletal muscle. The Journal of biological chemistry 281: 31478-31485

101 Sakamoto K, Goransson O, Hardie DG and Alessi DR 2004 Activity of LKB1 and AMPK-related kinases in skeletal muscle: effects of contraction, phenformin, and AICAR. Am J Physiol Endocrinol Metab 287: E310-317

102 Witczak CA, Fujii N, Hirshman MF and Goodyear LJ 2007 Ca2+/calmodulin-dependent protein kinase kinase-alpha regulates skeletal muscle glucose uptake independent of AMP-activated protein kinase and Akt activation. Diabetes 56: 1403-1409

103 Jensen TE, Rose AJ, Jorgensen SB, Brandt N, Schjerling P, Wojtaszewski JF and Richter EA 2007 Possible CaMKK-dependent regulation of AMPK phosphorylation and glucose uptake at the onset of mild tetanic skeletal muscle contraction. Am J Physiol Endocrinol Metab 292: E1308-1317 
104 Sakamoto K, McCarthy A, Smith D, Green KA, Grahame Hardie D, Ashworth A and Alessi DR 2005 Deficiency of LKB1 in skeletal muscle prevents AMPK activation and glucose uptake during contraction. The EMBO journal 24: 1810-1820

105 Thomson DM, Brown JD, Fillmore N, Condon BM, Kim HJ, Barrow JR and Winder WW 2007 LKB1 and the Regulation of Malonyl-CoA and Fatty Acid Oxidation in Muscle. Am J Physiol Endocrinol Metab 104: 429-438

106 Saddik M, Gamble J, Witters LA and Lopaschuk GD 1993 Acetyl-CoA carboxylase regulation of fatty acid oxidation in the heart. The Journal of biological chemistry 268: 25836-25845

107 Jensen TE, Rose AJ, Hellsten Y, Wojtaszewski JF and Richter EA 2007 Caffeine-induced $\mathrm{Ca}(2+)$ release increases AMPK-dependent glucose uptake in rodent soleus muscle. Am J Physiol Endocrinol Metab 293: E286-292

108 Treebak JT, Glund S, Deshmukh A, Klein DK, Long YC, Jensen TE, Jorgensen SB, Viollet B, Andersson L, Neumann D, Wallimann T, Richter EA, Chibalin AV, Zierath JR and Wojtaszewski JF 2006 AMPK-mediated AS160 phosphorylation in skeletal muscle is dependent on AMPK catalytic and regulatory subunits. Diabetes 55: 2051-2058

109 Hayashi T, Hirshman MF, Kurth EJ, Winder WW and Goodyear LJ 1998 Evidence for 5' AMPactivated protein kinase mediation of the effect of muscle contraction on glucose transport. Diabetes 47 : 1369-1373

110 Russell RR, 3rd, Bergeron R, Shulman GI and Young LH 1999 Translocation of myocardial GLUT-4 and increased glucose uptake through activation of AMPK by AICAR. Am J Physiol 277: H643-649

111 Marsin AS, Bertrand L, Rider MH, Deprez J, Beauloye C, Vincent MF, Van den Berghe G, Carling D and Hue L 2000 Phosphorylation and activation of heart PFK-2 by AMPK has a role in the stimulation of glycolysis during ischaemia. Curr Biol 10: 1247-1255

112 Bertrand L, Ginion A, Beauloye C, Hebert AD, Guigas B, Hue L and Vanoverschelde JL 2006 AMPK activation restores the stimulation of glucose uptake in an in vitro model of insulin-resistant cardiomyocytes via the activation of protein kinase B. Am J Physiol Heart Circ Physiol 291: H239-250

113 Chabowski A, Coort SL, Calles-Escandon J, Tandon NN, Glatz JF, Luiken JJ and Bonen A 2005 The subcellular compartmentation of fatty acid transporters is regulated differently by insulin and by AICAR. FEBS Lett 579: 2428-2432

114 Habets DD, Coumans WA, Voshol PJ, den Boer MA, Febbraio M, Bonen A, Glatz JF and Luiken JJ 2007 AMPK-mediated increase in myocardial long-chain fatty acid uptake critically depends on sarcolemmal CD36. Biochemical and biophysical research communications 355: 204-210

115 Luiken JJ, Coort SL, Willems J, Coumans WA, Bonen A and Glatz JF 2004 Dipyridamole alters cardiac substrate preference by inducing translocation of FAT/CD36, but not that of GLUT4. Mol Pharmacol 65: 639-645

116 Johnson RH, Walton JL, Krebs HA and Williamson DH 1969 Metabolic fuels during and after severe exercise in athletes and non-athletes. Lancet 2: 452-455

117 Nilsson NO, Stralfors P, Fredrikson G and Belfrage P 1980 Regulation of adipose tissue lipolysis: effects of noradrenaline and insulin on phosphorylation of hormone-sensitive lipase and on lipolysis in intact rat adipocytes. FEBS Lett 111: 125-130

118 Lopaschuk GD 2002 Metabolic abnormalities in the diabetic heart. Heart Fail Rev 7: 149-159

119 Lopaschuk GD, Folmes CD and Stanley WC 2007 Cardiac energy metabolism in obesity. Circulation research 101: 335-347

120 Sambandam N, Lopaschuk GD, Brownsey RW and Allard MF 2002 Energy metabolism in the hypertrophied heart. Heart Fail Rev 7: 161-173

121 Sambrano GR, Fraser I, Han H, Ni Y, O'Connell T, Yan Z and Stull JT 2002 Navigating the signalling network in mouse cardiac myocytes. Nature 420: 712-714 


\section{CHAPTER 2}

\section{Oligomycin as tool to mimic contraction signaling to metabolism in cardiomyocytes}

Daphna D.J. Habets ${ }^{1}$, Robert W. Schwenk ${ }^{1}$ Arend Bonen $^{2}$, Joost J.F.P. Luiken ${ }^{1}$ and Jan F.C. Glatz ${ }^{1}$

${ }^{1}$ Department of Molecular Genetics, Cardiovascular Research Institute Maastricht (CARIM), Maastricht University, Maastricht, the Netherlands

${ }^{2}$ Department of Human Health and Nutritional Sciences, University of Guelph, Guelph, Ontario N1G 2W1, Canada

In preparation 


\section{Abstract}

Mechanical, electrical and pharmacological tools can be used to study cardiac metabolism in in vivo/ex vivo models such as the working heart and isolated cardiomyocytes preparations, to maintain metabolic demand of the heart that is indicative of the metabolic demand seen in vivo. The pharmacological mitochondrial $\mathrm{F}_{1} \mathrm{~F}_{0}$-ATPase inhibitor oligomycin has proven a valuable tool to increase long-chain fatty acid (LCFA) and glucose utilization in these models. Therefore, changes in cardiac energy metabolism induced by increased workload in working heart preparations and in electrically stimulated cardiomyocytes can be mimicked by oligomycin. The conclusion that oligomycin mimics the effects of cellular contraction is based on crucial metabolic parameters of contraction that are also observed during oligomycin stimulation: (i) increase of the AMP/ATP ratio; (ii) activation of the signaling pathway, including AMP-activated protein kinase, acetyl-CoA carboxylase, 6-phosphofructo-2-kinase, protein kinase D and cardiac troponin-I; and (iii) translocation of fatty acid translocase/CD36 and GLUT4 to the sarcolemma to increase LCFA and glucose uptake, respectively. These findings indicate that increased workload in the working heart preparation, electrical stimulation of isolated cardiomyocytes, and oligomycin treatment of cardiomyocytes mutually share a common regulatory mechanism finally leading to increased ATP production. Taken together, oligomycin represents a powerful tool to study the consequence of metabolic challenges in the heart. 


\section{Introduction}

Most of the heart is made up of contractile muscle cells, also known as myocytes or, more specifically, cardiomyocytes. The continuous contractile function of the heart muscle requires that the myocytes produce large amounts of ATP. This high ATP demand is met primarily by the utilization of the predominant substrates of the heart, i.e., fatty acids and carbohydrates $[1,2]$. Because measurement of cardiac metabolic parameters in vivo are difficult and often indirect, in vitro/ex vivo techniques for measuring energy metabolism in the heart have been developed [3, 4]. The working heart and isolated cardiomyocytes preparations are models most widely used for investigating energy metabolism in a variety of physiological and pathological states. These models permit simultaneous measurements of metabolic rates and avoid confounding systemic factors (e.g., uncontrolled endocrine, metabolic and workload changes), while isolated cardiomyocytes preparations also eliminate cardiovascular factors and the endothelial barrier. A key factor controlling flux through the various metabolic pathways is the work being performed by the heart. Rates of ATP production by the heart depend on ATP utilization rates [5]. As cardiac work decreases, ATP utilization rates decrease and this directly or indirectly results in a feedback inhibition on all of the pathways involved in ATP production. As a result, flux through glycolysis, glucose oxidation, lactate oxidation, fatty acid oxidation, tricarboxylic acid cycle activity, and electron transport chain activity is critically dependent on the work performed by the heart. It is therefore desirable to use experimental models in which the heart is functioning at physiologically relevant workloads. This is neither a problem with in vivo studies nor with isolated working heart preparations, but can be an important factor in many in vitro/ex vivo studies. For instance, isolated cardiomyocytes consume oxygen at a rate that is approximately $10 \%$ of that of the intact working heart, as a result of which it seems likely that the metabolic demand is reduced $[6,7]$. Indeed, because of this quiescent nature oxidative metabolism in isolated cardiomyocytes can be 50-100 times lower than rates in intact working hearts $[8,9]$. For the proper investigation of the regulation of cardiac metabolism, especially its changes during the transition between distinct levels of ATP production, the hearts should be performing relevant levels of cardiac work or the metabolic rates should be similarly high.

A number of techniques have been developed to stimulate cardiac energy metabolism for in vitro/ex vivo approaches. An experimental setup which can be used in a variety of small animals is the isolated working heart preparation [3]. The preparation is a left ventricular ejecting heart, in which both preload and afterload are controlled. Increased workload in working heart preparations can be induced by simultaneous adrenergic stimulation, parasympathic blockade, or aortic constriction [10-12]. To study cardiac contraction in isolated cardiomyocytes, an approach was developed to electrically stimulate cardiomyocytes in suspension [7]. The applied 
frequency can be varied, thereby increasing the rate of oxygen consumption up to approximately $50 \%$ of that in vivo. This system can be properly used to stimulate isolated rat cardiomyocytes in a controlled manner with $100 \mathrm{~V}$ up to $250 \mathrm{~V}$ and up to $5 \mathrm{~Hz}$, cardiomyocytes optimally contract at $4 \mathrm{~Hz} / 200 \mathrm{~V}$. However, this system has not yet been adapted for the stimulation of mouse cardiomyocytes because myocytes isolated from this specie appear relatively fragile.

Various pharmacological tools also stimulate cardiac metabolism in both in vitro/ex vivo approaches in a wide range of species. Mitochondrial inhibitors that reduce oxidative phosphorylation, like oligomycin, rotenone, 2,4-dinitrophenol and sodiumazide are widely used for this purpose [13-15]. It has been established that oligomycin is the best mimeticum to stimulate cardiac metabolism under physiological conditions because only oligomycin increases both long-chain fatty acid (LCFA) and glucose utilization [16]. In response to oligomycin the myocardial metabolic rates increase comparably to electrically-stimulated cardiomyocytes [14]. Also in the working heart [17] and in several cells lines (with and without a contractile apparatus) [18] oligomycin mimics the physiological metabolic events of the heart.

This review will summarize the current state of knowledge regarding the use of oligomycin as a tool to increase energy metabolism in the heart. First, the characteristics of oligomycin and its inhibitory action on mitochondria are described. Second, evidence is presented that oligomycin elevates cardiac substrate utilization comparable to cellular contractions and increased workload. The effects of oligomycin on selected metabolic parameters, e.g., glucose and LCFA uptake and oxidation, will be discussed. Finally, examples are given of the application of oligomycin in studies on the regulation of cardiac energy metabolism.

\section{Characterization and inhibitory mechanism of oligomycin}

Oligomycins, a family of natural antibiotics, were discovered by Smith et al. [19] in the early fifties and isolated from Streptomyces diastatochromogenes. The original complex was separated into three components, designated A, B and C [20]. The slight chemical differences between oligomycins A, B and C (Fig. 2.1A) do not affect the ability of these compounds to inhibit oxidative phosphorylation [21]. A combination of the three components, of which oligomycin A is the major component (comprising $\sim 65 \%$ ), is commonly used as an inhibitor of oxidative phosphorylation.

Oligomycin is characterized as an inhibitor of the ATP synthase [22, 23] (Fig. 2.1B). ATP synthase, also called complex V, is the final enzyme in the oxidative phosphorylation pathway. Under oxidative conditions, the role of this enzyme is to catalyze the formation of ATP from ADP and inorganic phosphate using energy from a proton motive force across the membrane to drive the reaction. The ATP 
synthase is composed of two structurally and functionally distinct domains, a transmembrane domain known as $\mathrm{F}_{0}$ and an intracellular globular domain, called $\mathrm{F}_{1}$, linked together by a central and peripheral stalk [24]. $F_{1}$ is the catalytic domain comprising the ATPase activity while $\mathrm{F}_{0}$ mediates the transmembrane proton transport and energy transfer to and from $F_{1}$. Thus, when $F_{1}$ is bound to $F_{0}$, the whole complex catalyzes ATP synthesis and hydrolysis, and in both cases these reactions are coupled to proton transport across the membrane through $F_{0}$ [25]. Oligomycin binds to the $\mathrm{F}_{0}$ subunit $[23,26,27]$ that blocks proton transport leading to inhibition of ATP synthesis. The inhibitory effect of oligomycin on complex V has been investigated in isolated bovine heart mitochondria. In these mitochondria complex V was inhibited for $90 \%$ by oligomycin with an IC50 value of $8 \mathrm{nM}$ [28].

\section{Cellular effects of oligomycin in the heart}

For the regulation of many cellular processes a maintained level of ATP is required. This applies that high amounts of ATP are needed for the regulation of calcium flux and contractile function during increased workload or contraction. Oligomycin has been used in many cardiac studies to investigate the role of the $F_{1} F_{0}$-ATPase complex or to prevent mitochondrial ATP synthesis by using low concentrations (< $1 \mu \mathrm{M})$. High concentrations of oligomycin have other effects on cellular function (e.g., heart function, oxygen consumption, $\mathrm{Ca}^{2+}$ influx and apoptosis) than only inhibition of ATP synthesis ( $>15-50 \mu \mathrm{M}$, depending on incubation conditions), as described below. However, many of these impaired cellular processes are an indirect result of low ATP content induced by oligomycin.

The heart is an adaptive organ, responding to changing needs by modifying contractile strength and beating rate. Perfusion of isolated rat hearts for 2 min with $10 \mu \mathrm{M}$ oligomycin did not change heart rate, but decreased cardiac function and increased coronary flow [29]. It has been suggested that decrease of cardiac function is the result of this marked decrease of ATP levels by $31 \%$. Oligomycinstimulated coronary flow suggests that there is a feedback mechanism to maintain the cardiac ATP content. It can be speculated that enhanced coronary flow results in elevated substrate supply to the heart for ATP production.

To maintain its function, the heart requires a constant supply of oxygen. High cardiac contractile performance leads to higher oxygen consumption in isolated cardiomyocytes [6] and in working heart preparations [12]. The workload related oxygen consumption is necessary for aerobic metabolic rates in the heart [3]. Oxygen consumption resulting from oxidation of cardiac substrates is increased after acute and prolonged workload stimulation [12]. Therefore, when cardiac substrate utilization is measured, oligomycin should not disrupt oxygen consumption. Indeed, to inhibit the oxygen consumption by $50 \%$ an oligomycin concentration five times higher than for ATPase inhibition has to be used [30]. In 
conclusion, when used at low concentrations, oligomycin can be applied to stimulate cardiac energy metabolism without disruption of oxygen levels.

Besides the substrates for ATP production, also myoplasmic $\mathrm{Ca}^{2+}$ is required during contraction. It is known that only high concentrations of oligomycin do interrupt calcium flux. The concentrations of oligomycin required to inhibit $\mathrm{Ca}^{2+}$ influx and efflux were nearly 50-fold higher than the concentrations that blocked mitochondrial ATP production [31].

Because oligomycin is leading to ATP depletion, this could affect the yield of cells during treatment with this compound. However, short incubation of oligomycin of maximally 30 minutes does not decrease the viability of isolated rat and mouse cardiomyocytes [14]. In contrast, incubations of cultured neonatal rat cardiomyocytes with $1 \mu \mathrm{M}$ oligomycin for 7 hours showed increased apoptosis [32]. Perhaps the inhibitory effect of oligomycin on ATP production is too strong to use it for long incubations. For instance, incubation of cells for 24 hours with 20 $\mu \mathrm{M}$ or $40 \mu \mathrm{M}$ oligomycin reduced the cellular ATP content by $80 \%$ and $90 \%$, respectively [33].

As described above, high concentrations of oligomycin can display other effects than only inhibition of the $\mathrm{F}_{1} \mathrm{~F}_{0}$-ATPase complex. This could complicate measurements of energy substrate metabolism in the heart. As a result, measurements of energy metabolism in working heart preparations and cardiomyocyte preparations should be performed with relatively low concentrations of oligomycin. A concentration of $1-15 \mu \mathrm{M}$ of oligomycin is preferred, depending on the incubation conditions and experimental setup.

\section{Effects of oligomycin on myocardial adenosine nucleotide concentrations}

Increased workload results in elevated intracellular concentrations of AMP at the expense of that of ATP. These changes are mimicked by oligomycin via inhibition of the mitochondrial ATPase which is leading to a drop in intracellular ATP concentration and a subsequent increased AMP/ATP ratio. In this section we will discuss the effect of oligomycin on the AMP/ATP ratio in different models, like the isolated working heart preparations, isolated cardiomyocytes preparations from rat or mouse hearts, and cell lines.

The metabolic status of the model studied could influence the effects of oligomycin. Perfusion of rat hearts with $5 \mu \mathrm{M}$ oligomycin for 10 minutes evokes an 44-fold increase of the cardiac AMP/ATP ratio [17]. Another study also showed that perfusion of rat hearts with $10 \mu \mathrm{M}$ oligomycin for 2 minutes reduces ATP concentration by $31 \%$ [29]. The impact of oligomycin on high-energy phosphate concentrations is greater in working heart preparations compared to isolated 
A

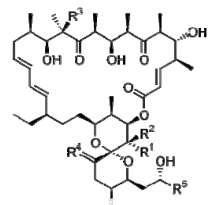

Oligomycins:
B

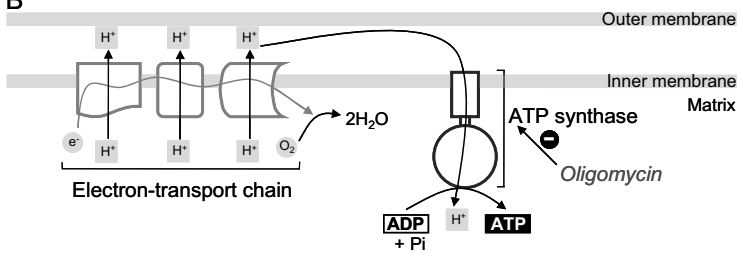

$\mathrm{A}: \mathrm{R}^{1}=\mathrm{CH}_{3}, \mathrm{R}^{2}=\mathrm{H}, \mathrm{R}^{3}=\mathrm{OH}, \mathrm{R}^{4}=-\mathrm{CH}_{2}$ -

B: $\mathrm{R}^{1}=\mathrm{H}, \mathrm{R}^{2}=\mathrm{CH}_{3}, \mathrm{R}^{3}=\mathrm{OH}, \mathrm{R}^{4}=\mathrm{C}=\mathrm{O}$

C: $\mathrm{R}^{1}=\mathrm{H}, \mathrm{R}^{2}=\mathrm{CH}_{3}, \mathrm{R}^{3}=\mathrm{H}, \mathrm{R}^{4}=-\mathrm{CH}_{2}-$
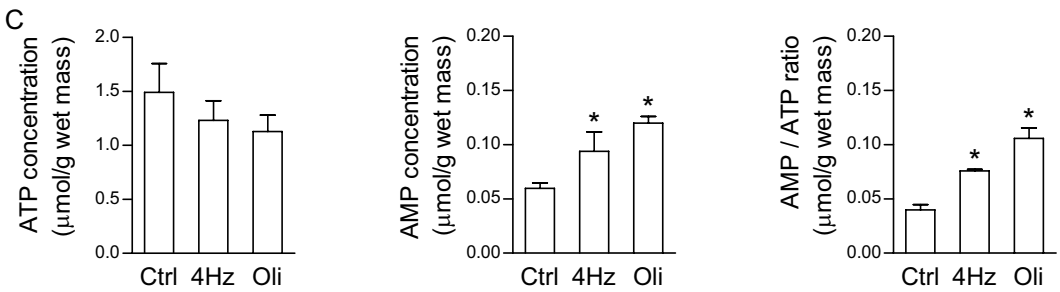

Figure 2.1 The structure of oligomycin, its inhibitory mechanism, and its effect on intracellular nucleoside phosphates in cardiomyocytes

Oligomycin occurs in three different isoforms, which vary in the composition of four residues (panel A). Oligomycin inhibits the ATP synthase present on the inner mitochondrial membrane by blocking its proton channel necessary for oxidative phosphorylation of ADP to ATP (panel B). Isolated cardiomyocytes from rats incubated for $15 \mathrm{~min}$ in the absence (Ctrl) or presence of electrical stimulation at $200 \mathrm{~V} / 4 \mathrm{~Hz}(4 \mathrm{~Hz})$ or $30 \mu \mathrm{M}$ oligomycin (Oli) stimulation showed changes in intracellular levels of ATP, AMP, and the AMP/ATP ratio (panel C). Data are means \pm SD of three to six experiments carried out with different cardiomyocyte preparations. *Significantly different from Ctrl $(\mathrm{P}<0.05)$.

cardiomyocyte preparations. Stimulation of rat cardiomyocytes with $30 \mu \mathrm{M}$ oligomycin for $15 \mathrm{~min}$ decreases the ATP concentration by $24 \%$, leading to an elevation of cardiomyocytic AMP/ATP ratio by 2.5-fold [14] (Fig. 2.1C). In mouse cardiomyocytes, oligomycin ( $1 \mu \mathrm{M}$ for $20 \mathrm{~min}$ ) induced a $47 \%$ drop in the ATP content resulting in a 6.3 -fold increase of AMP/ATP ratio. The difference in changes of high-energy phosphate concentration between species, i.e., rat and mouse, could be explained by difference in mitochondrial volume leading to higher oxidative metabolism. As mammals become smaller in body size, the volume that mitochondria occupy within the myocytes increases, as does the surface area of the inner mitochondrial membrane within the mitochondria itself [34-36]. 
As in isolated working hearts and in cardiomyocyte preparations, oligomycin has also been used in different cell lines. Treatment of Dmel2 (Drosophila embryonic cell line) cells with oligomycin (100 nM for 1 hour) caused very large increases in the cellular AMP/ATP ratio and ADP/ATP ratio (40-fold and 14-fold, respectively) [37]. Also in H4IIE (rat hepatoma cell line) cells $10 \mathrm{nM}$ oligomycin increased the $\mathrm{ADP} / \mathrm{ATP}$ ratio by 2-fold [18]. However, in $\mathrm{CHO}$ (Chinese hamster ovary fibroblasts) cells oligomycin stimulation ranging from 1 to $5 \mathrm{mM}$ did not significantly change the cellular ADP/ATP ratio [18]. The fact that $\mathrm{CHO}$ cells were resistant to inhibition of mitochondrial ATP synthesis shows that these cells must be capable of generating sufficient amounts of ATP by glycolysis only [18] rather than by oxidative metabolism [38]. In summary, oligomycin can be applied to change high-energy nucleotide concentrations in perfused hearts and isolated cardiomyocytes, although the effect on cell lines depends on the quantity of aerobic versus anaerobic metabolism of the cell.

Similar changes in the high-energy phosphate concentrations, as induced by oligomycin, have been observed after physiological manipulation (like cellular contractions and increased workload) [12]. This suggests that the onset of a higher metabolic demand induced by oligomycin is comparable with physiological situations, like contractions, in the heart. For example, in rat cardiomyocytes the use of oligomycin has been fully adapted to the metabolic alterations of electrical stimulation of cardiomyocytes. The ATP content in cardiomyocytes was reduced by $24.2 \%$ with oligomycin and by $17.4 \%$ with $4 \mathrm{~Hz}$ contractions while the AMP levels were elevated by $50 \%$ and $36.1 \%$, respectively (Fig. 2.1C). This results in an oligomycin-stimulated increase of the AMP/ATP ratio by 2.5 -fold, whereas $4 \mathrm{~Hz}$ contractions evokes a 1.9-fold increase (Fig. 2.1C). Although the mechanism of the applied tools is different (oligomycin inhibits ATP production while $4 \mathrm{~Hz}$ stimulation enhances the ATP consumption) the result in the AMP/ATP ratio is comparable. The changes in adenosine nucleotide phosphates show that the heart highly regulates processes to maintain the ATP content. In the next section we will discuss whether the reduced ATP content induced by oligomycin is leads to the activation of metabolic processes that produces ATP in the heart, i.e., cardiac substrate utilization.

\section{Effect of oligomycin on myocardial substrate uptake and oxidation}

The major substrates for the heart are fatty acid and carbohydrate. Long-chain fatty acids (LCFA) are the key lipids oxidized; glucose and lactate are the carbohydrates primary utilized. However, LCFA oxidation is the principal route for ATP synthesis with glucose being used to a minor extent both at rest and during exercise $[1,39]$. In 
order to investigate whether oligomycin mimics the metabolic effects of increased contractions, such as during exercise, we treated isolated cardiomyocytes derived from rat and mouse with oligomycin and determined LCFA and glucose uptake and oxidation. Indeed, oligomycin dose-dependently elevates the uptake rates of LCFA and glucose. When LCFA uptake was studied as a function of the oligomycin concentration, LCFA uptake was found to be maximally stimulated at 5-25 $\mu \mathrm{M}$ in rat cardiomyocytes (Fig. 2.2A) and $1-5 \mu \mathrm{M}$ in mouse cardiomyocytes (Fig. 2.2B). However, in both rat and mouse cardiomyocytes glucose uptake was already maximally stimulated at a lower concentration of oligomycin, namely $1 \mu \mathrm{M}$ and $0.2-1 \mu \mathrm{M}$, respectively. This suggests that the glucose uptake rates are stimulated by a more sensitive mechanism than LCFA uptake rates. Interestingly, although that the basal glucose uptake rates and rat or mouse cardiomyocytes differ, the relative impact of oligomycin is comparable (Fig. 2.2A).

Subsequently, the metabolic effects of oligomycin were compared with electricallystimulated rat cardiomyocytes. LCFA and glucose uptake increased with the pulse frequency up to $4 \mathrm{~Hz}$. Contractile activity elevates LCFA and glucose uptake by 1.5 fold and 2.0-fold, respectively, which is, however, lower than the stimulating effect of oligomycin on LCFA and glucose uptake (2.1-fold and 2.6-fold stimulation, respectively; Fig. 2.2C and 2.2D). Thus, when considering these two stimuli, there is a positive correlation between the AMP/ATP ratio and the uptake of LCFA and glucose. This suggests that both stimuli activate a common mechanism. This conclusion is strengthened by the observation that elevated LCFA uptake induced by oligomycin is ineffective in contracting cardiomyocytes (Fig. 2.2C).

Moreover, intracellular lipid metabolism (oxidation and esterification) was determined for both stimuli in rat cardiomyocytes. Again the effect of oligomycin (3.7-fold increase) on LCFA oxidation is larger compared to $4 \mathrm{~Hz}$ contractions (2.8fold increase). In addition, both stimuli do not change the esterification of LCFA into the lipid storage compartments [14]. Not only LCFA oxidation was stimulated by oligomycin but also glycolysis was increased in perfused rat heart as has also been observed during increased workload [40, 41]. Studies with working heart preparations in which LCFA and glucose were simultaneously measured showed opposite results regarding the preferred substrate during increased workload. Some studies demonstrated a selective increase in glucose utilization [42, 43], in contrast, other studies demonstrated a selective increase in LCFA utilization [44, 45] or a parallel increase in LCFA and glucose oxidation during increased workload [1, 12, $46,47]$. When working hearts were perfused with high palmitate levels, LCFA oxidation was increased at the expense of carbohydrates, as observed in oligomycin and electrically-stimulated cardiomyocytes [1, 12]. Because during exercise the blood supplies the heart with high levels of lipids $[48,49]$ these measurements are regarded more representative for the situation in vivo [39]. To summarize, in 
response to oligomycin, electrostimulation or increased workload, all of which cause the ATP concentration in the heart to decrease, a simultaneous LCFA oxidation and glucose oxidation accounts for ATP production, with LCFA oxidation being the main source of ATP.
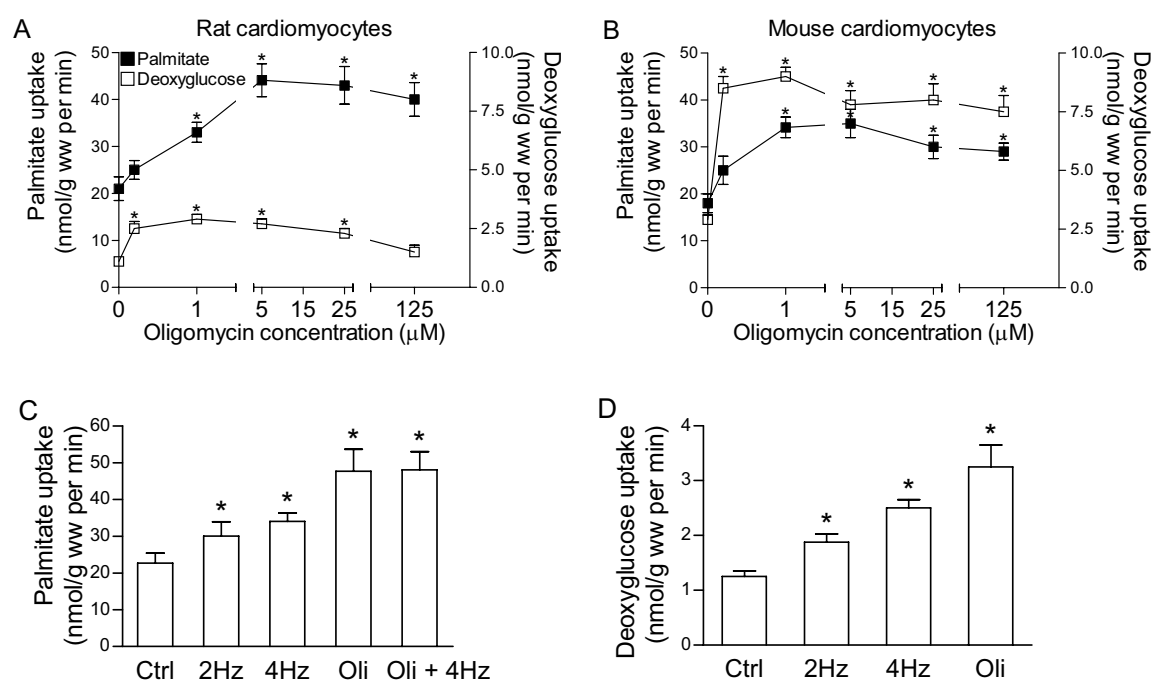

Figure 2.2 Frequency-dependent and dose-dependent effect of electrical stimulation and of oligomycin treatment, respectively, on substrate uptake in cardiomyocytes

Isolated cardiomyocytes from rat (panel A) and mouse (panel B) were incubated for 20 min with various concentrations of oligomycin $(0.2-125 \mu \mathrm{M})$. Subsequently, ${ }^{14} \mathrm{C}$-palmitate (left axis) and ${ }^{3} \mathrm{H}$-deoxyglucose (right axis) uptake were measured. The effects of 15 min treatment of rat cardiomyocytes in the absence (Ctrl) or presence of $30 \mu \mathrm{M}$ oligomycin (Oli) on ${ }^{14} \mathrm{C}$-palmitate (panel C) and ${ }^{3} \mathrm{H}$-deoxyglucose (panel D) were compared with electrostimulation at $2 \mathrm{~Hz}$, and $4 \mathrm{~Hz}$. Data are means $\pm \mathrm{SD}$ of 4 experiments carried out with different cardiomyocyte preparations. *Significantly different from $\mathrm{Ctrl}(\mathrm{P}<0.05)$.

\section{Application of oligomycin in studies on the regulation of cardiac energy metabolism}

Cardiac metabolism is regulated by a complex process which has been unraveled only partly. Oligomycin has been used successfully in different studies to identify important key players in the regulation of cardiac substrate transport (e.g., glucose and LCFA) and signal transduction pathways involved in substrate uptake and metabolism. These examples are reviewed below. 
Glucose uptake into cardiomyocytes has long been recognized to occur via a protein mediated process involving the glucose transporters 1 and 4 (GLUT1 and GLUT4). It is well documented that upon stimulation by insulin, GLUT4 is recruited from an intracellular membrane compartment to the sarcolemma concomitant with an increase in glucose uptake. In addition, increased sarcolemmal GLUT4 can be achieved by a drop in oxygen supply (anoxia/ischemia), by mitochondrial inhibitors, or by increased mechanical activity of the heart [15, 50, 51]. The observation that each factor induces a drop in cardiac ATP concentration, suggests that they share a common signaling pathway. Since oligomycin depletes the ATP content it seems likely that oligomycin also induces GLUT4-mediated glucose uptake. Indeed, the oligomycin-induced glucose uptake is associated with increased sarcolemmal GLUT4 [14, 52] (Fig. 2.3A). Subsequently, in several studies it has been observed that oligomycin stimulates glucose uptake in both rat [14, 52-54] and mouse [55] cardiomyocytes. Interestingly, it has been observed that the effects of oligomycin and cellular contractions on the trafficking cycle of GLUT4 are distinct. Oligomycin slows endocytosis of GLUT4 mediated transport while in contracting cardiomyocytes exocytosis of GLUT4 transport is stimulated [52]. Although the GLUT4-trafficking steps modulated by contraction and oligomycin are different, the result is the same: increased sarcolemmal GLUT4 concomitant with increased glucose uptake $[14,52]$. Thus, oligomycin can be used to stimulate GLUT4mediated glucose uptake in the heart but oligomycin is less appropriate to mimic contraction events in trafficking processes.

Oligomycin has been successfully used to delineate the regulation of LCFA uptake. LCFA uptake is mainly protein dependent, with sarcolemmal fatty acid translocase/CD36 (CD36) mediated uptake accounting for $70 \%$ of the total LCFA uptake rate. Like for GLUT4-mediated glucose uptake, the LCFA uptake rate increases with higher amounts of CD36 present at the sarcolemma [4]. The translocation of CD36 from intracellular compartments to the plasma membrane can be stimulated acutely by different stimuli like insulin and cellular contractions. CD36 is especially important during situations of higher metabolic demands in muscle tissue [56]. Just as insulin and contraction also oligomycin treatment results in increased LCFA uptake. The involvement of CD36 in oligomycin-induced LCFA uptake has been confirmed in both rat and mouse cardiomyocytes in different experimental setups. As observed during contractions, in oligomycin-stimulated rat cardiomyocytes both rates of LCFA uptake and amounts of sarcolemmal CD36 were increased (Fig. 2.3A). In addition, the oligomycin-induced increase in LCFA uptake could be completely inhibited with sulfo-N-succinimidyl oleate (SSO), a specific inhibitor of CD36 [14]. This suggests that oligomycin-induced LCFA uptake into cardiomyocytes is CD36 dependent. The use of cardiomyocytes from CD36 knockout mice strengthens this finding. In cardiomyocytes from CD36 
A

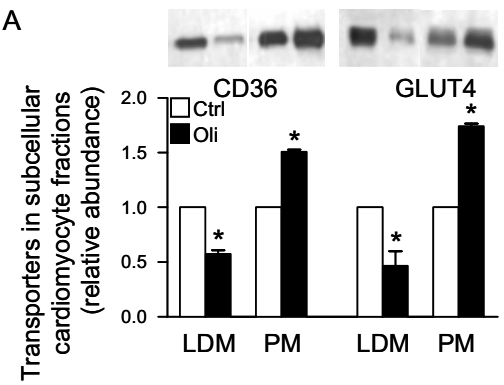

B

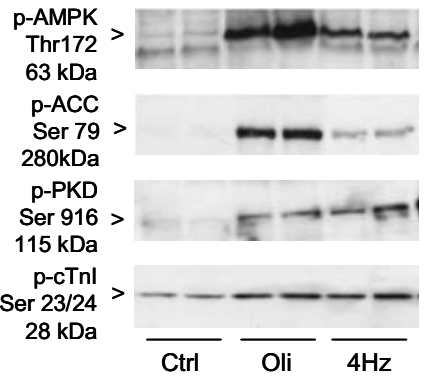

Figure 2.3 The effects of oligomycin and contraction on sarcolemmal transporter abundance and on signal transduction

Cardiomyocytes were incubated for 15 min with $30 \mu \mathrm{M}$ oligomycin (Oli) whereafter the cells were subjected to subcellular fractionation. The low-density microsomal (LDM) and plasma membrane (PM) fractions were subjected to electrophoresis and Western Blotting (panel A) to detect glucose transporter 4 (GLUT4) at $45 \mathrm{kDa}$ and fatty acid translocase/CD36 (CD36) at $88 \mathrm{kDa}$. Cardiomyocytes were treated with $1 \mu \mathrm{M}$ oligomycin (Oli), or with $4 \mathrm{~Hz}$ electrostimulation $(4 \mathrm{~Hz})$ during $15 \mathrm{~min}$ (panel B). For assessment of phosphorylation of protein kinase D (PKD)-Ser916 ( $\mathrm{n}=9$ ), cardiac troponin-I (cTnI)Ser23/24 ( $\mathrm{n}=5)$, AMP-activated protein kinase (AMPK)-Thr172 $(\mathrm{n}=10)$ and acetyl-CoA carboxylase (ACC)-Ser79 $(\mathrm{n}=10)$, cardiomyocytes were pelleted, dissolved in sample buffer, and thereafter which Western Blotting was performed with phosphospecific antibodies. Gels were loaded with equal quantities of protein for each cell lysate $(20 \mu \mathrm{g}$ per lane). Signals were quantified by densitometry. Transporter content is expressed as multiple of control (Ctrl) in the corresponding fraction. Data are means \pm SD of at least four experiments carried out with different cardiomyocyte preparations. Representative Western Blots are shown. *Significantly different from $\mathrm{Ctrl}(\mathrm{P}<0.05)$.

knockout mice the oligomycin-stimulated LCFA uptake was largely reduced [55] (see chapter 3). Taken together, these findings show that oligomycin can be applied to study myocardial CD36-mediated LCFA uptake.

As for the regulation of protein-mediated substrate uptake into the heart, oligomycin was crucial to study the signal transduction cascade involved in stimulated cardiac metabolism. AMP-activated protein kinase (AMPK), especially AMPK $\alpha 2$ which is the predominant subunit in the heart [57], has been established as a key player involved the activation of catabolic pathways (such as LCFA and glucose oxidation) and de-activation of anabolic pathways (such as LCFA and glucose storage). The first evidence that AMPK was involved in the regulation of LCFA uptake came from studies with isolated cardiomyocytes from rats that had been stimulated with oligomycin. Activation of AMPK was assessed by determining its ability to phosphorylate acetyl-CoA carboxylase (ACC), one of the major substrates of AMPK [58]. The phosphorylation of ACC by AMPK decreases its activity and results in a drop in the intracellular malonyl-CoA concentration and 
de-inhibition of mitochondrial LCFA oxidation [59]. Recently, we showed in cardiomyocytes from AMPK kinase-dead and AMPK $\alpha 2$ knockout mice that the effects of oligomycin on LCFA and glucose uptake were AMPK dependent (see chapter 4). Furthermore, the effects of oligomycin on the activation of AMPK signaling are comparable with that of electrostimulation. With both manipulations (oligomycin and electrostimulation) the rise in the AMP/ATP ratio was found to be sufficient to activate AMPK [14], but oligomycin (12.2-fold increase) is more potent than $4 \mathrm{~Hz}$ contractions (5.8-fold increase; Fig. 2.3B). In line with this, $4 \mathrm{~Hz}$ contractions substantially (5.0-fold) increased the phosphorylation of ACC. This increase is also of a lesser magnitude than that of oligomycin (8.7-fold). 6phosphofructo-2-kinase (PFK-2) another AMPK downstream kinase, is responsible for the synthesis of fructose 2,6-biphosphate, a potent stimulator of glycolysis [60, 61]. Oligomycin elevates PFK-2 phosphorylation and activity in perfused hearts $[17,61]$ and monocytes [41]. There is some controversy whether PFK-2 in the heart can be activated by AMPK or by a wortmannin-sensitive mechanism. In the heart PFK-2 can be activated AMPK-dependent by oligomycin [17], but AMPKindependent by increased workload [40]. To summarize, in isolated cardiomyocytes, treated with oligomycin or electrostimulation, AMPK is a crucial kinase in the regulation of substrate utilization, however, in working heart preparations and in vivo studies there is some controversy about the effect on AMPK activation in response to increased workload [40, 62-64].

Recently, two protein kinases upstream of AMPK have been identified, namely LKB1 and $\mathrm{Ca}^{2+}$-calmodulin-dependent protein kinase kinase- $\beta$ (CaMKK $\beta$ ) [65-67]. CaMKK $\beta$ activity is enhanced by an intracellular rise of calcium concentration, as observed after treating cells with $\mathrm{Ca}^{2+}$ ionophores [68] and during contractions of skeletal muscle [69]. In the heart CaMKK $\beta$ was able to strongly activate AMPK [70]. Since low concentrations of oligomycin do not affect the $\mathrm{Ca}^{2+}$ levels [31], the role of $\mathrm{Ca}^{2+}$-mediated CaMKK $\beta$ activity after oligomycin stimulation could be excluded. In contrast to CaMKK $\beta$, which is activated by an increase in intracellular $\mathrm{Ca}^{2+}$, LKB1 is constitutively active [71]. LKB1 is necessary for AMPK activation but has no regulatory role as its activity is not increased during contraction. In skeletal muscle the contraction-induced AMPK activity was greatly reduced in LKB1 knockout mice [72]. In LKB1 knockout mice the cardiomyocytic response of oligomycin-stimulated AMPK and ACC phosphorylation was markedly reduced (see chapter 4). In addition, the uptake rates of LCFA and glucose were totally inhibited in oligomycin-stimulated cardiomyocytes from these mice. In summary, oligomycin activates a similar signal transduction cascade as observed during increased workload and contraction, namely, the LKB1-AMPK axis as well as the downstream targets, i.e., ACC and PFK-2. 
Table 2.1 Effects of $4 \mathrm{~Hz}$ stimulation and of oligomycin on contraction signaling and transporter-mediated substrate uptake in cardiomyocytes.

\begin{tabular}{lcccccc}
\hline Intervention & \multicolumn{3}{c}{ Activation of } & & $\begin{array}{c}\text { CD36-mediated } \\
\text { LCFA uptake }\end{array}$ & $\begin{array}{c}\text { GLUT4-mediated } \\
\text { glucose uptake }\end{array}$ \\
\cline { 2 - 5 } & AMPK/ACC & PKD & CaMKK & & + \\
\hline 4Hz/ contraction & + & + & + & & + & + \\
Oligomycin & + & + & - & & & + \\
\hline
\end{tabular}

Electrical stimulation $(4 \mathrm{~Hz})$ and oligomycin treatment have similar effects on protein-mediated substrate uptake in cardiomyocytes. The signal transduction pathway activated by $4 \mathrm{~Hz}$ electrostimulation includes AMP-activated protein kinase (AMPK) / acetyl-CoA carboxylase (ACC), protein kinase $\mathrm{D}(\mathrm{PKD})$ and $\mathrm{Ca}^{2+}$-calmodulin-dependent protein kinase kinase (CaMKK) whereas oligomycin activates AMPK/ACC and PKD but not CaMKK in cardiomyocytes. Subsequently, activation of the contraction signaling pathway by $4 \mathrm{~Hz}$ stimulation and oligomycin simultaneously increased long-chain fatty acid (LCFA) and glucose uptake. This is mediated by the translocation of fatty acid translocase/CD36 (CD36) and the glucose transport protein 4 (GLUT4), respectively, from intracellular storage compartments to the plasma membrane.

Recently, we identified another protein kinase that is activated upon contraction, protein kinase D (PKD) [70]. Contractions of cardiomyocytes increased PKD phosphorylation to 5.1-fold, a similar order of magnitude compared to oligomycin stimulation (Fig. 2.3B). Since PKD is closely related to that of the CaMKK [73] it seems possible that contractions increase the activity of this protein. It has been observed that oligomycin and $4 \mathrm{~Hz}$-electrostimulation similarly increase PKD activity and, upon this, autophosphorylation of Ser916 [70]. The role of CaMKK $\beta$ and AMPK seems to be less important since in vitro phosphorylation assays: (i) inhibitors of CaMKK did not inhibit oligomycin-induced PKD phosphorylation, and (ii) studies with cardiomyocytes from AMPK $\alpha 2$ knockout mice had no impact on PKD activity. This suggests that contraction and oligomycin also activate a pathway independent of AMPK which involves PKD. One possibility to explain contraction-induced PKD activation could be via reactive oxygen species (ROS) as a by-product of oxidative phosphorylation, which are elevated during contraction and upon oligomycin treatment $[74,75]$. Indeed, ROS has found to be capable of inducing PKD activation [76], and ROS could also induce glucose uptake [77-79]. Moreover, by using inhibitors of PKD it has been shown that oligomycin-induced PKD activity could increase glucose uptake [70]. In a yeast 2-hybrid screen, troponin-I has been identified as substrate of PKD [80, 81]. Troponin-I is a contractile protein, it allows fast relaxation ensuring that heart muscle does not contract maximally $[82,83]$. Subsequently, troponin-I phosphorylation was noticed in both contracting and oligomycin-stimulated cardiomyocytes [70] (Fig. 2.3B). 


\section{Concluding remarks}

The molecular mechanisms regulating cardiac metabolism under different conditions are hard to study in vivo. Therefore, different approaches have been developed to investigate metabolic demands of the heart in vitro/ex vivo that is indicative of the metabolic demands seen in vivo. The pharmacological agent oligomycin has been established as a tool to increase cardiac energy metabolism in working heart and cardiomyocyte preparations. In previous studies with isolated cardiomyocytes comparable results have been observed on cardiac metabolism after oligomycin treatment and contraction stimulation, especially with regard to LCFA and glucose utilization (see Table 2.1). Subsequently, oligomycin has been used to unravel important key players in the regulation of LCFA and glucose uptake. It has been observed that AMPK is centrally involved in the CD36-mediated LCFA uptake and GLUT4-mediated glucose uptake. Recently, it has been shown that oligomycin could activate PKB [54] and PKD [70] concomitant with substrate uptake. Thus, oligomycin is a useful tool to unravel molecular processes and key players involved in metabolic events induced by contraction. However, oligomycin also has side-effects related to its main effect on cellular depletion. Importantly, these side-effects are seen at high oligomycin concentrations $(>25 \mu \mathrm{M})$ and/or during prolonged treatment $(>1 \mathrm{~h})$. A low concentration of oligomycin only inhibits the ATPase and will not interfere with the cellular process of interest. Therefore, the optimal concentration of oligomycin should be determined before using oligomycin as tool. In conclusion, oligomycin is a powerful tool to study physiological relevant levels of cardiac work and subsequently identify key players involved in cardiac metabolism. 


\section{References}

1 Belke DD, Larsen TS, Lopaschuk GD and Severson DL 1999 Glucose and fatty acid metabolism in the isolated working mouse heart. Am J Physiol 277: R1210-1217

2 Stanley WC, Recchia FA and Lopaschuk GD 2005 Myocardial substrate metabolism in the normal and failing heart. Physiol Rev 85: 1093-1129

3 Barr RL and Lopaschuk GD 2000 Methodology for measuring in vitro/ex vivo cardiac energy metabolism. J Pharmacol Toxicol Methods 43: 141-152

4 Luiken JJ, van Nieuwenhoven FA, America G, van der Vusse GJ and Glatz JF 1997 Uptake and metabolism of palmitate by isolated cardiac myocytes from adult rats: involvement of sarcolemmal proteins. J Lipid Res 38: 745-758

5 Neely JR and Morgan HE 1974 Relation between carbohydrate and lipid metabolism and the energy balance of the heart muscle. Annu Rev Biochem 36: 413-459

6 Luiken JJ, Coort SL, Koonen DP, Bonen A and Glatz JF 2004 Signalling components involved in contraction-inducible substrate uptake into cardiac myocytes. Proc Nutr Soc 63: 251-258

7 Luiken JJ, Willems J, van der Vusse GJ and Glatz JF 2001 Electrostimulation enhances FAT/CD36mediated long-chain fatty acid uptake by isolated rat cardiac myocytes. Am J Physiol Endocrinol Metab 281: E704-712

8 Awan MM and Saggerson ED 1993 Malonyl-CoA metabolism in cardiac myocytes and its relevance to the control of fatty acid oxidation. Biochem J 295: 61-66

9 Saddik M, Gamble J, Witters LA and Lopaschuk GD 1993 Acetyl-CoA carboxylase regulation of fatty acid oxidation in the heart. $J$ Biol Chem 268: 25836-25845

10 King KL, Okere IC, Sharma N, Dyck JR, Reszko AE, McElfresh TA, Kerner J, Chandler MP, Lopaschuk GD and Stanley WC 2005 Regulation of cardiac malonyl-CoA content and fatty acid oxidation during increased cardiac power. Am J Physiol Heart Circ Physiol 289: H1033-1037

11 Zhou L, Cabrera ME, Huang H, Yuan CL, Monika DK, Sharma N, Bian F and Stanley WC 2007 Parallel activation of mitochondrial oxidative metabolism with increased cardiac energy expenditure is not dependent on fatty acid oxidation in pigs. J Physiol 579: 811-821

12 Goodwin GW and Taegtmeyer H 2000 Improved energy homeostasis of the heart in the metabolic state of exercise. Am J Physiol Heart Circ Physiol 279: H1490-1501

13 Colston VL and Wheeler TJ 2001 Stimulation of cardiac glucose transport by inhibitors of oxidative phosphorylation. Life Sci 69: 2383-2398

14 Luiken JJ, Coort SL, Willems J, Coumans WA, Bonen A, van der Vusse GJ and Glatz JF 2003 Contraction-induced fatty acid translocase/CD36 translocation in rat cardiac myocytes is mediated through AMP-activated protein kinase signaling. Diabetes 52: 1627-1634

15 Wheeler TJ, Fell RD and Hauck MA 1994 Translocation of two glucose transporters in heart: effects of rotenone, uncouplers, workload, palmitate, insulin and anoxia. Biochim Biophys Acta 1196: 191-200

16 Luiken JJ, Coort SL, Koonen DP, van der Horst DJ, Bonen A, Zorzano A and Glatz JF 2004 Regulation of cardiac long-chain fatty acid and glucose uptake by translocation of substrate transporters. Pflugers Arch 448: 1-15

17 Marsin AS, Bertrand L, Rider MH, Deprez J, Beauloye C, Vincent MF, Van den Berghe G, Carling D and Hue L 2000 Phosphorylation and activation of heart PFK-2 by AMPK has a role in the stimulation of glycolysis during ischaemia. Curr Biol 10: 1247-1255

18 Hawley SA, Gadalla AE, Olsen GS and Hardie DG 2002 The antidiabetic drug metformin activates the AMP-activated protein kinase cascade via an adenine nucleotide-independent mechanism. Diabetes 51: $2420-2425$

19 Smith RM, Peterson WH and McCoy E 1954 Oligomycin, a new antifungal antibiotic. Antibiotics and Chemotherapy 4: 962-970

20 Masamune S, Sehgal JM, Van Tamelen EE, Strong FM and Peterson WH 1958 Seperation and preliminary characterization of oligomycins A, B, and C. J Am Chem Soc 80

21 Lardy HA, Witonsky P and Johnson D 1965 Antibiotics as Tools for Metabolic Studies. Iv. Comparative Effectiveness of Oligomycins a, B, C, and Rutamycin as Inhibitors of Phosphoryl Transfer Reactions in Mitochondria. Biochemistry 4: 552-554 
22 Chappell JB and Greville GD 1961 Effects of oligomycin on respiration and swelling of isolated liver mitochondria. Nature 190: 502-504

23 Lardy HA, Johnson D and Mc MW 1958 Antibiotics as tools for metabolic studies. I. A survey of toxic antibiotics in respiratory, phosphorylative and glycolytic systems. Arch Biochem Biophys 78: 587-597

24 Gaballo A, Zanotti F and Papa S 2002 Structures and interactions of proteins involved in the coupling function of the protonmotive F(o)F(1)-ATP synthase. Curr Protein Pept Sci 3: 451-460

25 Walker JE and Dickson VK 2006 The peripheral stalk of the mitochondrial ATP synthase. Biochim Biophys Acta 1757: 286-296

26 Kim SB and Berdanier CD 1999 Oligomycin sensitivity of mitochondrial F(1)F(0)-ATPase in diabetesprone BHE/Cdb rats. Am J Physiol 277: E702-707

27 Penefsky HS 1985 Mechanism of inhibition of mitochondrial adenosine triphosphatase by dicyclohexylcarbodiimide and oligomycin: relationship to ATP synthesis. Proc Natl Acad Sci U S A 82: 1589-1593

28 Nadanaciva S, Bernal A, Aggeler R, Capaldi R and Will Y 2007 Target identification of drug induced mitochondrial toxicity using immunocapture based OXPHOS activity assays. Toxicol In Vitro 21: $902-$ 911

29 Grover GJ, Atwal KS, Sleph PG, Wang FL, Monshizadegan H, Monticello T and Green DW 2004 Excessive ATP hydrolysis in ischemic myocardium by mitochondrial F1F0-ATPase: effect of selective pharmacological inhibition of mitochondrial ATPase hydrolase activity. Am J Physiol Heart Circ Physiol 287: H1747-1755

30 Ylitalo K, Ala-Rami A, Vuorinen K, Peuhkurinen K, Lepojarvi M, Kaukoranta P, Kiviluoma K and Hassinen I 2001 Reversible ischemic inhibition of $\mathrm{F}(1) \mathrm{F}(0)$-ATPase in rat and human myocardium. Biochim Biophys Acta 1504: 329-339

31 Cho JH, Balasubramanyam M, Chernaya G, Gardner JP, Aviv A, Reeves JP, Dargis PG and Christian EP 1997 Oligomycin inhibits store-operated channels by a mechanism independent of its effects on mitochondrial ATP. Biochem J 324: 971-980

32 Tatsumi T, Shiraishi J, Keira N, Akashi K, Mano A, Yamanaka S, Matoba S, Fushiki S, Fliss H and Nakagawa M 2003 Intracellular ATP is required for mitochondrial apoptotic pathways in isolated hypoxic rat cardiac myocytes. Cardiovasc Res 59: 428-440

33 Lim JH, Lee JI, Suh YH, Kim W, Song JH and Jung MH 2006 Mitochondrial dysfunction induces aberrant insulin signalling and glucose utilisation in murine C2C12 myotube cells. Diabetologia 49 : 1924-1936

34 Barth E, Stammler G, Speiser B and Schaper J 1992 Ultrastructural quantitation of mitochondria and myofilaments in cardiac muscle from 10 different animal species including man. J Mol Cell Cardiol 24: 669-681

35 Hoppeler H, Lindstedt SL, Claassen H, Taylor CR, Mathieu O and Weibel ER 1984 Scaling mitochondrial volume in heart to body mass. Respir Physiol 55: 131-137

36 Oron U and Mandelberg M 1985 Comparative morphometry of the mitochondria and activity of some enzymes in the myocardium of small mammals. J Mol Cell Cardiol 17: 627-632

37 Pan DA and Hardie DG 2002 A homologue of AMP-activated protein kinase in Drosophila melanogaster is sensitive to AMP and is activated by ATP depletion. Biochem J 367: 179-186

38 van Oort MM, van Doorn JM, Bonen A, Glatz JF, van der Horst DJ, Rodenburg KW and Luiken JJ 2008 Insulin-induced translocation of CD36 to the plasma membrane is reversible and shows similarity to that of GLUT4. Biochim Biophys Acta 1781: 61-71

39 Saddik M and Lopaschuk GD 1991 Myocardial triglyceride turnover and contribution to energy substrate utilization in isolated working rat hearts. J Biol Chem 266: 8162-8170

40 Beauloye C, Marsin AS, Bertrand L, Vanoverschelde JL, Rider MH and Hue L 2002 The stimulation of heart glycolysis by increased workload does not require AMP-activated protein kinase but a wortmannin-sensitive mechanism. FEBS Lett 531: 324-328

41 Marsin AS, Bouzin C, Bertrand L and Hue L 2002 The stimulation of glycolysis by hypoxia in activated monocytes is mediated by AMP-activated protein kinase and inducible 6-phosphofructo-2-kinase. $J$ Biol Chem 277: 30778-30783 
42 Kreisberg RA 1966 Effect of epinephrine on myocardial triglyceride and free fatty acid utilization. Am J Physiol 210: 385-389

43 Williamson JR 1964 Metabolic Effects of Epinephrine in the Isolated, Perfused Rat Heart. I. Dissociation of the Glycogenolytic from the Metabolic Stimulatory Effect. J Biol Chem 239: 2721-2729

44 Alousi AA and Mallow S 1964 Effects of Hyperthyroidism, Epinephrine, and Diet on Heart Lipoprotein Lipase Activity. Am J Physiol 206: 603-609

45 Gold M, Attar HJ, Spitzer JJ and Scott JC 1965 Effect of Norepinephrine on Myocardial Free Fatty Acid Uptake and Oxidation. Proc Soc Exp Biol Med 118: 876-879

46 Collins-Nakai RL, Noseworthy D and Lopaschuk GD 1994 Epinephrine increases ATP production in hearts by preferentially increasing glucose metabolism. Am J Physiol 267: H1862-1871

47 Zhou L, Huang H, Yuan CL, Keung W, Lopaschuk GD and Stanley WC 2008 Metabolic response to an acute jump in cardiac workload: effects on malonyl-CoA, mechanical efficiency, and fatty acid oxidation. Am J Physiol Heart Circ Physiol 294: H954-960

48 Gertz EW, Wisneski JA, Stanley WC and Neese RA 1988 Myocardial substrate utilization during exercise in humans. Dual carbon-labeled carbohydrate isotope experiments. J Clin Invest 82: 2017-2025

49 Johnson RH, Walton JL, Krebs HA and Williamson DH 1969 Metabolic fuels during and after severe exercise in athletes and non-athletes. Lancet 2: 452-455

50 Kolter T, Uphues I, Wichelhaus A, Reinauer H and Eckel J 1992 Contraction-induced translocation of the glucose transporter Glut4 in isolated ventricular cardiomyocytes. Biochem Biophys Res Commun 189: $1207-1214$

51 Zaninetti D, Greco-Perotto R and Jeanrenaud B 1988 Heart glucose transport and transporters in rat heart: regulation by insulin, workload and glucose. Diabetologia 31: 108-113

52 Yang J and Holman GD 2005 Insulin and contraction stimulate exocytosis, but increased AMP-activated protein kinase activity resulting from oxidative metabolism stress slows endocytosis of GLUT4 in cardiomyocytes. J Biol Chem 280: 4070-4078

53 Bergemann C, Loken C, Becker C, Graf B, Hamidizadeh M and Fischer Y 2001 Inhibition of glucose transport by cyclic GMP in cardiomyocytes. Life Sci 69: 1391-1406

54 Bertrand L, Ginion A, Beauloye C, Hebert AD, Guigas B, Hue L and Vanoverschelde JL 2006 AMPK activation restores the stimulation of glucose uptake in an in vitro model of insulin-resistant cardiomyocytes via the activation of protein kinase B. Am J Physiol Heart Circ Physiol 291: H239-250

55 Habets DD, Coumans WA, Voshol PJ, den Boer MA, Febbraio M, Bonen A, Glatz JF and Luiken JJ 2007 AMPK-mediated increase in myocardial long-chain fatty acid uptake critically depends on sarcolemmal CD36. Biochem Biophys Res Commun 355: 204-210

56 Bonen A, Han XX, Habets DD, Febbraio M, Glatz JF and Luiken JJ 2007 A null mutation in skeletal muscle FAT/CD36 reveals its essential role in insulin- and AICAR-stimulated fatty acid metabolism. Am J Physiol Endocrinol Metab 292: E1740-1749

57 Stapleton D, Mitchelhill KI, Gao G, Widmer J, Michell BJ, Teh T, House CM, Fernandez CS, Cox T, Witters LA and Kemp BE 1996 Mammalian AMP-activated protein kinase subfamily. J Biol Chem 271: 611-614

58 Dyck JR, Kudo N, Barr AJ, Davies SP, Hardie DG and Lopaschuk GD 1999 Phosphorylation control of cardiac acetyl-CoA carboxylase by cAMP-dependent protein kinase and 5'-AMP activated protein kinase. Eur J Biochem 262: 184-190

59 Rider MH, Bertrand L, Vertommen D, Michels PA, Rousseau GG and Hue L 2004 6-phosphofructo-2kinase/fructose-2,6-bisphosphatase: head-to-head with a bifunctional enzyme that controls glycolysis. Biochem J 381: 561-579

60 Depre C, Rider MH and Hue L 1998 Mechanisms of control of heart glycolysis. Eur J Biochem 258: 277-290

61 Musi N, Fujii N, Hirshman MF, Ekberg I, Froberg S, Ljungqvist O, Thorell A and Goodyear LJ 2001 AMP-activated protein kinase (AMPK) is activated in muscle of subjects with type 2 diabetes during exercise. Diabetes 50: 921-927

62 Roepstorff C, Donsmark M, Thiele M, Vistisen B, Stewart G, Vissing K, Schjerling P, Hardie DG, Galbo H and Kiens B 2006 Sex differences in hormone-sensitive lipase expression, activity, and 
phosphorylation in skeletal muscle at rest and during exercise. Am J Physiol Endocrinol Metab 291: E1106-1114

63 Coven DL, Hu X, Cong L, Bergeron R, Shulman GI, Hardie DG and Young LH 2003 Physiological role of AMP-activated protein kinase in the heart: graded activation during exercise. Am J Physiol Endocrinol Metab 285: E629-636

64 Hawley SA, Boudeau J, Reid JL, Mustard KJ, Udd L, Makela TP, Alessi DR and Hardie DG 2003 Complexes between the LKB1 tumor suppressor, STRAD alpha/beta and MO25 alpha/beta are upstream kinases in the AMP-activated protein kinase cascade. $J$ Biol 2: 28

65 Hurley RL, Anderson KA, Franzone JM, Kemp BE, Means AR and Witters LA 2005 The $\mathrm{Ca} 2+/$ calmodulin-dependent protein kinase kinases are AMP-activated protein kinase kinases. $J$ Biol Chem 280: 29060-29066

66 Woods A, Vertommen D, Neumann D, Turk R, Bayliss J, Schlattner U, Wallimann T, Carling D and Rider MH 2003 Identification of phosphorylation sites in AMP-activated protein kinase (AMPK) for upstream AMPK kinases and study of their roles by site-directed mutagenesis. J Biol Chem 278: 2843428442

67 Hawley SA, Pan DA, Mustard KJ, Ross L, Bain J, Edelman AM, Frenguelli BG and Hardie DG 2005 Calmodulin-dependent protein kinase kinase-beta is an alternative upstream kinase for AMP-activated protein kinase. Cell Metab 2: 9-19

68 Jensen TE, Rose AJ, Jorgensen SB, Brandt N, Schjerling P, Wojtaszewski JF and Richter EA 2007 Possible CaMKK-dependent regulation of AMPK phosphorylation and glucose uptake at the onset of mild tetanic skeletal muscle contraction. Am J Physiol Endocrinol Metab 292: E1308-1317

69 Luiken JJ, Vertommen D, Coort SL, Habets DD, El Hasnaoui M, Pelsers MM, Viollet B, Bonen A, Hue L, Rider MH and Glatz JF 2008 Identification of protein kinase D as a novel contraction-activated kinase linked to GLUT4-mediated glucose uptake, independent of AMPK. Cell Signal 20: 543-556

70 Sakamoto K, Goransson O, Hardie DG and Alessi DR 2004 Activity of LKB1 and AMPK-related kinases in skeletal muscle: effects of contraction, phenformin, and AICAR. Am J Physiol Endocrinol Metab 287: E310-317

71 Sakamoto K, McCarthy A, Smith D, Green KA, Grahame Hardie D, Ashworth A and Alessi DR 2005 Deficiency of LKB1 in skeletal muscle prevents AMPK activation and glucose uptake during contraction. Embo J 24: 1810-1820

72 Rozengurt E, Sinnett-Smith J, Van Lint J and Valverde AM 1995 Protein kinase D (PKD): a novel target for diacylglycerol and phorbol esters. Mutat Res 333: 153-160

73 Cortassa S, Aon MA, Winslow RL and O'Rourke B 2004 A mitochondrial oscillator dependent on reactive oxygen species. Biophys $J$ 87: 2060-2073

74 Katz A 2007 Modulation of glucose transport in skeletal muscle by reactive oxygen species. $J$ Appl Physiol 102: 1671-1676

75 Storz P, Doppler H, Johannes FJ and Toker A 2003 Tyrosine phosphorylation of protein kinase D in the pleckstrin homology domain leads to activation. J Biol Chem 278: 17969-17976

76 Derave W, Straumann N, Olek RA and Hespel P 2006 Electrolysis stimulates creatine transport and transporter cell surface expression in incubated mouse skeletal muscle: potential role of ROS. $\mathrm{Am} \mathrm{J}$ Physiol Endocrinol Metab 291: E1250-1257

77 Higaki Y, Hirshman MF, Fujii N and Goodyear LJ 2001 Nitric oxide increases glucose uptake through a mechanism that is distinct from the insulin and contraction pathways in rat skeletal muscle. Diabetes 50: 241-247

78 Sandstrom ME, Zhang SJ, Bruton J, Silva JP, Reid MB, Westerblad H and Katz A 2006 Role of reactive oxygen species in contraction-mediated glucose transport in mouse skeletal muscle. $J$ Physiol 575: 251262

79 Cuello F, Bardswell SC, Haworth RS, Yin X, Lutz S, Wieland T, Mayr M, Kentish JC and Avkiran M 2007 Protein kinase D selectively targets cardiac troponin I and regulates myofilament Ca2+ sensitivity in ventricular myocytes. Circ Res 100: 864-873

80 Haworth RS, Cuello F, Herron TJ, Franzen G, Kentish JC, Gautel M and Avkiran M 2004 Protein kinase $\mathrm{D}$ is a novel mediator of cardiac troponin I phosphorylation and regulates myofilament function. Circ Res 95: 1091-1099 
81 Schaub MC and Kunz B 1986 Regulation of contraction in cardiac and smooth muscles. J Cardiovasc Pharmacol 8 Suppl 8: S117-123

82 Layland J, Solaro RJ and Shah AM 2005 Regulation of cardiac contractile function by troponin I phosphorylation. Cardiovasc Res 66: 12-21 


\section{CHAPTER 3}

\section{AMPK-mediated increase in myocardial long-chain fatty acid uptake critically depends on CD36}

Daphna D.J. Habets ${ }^{1}$, Will A. Coumans ${ }^{1}$, Peter J. Voshol' ${ }^{2}$, Marion A. M. den Boer ${ }^{2}$, Maria Febbraio ${ }^{3}$, Arend Bonen $^{4}$, Jan F.C. Glatz ${ }^{1}$ and Joost J.F.P. Luiken ${ }^{1,5}$

${ }^{1}$ Department of Molecular Genetics, Cardiovascular Research Institute Maastricht (CARIM), Maastricht University, Maastricht, the Netherlands

${ }^{2}$ Department of Endocrinology and Diabetes, Leiden University Medical Center, Leiden, the Netherlands ${ }^{3}$ Departments of Cell Biology and Molecular Cardiology, the Center for Cardiovascular Diagnostics and Prevention, Lerner Research Institute, Cleveland Clinic Foundation, Cleveland, OH, USA

${ }^{4}$ Department of Human Health and Nutritional Sciences, University of Guelph, Guelph, Ontario N1G 2W1, Canada

${ }^{5}$ Department of Biochemical Physiology and Institute of Biomembranes, Utrecht University, Utrecht, the Netherlands

Biochem. Biophys. Res. Commun. 2007; 355:204-210 


\section{Abstract}

CD36, also named fatty acid translocase/CD36, has been identified as a putative membrane transporter for long-chain fatty acids (LCFA). In the heart, contractioninduced AMP-activated protein kinase (AMPK) signaling regulates cellular LCFA uptake through translocation of CD36 and possibly of other LCFA transporters from intracellular storage compartments to the sarcolemma. In this study isolated cardiomyocytes from WT and CD36 knockout mice were used to investigate to what extent basal and AMPK-mediated LCFA uptake are CD36-dependent. Basal LCFA uptake was not altered in CD36 knockout cardiomyocytes, most likely resulting from a (1.8-fold) compensatory upregulation of fatty acid-transport protein 1. The stimulatory effect of contraction-mimetic stimuli, oligomycin (2.5-fold) and dipyridamole (1.6-fold), on LCFA uptake into WT cardiomyocytes was almost completely lost in CD36 knockout cardiomyocytes, despite that AMPK signaling was fully intact. CD36 is almost entirely responsible for AMPK-mediated stimulation of LCFA uptake into cardiomyocytes, indicating a pivotal role for CD36 in mediating changes in cardiac LCFA fluxes. 


\section{Introduction}

Long-chain fatty acid (LCFA) and glucose are the predominant substrates for the heart, and contribute, under normal circumstances, for approximately $70 \%$ and $20 \%$, respectively, to cardiac energy production $[1,2]$. Cardiac LCFA uptake in rodents is largely mediated by protein-mediated transport, with a minor $(<20 \%)$ part attributable to passive diffusion [3]. Three proteins have been identified as functioning in transmembrane transport of LCFA and each is expressed in the cardiac muscle: fatty acid translocase/CD36 (CD36), plasma membrane fatty acidbinding protein (FABPpm), and fatty acid-transport protein (FATP) [4]. Transgenic mice would present an ideal model to investigate the contribution of each individual transporter to the cardiac LCFA flux.

The first studies with CD36 transgenic mice were performed by Febbraio et al. in 1999 [5]. CD36 knockout (CD36 KO) mice showed a significant increase in fasting plasma levels of cholesterol, (nonesterified) LCFA, and triacylglycerol, suggesting a functionally important role for CD36 in whole body lipid metabolism [5]. Tail vein injections of CD36 KO mice with radio-iodinated LCFA derivatives (BMIPP, IPPA) revealed that LCFA uptake into adipose tissue, skeletal muscle, and heart was reduced, and was associated with lower LCFA esterification into triacylglycerols in each tissue [6]. In addition, experiments with perfused hearts indicated that cardiac LCFA oxidation was markedly decreased in CD36 KO mice. This depressed cardiac LCFA oxidation was accompanied by a compensatory increase in glucose oxidation [7], highlighting the metabolic flexibility of the heart. Conversely, muscle-specific overexpression of CD36 elicits higher LCFA oxidation rates in skeletal muscle in response to contraction, but not during rest [8]. Only during an extra demand for energy, increased CD36 expression results in increased utilization of LCFA. Altogether, these studies with transgenic mouse models suggest that CD36-mediated LCFA uptake into heart and muscle is closely linked to changes in LCFA metabolism [9]. However, possible compensatory alterations in the expression of other LCFA transporters in these mice have not yet been evaluated, so that the quantitative involvement of CD36 in cardiac LCFA uptake remains unknown.

CD36 is not only a facilitator for LCFA uptake but also appears to be involved in the acute regulation of LCFA uptake. This regulation occurs by stimulus-induced reversible CD36 translocation from intracellular storage compartments to the sarcolemma [10]. These stimuli include cellular contractions and the hormone insulin, both of which have been found to induce glucose uptake through translocation of the glucose transporter 4 (GLUT4) [11, 12]. Just like insulininduced GLUT4 translocation, insulin-induced CD36 translocation, but not contraction-induced CD36 translocation was found to be dependent on activation of phosphatidylinositol-3-kinase [11]. Recently, studies have started to disclose the 
contraction signaling cascade involved in translocation of CD36 and GLUT4 in rat cardiomyocytes. This cascade is elicited by elevation of intracellular levels of AMP, leading to activation of AMP-activated protein kinase (AMPK) and, subsequently, downstream kinases, eventually resulting in the concomitant translocation of both CD36 and GLUT4 [13]. Interestingly, several pharmacological agents, among which oligomycin and dipyridamole, were also found to stimulate LCFA uptake through CD36 translocation $[13,14]$. Both oligomycin, a mitochondrial $F_{1} F_{0^{-}}$ ATPase inhibitor, and dipyridamole, a phosphodiesterase V/VI inhibitor, stimulated LCFA uptake in a non-additive manner to contractions, indicating that these agents activate the same signaling cascade as contractions. Indeed, oligomycin was found to potently activate AMPK. The stimulatory action of dipyridamole on LCFA uptake was unrelated to inhibition of phosphodiesterase activity, since zaprinast, another phosphodiesterase V/VI inhibitor, and isobutyl-methylxanthine, a general phosphodiesterase inhibitor, had no effect on LCFA uptake [15]. In fact, dipyridamole was able to translocate CD36 without influencing subcellular GLUT4 localization, indicating that it activates a signaling compound downstream of AMPK [14].

Besides regulating LCFA uptake, AMPK signaling is also involved in regulation of LCFA oxidation via control of the phosphorylation state of acetyl-CoA carboxylase (ACC), intracellular malonyl-CoA levels and of inhibition of carnitine palmitoyltransferases-I (CPT-I) [16]. The simultaneous recruitment of CD36 and activation of CPT-I by AMPK signaling serves to channel the extra LCFA taken up specifically into oxidative metabolism to increase ATP production needed for increased cardiac workload.

In order to properly assess the quantitative contribution of CD36 to initial LCFA uptake rate both in the absence and presence of AMPK stimulation we used freshly isolated cardiomyocytes as a model system for allowing to study LCFA uptake under carefully controlled conditions. Measurements of LCFA uptake and, for comparison, glucose uptake were performed in cardiomyocytes from both CD36 wild-type (WT) mice and CD36 KO mice under quiescent conditions and upon addition of oligomycin or dipyridamole. Sulfo- $N$-succinimidyl palmitate (SSP) which specifically inhibits CD36 [17] was used to determine the involvement of CD36 in LCFA uptake in WT mice.

\section{Materials and methods}

\section{Materials}

$\left[1-{ }^{14} \mathrm{C}\right]$ palmitic acid and 2-deoxy-D-[1- $\left.{ }^{3} \mathrm{H}\right]$ glucose were obtained from Amersham Life Science (Little Chalfont, U.K.). BSA (fraction V, essentially fatty acid free), DMSO, phloretin, oligomycin, and dipyridamole were obtained from Sigma (St. 
Louis, MO). Liberase blendzyme 1 was purchased from Roche Diagnostics (Indianapolis, IN). SSP is routinely synthesized in our laboratory, as has been previously described [18]. The antibody directed against phosphorylated ACC was from Upstate (Dundee, UK), and anti-phospho-AMPK from Cell Signalling (Danvers, MA). Antibodies directed against CD36 and GLUT4 were obtained from Chemicon International Inc. (Temecula, USA), and FATP1 and FATP4 from Santa Cruz Biotechnology Inc. (Santa Cruz, USA). Anti-FABPpm was a gift from Dr. J. Calles-Escandon, Wake Forest University School of Medicine \& Baptist Medical Center, Winston-Salem NC.

\section{Animals}

CD36 KO mice were generated by targeted homologous recombination and crossed back eight times to the $\mathrm{C} 57 \mathrm{Bl} / 6$ background [5]. CD36 $\mathrm{KO}$ and WT mice were bred at TNO Quality of Life, Leiden, the Netherlands. The Experimental Animal Committee of Maastricht University gave approval for all experiments involving animals.

\section{Isolation of mouse cardiomyocytes}

Adult mouse cardiomyocytes (mice 11-14 months of age) were isolated using a Langendorff perfusion system according to the procedure described by Severson et al. [19]. The main differences in cardiomyocyte isolation between mouse and rat include the type of collagenase used (Liberase blendzyme 1 versus Worthington collagenase type II) and the flow rate (constantly at $2.5 \mathrm{ml} / \mathrm{min}$ versus progressively increasing from $6 \mathrm{ml} / \mathrm{min}$ at the beginning till $11 \mathrm{ml} / \mathrm{min}$ at the end of the perfusion period) $[19,20]$. For all the experiments the viability of cardiomyocytes was $60-80 \%$ (data not shown).

\section{Substrate uptake by cardiomyocytes}

Cell suspensions were incubated with $1 \%$ dimethyl sulfoxide (DMSO) or 500 $\mu \mathrm{mol} / 1 \mathrm{SSP}$ in bicarbonate medium $\left(120 \mathrm{mM} \mathrm{NaCl}, 5.4 \mathrm{mM} \mathrm{KCl}, 1.2 \mathrm{mM} \mathrm{MgSO}_{4}\right.$, $1.2 \mathrm{mM} \mathrm{NaH}_{2} \mathrm{PO}_{4}, 20 \mathrm{mM} \mathrm{NaHCO} 3, \mathrm{pH} 7.5$ ) supplemented with $100 \mu \mathrm{M} \mathrm{CaCl}_{2}$ and $0.2 \%$ bovine serum albumin (BSA) during the recovery period of 30 minutes at room temperature, and subsequently washed and resuspended in bicarbonate medium supplemented with $100 \mu \mathrm{M} \mathrm{CaCl}$ and $2.0 \%$ BSA. Thereafter, cell suspensions $(2.0 \mathrm{ml} ; 5-9 \mathrm{mg}$ wet $\mathrm{mass} / \mathrm{ml})$ were pre-incubated in capped $20-\mathrm{ml}$ incubation vials with or without $15 \mu \mathrm{mol} / 1$ oligomycin or $100 \mu \mathrm{mol} / 1$ dipyridamole for $20 \mathrm{~min}$ at $37^{\circ} \mathrm{C}$ under continuous shaking. At the applied concentrations of oligomycin and dipyridamole, LCFA uptake rates were found to be maximally stimulated (data not shown). Oligomycin $(15 \mu \mathrm{mol} / \mathrm{l})$ increased the cellular 
AMP/ATP ratio by $>2$-fold, thereby increasing AMPK activity without inhibiting oxygen consumption [13]. To study palmitate and deoxyglucose uptake, $0.5 \mathrm{ml}$ of a mixture of $\left[1-{ }^{14} \mathrm{C}\right]$ palmitate/BSA complex and $\left[1-{ }^{3} \mathrm{H}\right]$ deoxyglucose was added at the start of the incubations so that the final concentration of both palmitate and deoxyglucose amounted to $100 \mu \mathrm{mol} / 1$ with a corresponding palmitate/BSA ratio of 0.3 [21]. Cellular uptake of palmitate (3-min incubation) and deoxyglucose (3-min incubation) was determined upon washing the cells three times for $2 \mathrm{~min}$ at $150 \mathrm{~g}$ in an ice-cold stop solution containing $0.2 \mathrm{mmol} / 1$ phloretin.

\section{Western Blotting}

The relative amounts of the substrate transporters CD36, FABPpm, FATP1, FATP4, and GLUT4 were determined in cardiomyocyte pellets obtained after a pulse spin in a microcentrifuge, and subsequently dissolved in sample buffer containing $62.5 \mathrm{mmol} / 1$ Tris- $\mathrm{HCl}$ (pH 6.8), 2 mmol/1 EDTA, 20 mmol/l dithiothreitol, 7.5\% (wt/vol) SDS, and 50\% sucrose. Upon SDS-ployacrylamide gel electrophoresis, we applied a mouse monoclonal anti-CD36 antibody 1258, a rabbit polyclonal anti-FABPpm antiserum, a goat polyclonal anti-FATP1 antiserum, antiFATP4 antiserum, and a sheep polyclonal anti-GLUT4 antiserum, respectively for the detection of these transporters according to manufacturer's instructions.

Upon pulse centrifugation of cardiomyocytes and dissolution of the pellet in sample buffer, activation of AMPK and ACC was measured with antibodies against phospho-AMPKa (Thr172) and phospho-ACC (Ser79), according to the manufacturer's instructions.

\section{Data presentation and statistics}

All data are present as means \pm S.E.M. for the indicated number of cardiomyocyte preparations. Statistical difference between means was analyzed by the paired Student's t test. P values $\leq 0.05$ were considered significant.

\section{Results and Discussion}

Prior studies addressing cardiac LCFA uptake in CD36 transgenic mice have only used semi-quantitative methods in assessing a role for CD36 in this process $[6,8]$. Our approach with freshly isolated cardiomyocytes in suspension provides accurate quantitative information about the initial LCFA uptake rate under controlled conditions. In addition with single-cell suspension of cardiomyocytes pharmacological agents such as the contraction-mimicking agents oligomycin and dipyridamole have easy access to their intracellular target allowing to study the dynamics of LCFA uptake, particularly in response to changes in energy demand that occur during alterations in myocytes contraction. 


\section{Involvement of CD36 in basal cardiac LCFA uptake}

Palmitate uptake into cardiomyocytes was studied at defined conditions at which the uptake rate is linear with time and linear with the exogenous concentration so as to allow the measurement of unidirectional influx in the absence of saturation of transporters [20]. Under basal conditions there is no difference in LCFA uptake between WT and CD36 KO cardiomyocytes (Fig. 3.1A). Remarkably, LCFA uptake into WT cardiomyocytes was decreased by $39 \%$ in the presence of SSP, while LCFA uptake into CD36 KO cardiomyocytes was unaffected by SSP (Fig. 3.1A). Several conclusions can be drawn from these observations. First, the lack of an effect of SSP on LCFA uptake into CD36 KO cardiomyocytes strongly confirms that SSP solely inhibits the CD36 component in the LCFA uptake process, and does not affect the activity of other transporters and/or passive diffusional uptake. Second, CD36 mediates 39\% of basal LCFA uptake into mouse cardiomyocytes, which is comparable to the CD36 component in basal LCFA uptake into cardiomyocytes from rat (50\%) [21]. Third, in CD36 KO cardiomyocytes there must be full compensation at the level of sarcolemmal transporters to maintain LCFA uptake. Therefore, we have measured in WT and CD36 KO cardiomyocytes expression levels of other LCFA transporters (Fig. 3.2). It appears that expression levels of FABPpm and FAPT4 were not different in WT and CD36 KO cardiomyocytes. However, FATP1 was 1.8 -fold $(\mathrm{P}<0.05)$ upregulated in CD36 KO cardiomyocytes, which could adequately explain the unaltered rate of basal cardiomyocytic LCFA uptake in the absence of CD36.

\section{Involvement of CD36 in AMPK-mediated cardiac LCFA uptake}

Two contraction-like pharmacological stimuli (oligomycin and dipyridamole) were used to study contraction-induced LCFA uptake into CD36 KO cardiomyocytes. We established previously that both agents stimulate AMPK signaling: oligomycin acts upstream of AMPK [13], and dipyridamole acts downstream of AMPK [14]. Accordingly, oligomycin potently stimulated phosphorylation of both AMPK and the AMPK target ACC in WT cardiomyocytes (Fig. 3.3A and 3.3B). Oligomycin had a similar effect on phosphorylation of both proteins in CD36 KO cardiomyocytes, indicating that AMPK-mediated signaling is fully intact in CD36 KO cardiomyocytes. Dipyridamole, which appears to act on a still unidentified protein kinase downstream of AMPK, did not significantly alter the phosphorylation states of AMPK-Thr172 and ACC-Ser79 either in WT or CD36 $\mathrm{KO}$ cardiomyocytes (Fig. 3.3A and 3.3B).

Just like in rat cardiomyocytes [13, 14], oligomycin (2.5-fold) and dipyridamole (1.6-fold) markedly stimulated LCFA uptake into WT cardiomyocytes (Fig. 3.1B). However, in CD36 KO cardiomyocytes, oligomycin-induced LCFA uptake was reduced by $79 \%$ to a residual (but significant) level of 1.3 -fold above basal. 
A

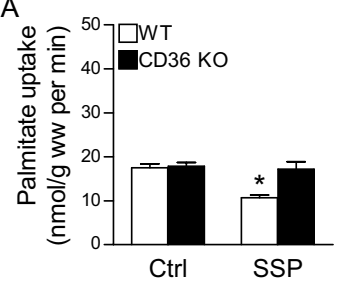

$\mathrm{C}$

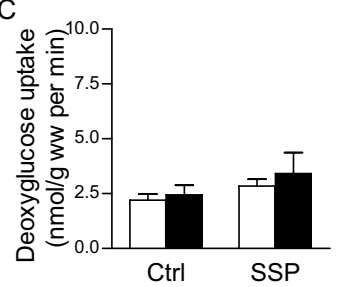

$\mathrm{B}$

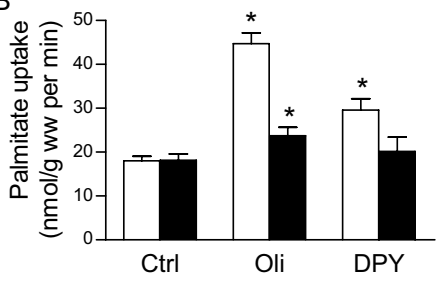

D

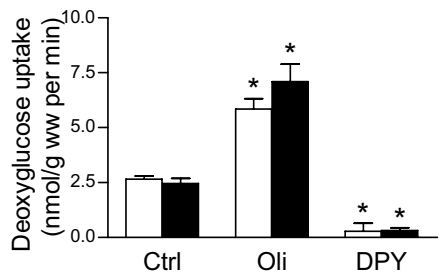

Figure 3.1 Effects of inhibition of CD36 and AMPK-mediated stimulation on substrate uptake by cardiomyocytes from WT and CD36 KO mice

WT (口) and CD36 KO cardiomyocytes ( $\square$ ) were incubated in the absence (Ctrl) or presence of 500 $\mu \mathrm{mol} / 1$ sulfo- $N$-succinimidyl palmitate (SSP; pre-incubation during the $30 \mathrm{~min}$ recovery period), centrifuged, washed and resuspended, whereafter uptake rates of palmitate (panel A) and deoxyglucose (panel C) were measured. To mimic contraction signaling, cardiomyocytes from WT mice ( $\square$ ) and CD36 KO mice (-) were incubated for $20 \mathrm{~min}$ in the absence (Ctrl) or presence of $15 \mu \mathrm{mol} / 1$ oligomycin (Oli) or $100 \mu \mathrm{mol} / \mathrm{l}$ dipyridamole (DPY) which was again followed by measurement of palmitate (panel B) and deoxyglucose (panel D) uptake. Values are means \pm S.E.M. for 4-7 animals per group. *Significantly different from $\mathrm{Ctrl}(\mathrm{P}<0.05)$.

Interestingly, we have recently shown in rat cardiomyocytes that the AMPK activation by the adenosine analog 5-aminoimidazole-4-carboxamide ribonucleoside (AICAR) results in translocation of both CD36 and FABPpm from an intracellular compartment to the sarcolemma [22]. Therefore, this small 1.3-fold increase in oligomycin-stimulated LCFA uptake into CD36 KO cardiomyocytes is most likely due to translocation of FABPpm. Just like genetic ablation of CD36, blocking CD36 with SSP in WT cardiomyocytes completely inhibited oligomycinstimulated LCFA uptake (oligomycin: $44.7 \pm 2.4$ i.e., 2.5 -fold basal versus oligomycin + SSP: $14.2 \pm 0.2$ i.e., 0.8 -fold basal; $\mathrm{n}=4, \mathrm{P}<0.05$ ), allowing us to estimate the contribution of CD36 to LCFA uptake into fully stimulated cardiomyocytes (i.e., optimal AMPK activation) to amount to $68 \%$.

The stimulatory effect of dipyridamole (1.6-fold) on LCFA uptake into WT cardiomyocytes was completely absent in CD36 KO cardiomyocytes (Fig. 3.1B). 


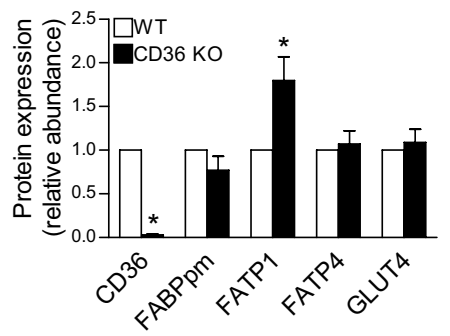

Figure 3.2 Expression of substrate transporters in cardiomyocytes from WT and CD36 KO mice

Protein expression of fatty acid translocase $/ \mathrm{CD} 36(\mathrm{CD} 36 ; 88 \mathrm{kDa})$, plasma membrane fatty acidbinding protein (FABPpm; $43 \mathrm{kDa}$ ), fatty acid-transport protein 1 (FATP1; $63 \mathrm{kDa})$, FATP4 (70 kDa), and glucose transporter 4 (GLUT4; $45 \mathrm{kDa}$ ) in cardiomyocytes from WT mice (口) and CD36 KO mice (-) was determined by Western Blotting followed by densitometry (relative abundance WT set at 1). From each sample, $20 \mu \mathrm{g}$ of myocytes wet mass was taken for electrophoresis. Western Blotting with antibodies against caveolin- 3 and $\beta$-actin further confirmed no differences in protein amount per lane (data not shown). Values are means \pm S.E.M for 6-10 animals per group. Representative Blots are shown. *Significantly different from WT $(\mathrm{P}<0.05)$.

Together, these findings strongly indicate that AMPK-mediated increase in LCFA uptake into the heart is critically dependent on the presence of CD36.

\section{Regulation of glucose uptake in CD36 KO hearts}

Similar to LCFA uptake, the rate of glucose uptake is not different between WT and CD36 KO cardiomyocytes under basal conditions (Fig. 3.1C). In line with this, the expression of GLUT4 is also not altered in CD36 KO cardiomyocytes (Fig. 3.2). SSP has no effect on glucose uptake (Fig. 3.1C), underlining that its inhibitory action is restricted to the LCFA uptake process. Oligomycin stimulated glucose uptake into CD36 KO (2.9-fold) and WT cardiomyocytes (2.2-fold) to a similar extent, while dipyridamole similarly inhibited glucose uptake into both WT $(-89 \%)$ and CD36 KO cardiomyocytes (-87\%; Fig. 3.1D). The inhibition of glucose uptake by dipyridamole is likely due to a direct interaction of dipyridamole with GLUT4 [23]. The selective inhibition of oligomycin-stimulated LCFA uptake, but not glucose uptake, into CD36 KO cardiomyocytes clearly illustrates that trafficking processes are not affected by CD36 ablation, and that AMPK-mediated GLUT4 translocation remains unaltered in CD36 KO cardiomyocytes. However, this study may seem in contrast to results obtained in a working heart model (continuous AMPK activation) [7]. In working hearts from CD36 KO mice, glucose oxidation 
A

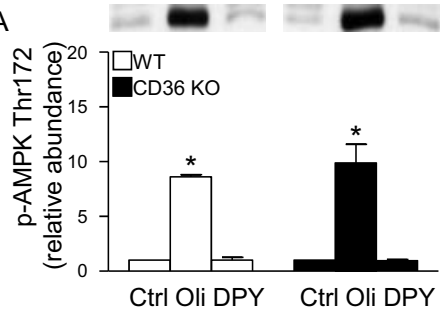

B

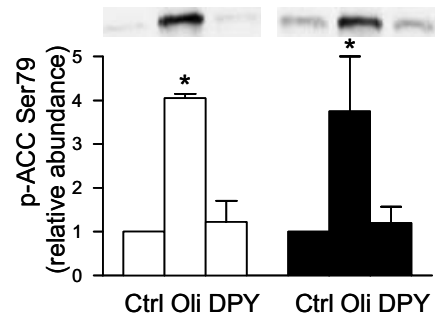

Figure 3.3 Effects of AMPK-mediated stimulation on the contraction signaling cascade in cardiomyocytes from WT and CD36 KO mice

Cardiomyocytes from WT mice (口) and CD36 KO mice (-) were incubated for $20 \mathrm{~min}$ in the absence (Ctrl) or presence of $15 \mu \mathrm{mol} / 1$ oligomycin (Oli) or $100 \mu \mathrm{mol} / 1$ dipyridamole (DPY). Phosphorylation of AMP-activated protein kinase (AMPK)-Thr172 (panel A) and of acetyl-CoA carboxylase (ACC)-Ser79 (panel B) was determined by Western Blotting followed by densitometry (relative abundance Ctrl set at 1). From each sample, $20 \mu \mathrm{g}$ of myocytes wet mass was taken for electrophoresis. Western Blotting with antibodies against caveolin-3 and $\beta$-actin further confirmed no differences in protein amount per lane (data not shown). Values are means \pm S.E.M. for 5-7 animals per group. Representative Blots are shown. *Significantly different from $\mathrm{Ctrl}(\mathrm{P}<0.05)$.

was 3-fold upregulated relative to WT hearts to compensate for the drop in palmitate oxidation. In fact, we do not think that there is a conflict between our study and the study using the working heart model, because the present study only excludes that the compensatory increase in glucose oxidation observed in CD36 KO working hearts can be explained at the level of glucose transporters and their recycling. This leaves open other compensatory mechanisms such as improved channeling of glucose metabolites into mitochondria and/or decreased storage of glucose into glycogen.

\section{Concluding remarks}

The major conclusions that can be drawn from these observations on cardiac substrate uptake in CD36 KO mice are: (i) CD36 contributes significantly to facilitating basal LCFA uptake, and its ablation results in compensatory upregulation of the myocardial expression of FATP1; (ii) CD36 is almost entirely responsible for the AMPK-mediated increase in LCFA uptake which increase is not compensated in cardiomyocytes from CD36 KO mice at the level of other LCFA transporters. The low rate of LCFA uptake in the working CD36 KO heart will likely contribute to the development of cardiac hypertrophy, as is seen in aged CD36 KO mice (M. Febbraio, unpublished observation) and human subjects lacking this major cardiac LCFA transporter [24]. 


\section{Acknowledgements}

We gratefully acknowledge Ms Rogayah Carroll and Prof. dr. David Severson, Department of Pharmacology and Therapeutics, Faculty of Medicine, University of Calgary, Canada, for their expert help to optimize the technique of isolating mouse cardiomyocytes.

This study was supported by the Netherlands Organisation for Health Research and Development (ZonMw grant nr. 40-00812-98-03075) and by the European Community (Integrated Project LSHM-CT-2004-005272, Exgenesis), the Canadian Institutes of Health Research, the Natural Sciences and Engineering Research Council of Canada, the Heart and Stroke Foundation of Ontario, the Canada Research Chair program, and the NIH, Heart, Lung and Blood Institute (HL 7008301).

J.J.F.P. Luiken is the recipient of a VIDI-Innovational Research grant from the Netherlands Organisation for Health Research and Development (ZonMw grant nr. 016.036.305). J.F.C. Glatz is Netherlands Heart Foundation Professor of Cardiac Metabolism. A. Bonen is the Canada Research Chair in Metabolism and Health. Peter J. Voshol is the recipient of a VENI-Innovational Research grant from the Netherlands Organisation for Health Research and Development (ZonMw grant nr. 916.036.071). 


\section{References}

1 Belke DD, Larsen TS, Lopaschuk GD and Severson DL 1999 Glucose and fatty acid metabolism in the isolated working mouse heart. Am J Physiol 277: R1210-1217

2 Carley AN and Severson DL 2005 Fatty acid metabolism is enhanced in type 2 diabetic hearts. Biochim Biophys Acta 1734: 112-126

3 Glatz JF and van der Vusse GJ 1996 Cellular fatty acid-binding proteins: their function and physiological significance. Prog Lipid Res 35: 243-282

4 Koonen DP, Glatz JF, Bonen A and Luiken JJ 2005 Long-chain fatty acid uptake and FAT/CD36 translocation in heart and skeletal muscle. Biochim Biophys Acta 1736: 163-180

5 Febbraio M, Abumrad NA, Hajjar DP, Sharma K, Cheng W, Pearce SF and Silverstein RL 1999 A null mutation in murine CD36 reveals an important role in fatty acid and lipoprotein metabolism. $J$ Biol Chem 274: 19055-19062

6 Coburn CT, Knapp FF, Jr., Febbraio M, Beets AL, Silverstein RL and Abumrad NA 2000 Defective uptake and utilization of long chain fatty acids in muscle and adipose tissues of CD36 knockout mice. $J$ Biol Chem 275: 32523-32529

7 Kuang M, Febbraio M, Wagg C, Lopaschuk GD and Dyck JR 2004 Fatty acid translocase/CD36 deficiency does not energetically or functionally compromise hearts before or after ischemia. Circulation 109: 1550-1557

8 Ibrahimi A, Bonen A, Blinn WD, Hajri T, Li X, Zhong K, Cameron R and Abumrad NA 1999 Musclespecific overexpression of FAT/CD36 enhances fatty acid oxidation by contracting muscle, reduces plasma triglycerides and fatty acids, and increases plasma glucose and insulin. J Biol Chem 274: 2676126766

9 Brinkmann JF, Abumrad NA, Ibrahimi A, van der Vusse GJ and Glatz JF 2002 New insights into longchain fatty acid uptake by heart muscle: a crucial role for fatty acid translocase/CD36. Biochem $J 367$ : 561-570

10 Bonen A, Luiken JJ, Arumugam Y, Glatz JF and Tandon NN 2000 Acute regulation of fatty acid uptake involves the cellular redistribution of fatty acid translocase. J Biol Chem 275: 14501-14508

11 Luiken JJ, Koonen DP, Willems J, Zorzano A, Becker C, Fischer Y, Tandon NN, Van Der Vusse GJ, Bonen A and Glatz JF 2002 Insulin stimulates long-chain fatty acid utilization by rat cardiac myocytes through cellular redistribution of FAT/CD36. Diabetes 51: 3113-3119

12 Luiken JJ, Willems J, van der Vusse GJ and Glatz JF 2001 Electrostimulation enhances FAT/CD36mediated long-chain fatty acid uptake by isolated rat cardiac myocytes. Am J Physiol Endocrinol Metab 281: E704-712

13 Luiken JJ, Coort SL, Willems J, Coumans WA, Bonen A, van der Vusse GJ and Glatz JF 2003 Contraction-induced fatty acid translocase/CD36 translocation in rat cardiac myocytes is mediated through AMP-activated protein kinase signaling. Diabetes 52: 1627-1634

14 Luiken JJ, Coort SL, Willems J, Coumans WA, Bonen A and Glatz JF 2004 Dipyridamole alters cardiac substrate preference by inducing translocation of FAT/CD36, but not that of GLUT4. Mol Pharmacol 65: 639-645

15 Luiken JJ, Willems J, Coort SL, Coumans WA, Bonen A, Van Der Vusse GJ and Glatz JF 2002 Effects of cAMP modulators on long-chain fatty-acid uptake and utilization by electrically stimulated rat cardiac myocytes. Biochem J 367: 881-887

16 Hardie DG and Pan DA 2002 Regulation of fatty acid synthesis and oxidation by the AMP-activated protein kinase. Biochem Soc Trans 30: 1064-1070

17 Coort SL, Willems J, Coumans WA, van der Vusse GJ, Bonen A, Glatz JF and Luiken JJ 2002 Sulfo-Nsuccinimidyl esters of long chain fatty acids specifically inhibit fatty acid translocase (FAT/CD36)mediated cellular fatty acid uptake. Mol Cell Biochem 239: 213-219

18 Staros JV 1982 N-hydroxysulfosuccinimide active esters: bis(N-hydroxysulfosuccinimide) esters of two dicarboxylic acids are hydrophilic, membrane-impermeant, protein cross-linkers. Biochemistry 21: 3950-3955

19 Carroll R, Carley AN, Dyck JR and Severson DL 2005 Metabolic effects of insulin on cardiomyocytes from control and diabetic db/db mouse hearts. Am J Physiol Endocrinol Metab 288: E900-906 
20 Luiken JJ, Schaap FG, van Nieuwenhoven FA, van der Vusse GJ, Bonen A and Glatz JF 1999 Cellular fatty acid transport in heart and skeletal muscle as facilitated by proteins. Lipids 34 Suppl: S169-175

21 Luiken JJ, van Nieuwenhoven FA, America G, van der Vusse GJ and Glatz JF 1997 Uptake and metabolism of palmitate by isolated cardiac myocytes from adult rats: involvement of sarcolemmal proteins. J Lipid Res 38: 745-758

22 Chabowski A, Coort SL, Calles-Escandon J, Tandon NN, Glatz JF, Luiken JJ and Bonen A 2005 The subcellular compartmentation of fatty acid transporters is regulated differently by insulin and by AICAR. FEBS Lett 579: 2428-2432

23 Steinfelder HJ and Joost HG 1988 Inhibition of insulin-stimulated glucose transport in rat adipocytes by nucleoside transport inhibitors. FEBS Lett 227: 215-219

24 Okamoto F, Tanaka T, Sohmiya K and Kawamura K 1998 CD36 abnormality and impaired myocardial long-chain fatty acid uptake in patients with hypertrophic cardiomyopathy. Jpn Circ J 62: 499-504 
62 | 


\section{CHAPTER 4}

\section{Crucial role for LKB1 to AMPKa2 axis in the regulation of CD36- mediated long-chain fatty acid uptake into cardiomyocytes: comparison with GLUT4-mediated glucose uptake}

Daphna D.J. Habets ${ }^{1}$, Will A. Coumans ${ }^{1}$, Mohammed El Hasnaoui ${ }^{1}$, Elham Zarrinpashneh ${ }^{2}$, Luc Bertrand ${ }^{2}$, Benoit Viollet, ${ }^{3,4}$, Bente Kiens ${ }^{5}$, Thomas E. Jensen ${ }^{5}$, Erik A. Richter ${ }^{5}$, Arend Bonen ${ }^{6}$, Jan F.C. Glatz ${ }^{1}$ and Joost J.F.P. Luiken ${ }^{1}$

${ }^{1}$ Department of Molecular Genetics, Cardiovascular Research Institute Maastricht (CARIM), Maastricht University, Maastricht, the Netherlands

${ }^{2}$ Université catholique de Louvain, Division of Cardiology, Brussels, Belgium

${ }^{3}$ Institut Cochin, Université Paris Descartes, CNRS, UMR8104, Paris, France

${ }^{4}$ INSERUM, U567, Paris, France

${ }^{5}$ Copenhagen Muscle Research Centre, Molecular Physiology Group, Department of Exercise and Sport Sciences, University of Copenhagen, Copenhagen, Denmark

${ }^{6}$ Department of Human Health and Nutritional Sciences, University of Guelph, Guelph, Ontario N1G 2W1, Canada

Submitted 


\section{Abstract}

Enhanced contractile activity increases cardiac long-chain fatty acids (LCFA) and glucose uptake via translocation of the substrate transporters fatty acid translocase/CD36 and glucose transporter 4 to the sarcolemma, respectively. AMPactivated protein kinase (AMPK) is proposed to be involved in these translocation processes. Furthermore, no studies have been performed on the role of LKB1, a kinase with AMPKK activity, on regulation of cardiac LCFA uptake. Using different genetically engineered mouse models (AMPK 22 kinase-dead, AMPK 22 knockout and LKB1 knockout mice), we tested whether LKB1 and AMPK are required for stimulation of LCFA and glucose utilization upon treatment of cardiomyocytes with compounds that mimic the metabolic effects of contraction. In cardiomyocytes from AMPK $\alpha 2$ kinase-dead mice, the stimulating effects of oligomycin and AICAR on LCFA and deoxyglucose uptake and LCFA oxidation were almost completely lost. Moreover, in cardiomyocytes from AMPK $\alpha 2$ and LKB1 knockout mice, oligomycin-induced LCFA and glucose uptake were completely abolished. However, the stimulatory effect of dipyridamole, another compound inducing CD36 translocation in a contraction-mimetic manner, on LCFA uptake and oxidation was preserved in cardiomyocytes from AMPK $\alpha 2$ kinase-dead mice. In conclusion, in the heart there is a signaling axis consisting of LKB1 and AMPK $\alpha 2$ which activation results in enhanced LCFA and glucose utilization. In addition, an unknown dipyridamole-activated pathway, can stimulate cardiac LCFA utilization by activating signaling downstream of AMPK. 


\section{Introduction}

Long-chain fatty acid (LCFA; 60-70\%) and glucose (20-30\%) are the primary substrates for cardiac ATP production $[1,2]$. Glucose uptake into cardiomyocytes has long been recognized to occur via a protein mediated process involving glucose transporter 4 (GLUT4; >70\%) and glucose transporter 1 (GLUT1; <30\%) [3]. More recently, it has been shown that LCFA uptake is also protein-dependent [4], with fatty acid translocase/CD36 (CD36) accounting for $70 \%$ of the LCFA uptake rate $[5,6]$. In isolated cardiomyocytes, contraction induces the translocation of both CD36 and GLUT4, within minutes, from an intracellular membrane compartment to the sarcolemma $[7,8]$. Thus, substrate provision into cardiomyocytes can be rapidly upregulated in concert with increased energetic demands.

As to the signaling pathways involved in contraction-induced translocation of CD36 and GLUT4 in the heart, there are a number of possible routes, since contraction activates a great variety of protein kinases $[9,10]$. An important candidate kinase is AMP-activated protein kinase (AMPK), because it is rapidly activated by contraction and it orchestrates a variety of metabolic actions in heart and skeletal muscle [11]. AMPK is a heterotrimeric protein consisting of a catalytic $\alpha$ subunit and two regulatory subunits $\beta$ and $\gamma$. Two isoforms of the $\alpha$ subunit have been identified, i.e., AMPK $\alpha 1$ and $\mathrm{AMPK} \alpha 2$; and also for the other subunits, different isoforms are described. Both AMPK $\alpha 1$ and AMPK $\alpha 2$ are expressed in the heart, of which AMPK $\alpha 2$ is the predominant subunit [12].

Previously, the importance of AMPK activity in glucose utilization by skeletal muscle and heart was explored in different genetically manipulated mice. The increase in glucose uptake during ischemia [13] and reperfusion [14] was reduced in hearts from mice expressing a AMPK $\alpha 2$ kinase-dead subunit (AMPK KD) and in hearts from AMPK $\alpha 2$ knockout (AMPK $\alpha 2 \mathrm{KO}$ ) mice [15]. Not only glucose uptake but also LCFA oxidation was impaired during perfusion in AMPK KD hearts [14]. In skeletal muscle from muscle-specific AMPK $\alpha 2 \mathrm{KD}$ mice $[16,17], \mathrm{AMPK} \alpha 2 \mathrm{KO}$ mice [18] and AMPK $\gamma 3$ KO mice [19], 5-aminoimidazole-4-carboxamide ribonucleoside (AICAR)-induced glucose uptake was completely blocked. However, contraction-induced glucose uptake into skeletal muscle was not affected [17-19] or only partly reduced $[16,20]$ in these mouse models. Hence, these conflicting results cast doubt on the role of AMPK in contraction-induced glucose uptake in muscle tissues.

A number of protein kinases have been proposed to function in contraction signaling upstream of AMPK, including LKB1 and calmodulin-dependent protein kinase kinase (CaMKK) [11, 21]. In vivo, the upstream kinases LKB1 and CaMKK $\beta$ are each regulated differently. In muscle tissue, CaMKK $\beta$ is activated by an increase in intracellular $\mathrm{Ca}^{2+}$ [21]. In contrast, LKB1 is constitutively active [22], but it can only activate AMPK during conditions at which intracellular AMP is 
elevated. Namely, AMP-binding to AMPK induces a conformational change within the AMPK complex so that Thr172 becomes accessible to phosphorylation by LKB1 [23]. Whether CaMKK $\beta$ regulates contraction-stimulated glucose uptake in muscle via AMPK activation remains controversial $[20,24]$. However, in LKB1 knockout mice (LKB1 KO), contraction and AICAR-stimulated glucose uptake by muscle were reduced [25], as was LCFA oxidation [26]. However, no studies have been undertaken to assess the role of LKB1 in regulation of cardiac substrate uptake by contraction.

Pharmacological agents are commonly used to activate AMPK, including AICAR $[27,28]$ and the $\mathrm{F}_{1} \mathrm{~F}_{0}$-ATPase inhibitor oligomycin [7, 29]. At appropriate concentrations these agents stimulate LCFA and glucose uptake into cardiomyocytes, by inducing the translocation of CD36 and GLUT4 to the sarcolemma, respectively $[6,7,30,31]$. Importantly, the effects of AICAR and oligomycin on LCFA and glucose uptake in cardiomyocytes are not additive to that of contraction, suggesting that the signaling pathways activated by these agents converge with the contraction signaling pathway to induce CD36 and GLUT4 translocation. Dipyridamole is another compound that induces CD36 translocation in a contraction-mimetic manner, because, just like oligomycin and AICAR, it stimulates LCFA uptake into cardiomyocytes in a non-additive manner to contraction [32]. In contrast to oligomycin and AICAR, dipyridamole does not activate AMPK nor does it stimulate glucose uptake, suggesting that this compound acts on a component in the contraction pathway to CD36 translocation downstream of AMPK, resulting in a selective increase in LCFA uptake [6, 32].

Until now, the involvement of AMPK in the regulation of LCFA and glucose uptake in the heart has only been deduced from an association between AMPK activation by different stimuli, i.e., 4Hz-electrostimulation, biguanide molecules, oligomycin and AICAR, and their stimulating action on LCFA and glucose uptake into cardiomyocytes [7, 31]. Mice deficient for AMPK or its upstream kinases are excellently suited to provide definitive proof for a key role of AMPK in cardiac substrate uptake. Of the available mouse models, AMPK KD mice would be most suited because in this model both AMPK $\alpha 1$ and $\alpha 2$ activities are reduced [14]. On the other hand, in AMPK $\alpha 2 \mathrm{KO}$ mice, $\alpha 1$ activity is maintained in the heart [33] or even increased in skeletal muscle [18], and therefore might allow some residual AMPK activation. Furthermore, in cardiomyocytes from LKB1 KO mice, other putative AMPKK's, such as CaMKK $\beta$, could provide an alternative route to activate AMPK in response to contraction. Therefore, we started with cardiomyocytes from AMPK KD mice on characterizing AMPK signaling and energy metabolism, especially on the responses of these processes towards oligomycin, AICAR and dipyridamole. Upon establishment of the overall role of AMPK in contraction-induced substrate uptake in AMPK KD mice, we attempted 
to answer the questions which $\alpha$-isoform of AMPK and which upstream kinase are involved. For this purpose, we used AMPK $22 \mathrm{KO}$ mice and LKB1 KO mice, and studied the effects of oligomycin on glucose and LCFA uptake into cardiomyocytes isolated from these mice. Our studies demonstrate that activation of a signaling axis involving LKB1 and AMPK $\alpha 2$ results in stimulation of LCFA and glucose uptake into cardiomyocytes treated with agents that induce CD36 and GLUT4 translocation, respectively, in a contraction-mimetic manner. Interestingly, there is a signaling pathway activated by dipyridamole which converges with AMPK signaling downstream of AMPK, specifically leading to increased LCFA uptake and oxidation.

\section{Materials and methods}

\section{Materials}

$\left[1-{ }^{14} \mathrm{C}\right]$ palmitic acid, 2-deoxy-D-[1- $\left.{ }^{3} \mathrm{H}\right]$ glucose, $\left[\gamma_{-}{ }^{32} \mathrm{P}\right]$ ATP and protein G sepharose 4 were obtained from GE Healthcare (Piscataway, NJ, USA). BSA (fraction $\mathrm{V}$, essentially fatty acid free), laminin, phloretin, DMSO, oligomycin, AICAR and dipyridamole were obtained from Sigma (St. Louis, MO). Liberase blendzyme 1 and protease inhibitor cocktail tablets were purchased from Roche Diagnostics (Indianapolis, IN). Sulfo-NHS-LC-biotin and immobilized streptavidin were from Perbio Science (Etten-Leur, the Netherlands).The antibody directed against phosphorylated acetyl-CoA carboxylase (ACC) was from Upstate (Dundee, UK), and anti-phospho-AMPK from Cell Signalling (Danvers, MA). Antibodies directed against CD36 and GLUT4 were obtained from Chemicon International Inc. (Temecula, USA). The antibodies directed against AMPK $\alpha 1$ and AMPK $\alpha 2$, and the SAMS peptide were a gift from Prof. Grahame Hardie (University of Dundee, UK).

\section{Animals}

The following genetically manipulated mouse models were bred separately and studied: i) muscle-specific AMPK $\alpha 2$ kinase-dead [16] and wild-type (WT) mice from the University of Copenhagen, Denmark; ii) AMPK $\alpha 2$ knockout [34] and WT mice from the Universite Paris Descartes, France; and iii) muscle-specific $\mathrm{LKB1}^{\text {floxed/floxed }}$ Cre recombinase ${ }^{+/-}[25]$ and WT mice from the Université catholique de Louvain, Belgium. All these mouse models have a C57Bl/6 background. The Experimental Animal Committee of Maastricht University gave approval for all experiments involving animals.

\section{Isolation and pre-incubation of mouse cardiomyocytes}

Adult mouse cardiomyocytes (male mice 2-3 months of age) were isolated using a Langendorff perfusion system according to the procedure described by Severson et 
al. [35], which has been described previously [6]. For all the experiments the viability of cardiomyocytes was $60-80 \%$ (data not shown).

Cell suspensions $(2.0 \mathrm{ml} ; 5-10 \mathrm{mg}$ wet $\mathrm{mass} / \mathrm{ml})$ were pre-incubated in capped 20$\mathrm{ml}$ incubation vials either with $0.35 \%$ dimethyl sulfoxide (DMSO; Ctrl), $1 \mu \mathrm{mol} / 1$ oligomycin, $2 \mathrm{mmol} / 1 \mathrm{AICAR}$ or $100 \mu \mathrm{mol} / 1$ dipyridamole for $20 \mathrm{~min}$ at $37^{\circ} \mathrm{C}$ under continuous shaking. At the applied concentrations of oligomycin, AICAR and dipyridamole, LCFA uptake rates were found to be maximally stimulated (data not shown).

\section{Preparation of cardiomyocyte lysates}

Pellets of cardiomyocytes were obtained by a pulse centrifugation of pre-incubated cell suspensions whereafter supernatants were removed. Cardiomyocytes were incubated for $1 \mathrm{~h}$ with ice-cold lysis buffer containing $50 \mathrm{mmol} / \mathrm{l}$ Tris $\cdot \mathrm{HCl}, \mathrm{pH} 7.5$, $1 \mathrm{mmol} / \mathrm{l}$ EGTA, $1 \mathrm{mmol} / \mathrm{l}$ EDTA, 1\% Triton X-100, $1 \mathrm{mmol} / \mathrm{l}$ sodium orthovanadate, $50 \mathrm{mmol} / 1$ sodium fluoride, $5 \mathrm{mmol} / 1$ sodium pyrophosphate, 0.27 mol/1 sucrose, $0.1 \%$ 2-mercaptoethanol, and Complete protease inhibitor cocktail (Roche, 1 tablet per $50 \mathrm{ml}$ ). Homogenates were centrifuged at 13,000 g for $10 \mathrm{~min}$ at $4{ }^{\circ} \mathrm{C}$, supernatants were removed, and aliquots were frozen in liquid nitrogen.

\section{Expression of AMPKa1, AMPKa2, p-AMPK, p-ACC, CD36 and GLUT4 in cardiomyocytes}

Cardiomyocyte lysates $(20 \mu \mathrm{g}$ protein $)$ containing sample buffer $(62.5 \mathrm{mmol} / \mathrm{l}$ Tris$\mathrm{HCl}$ (pH 6.8), 2 mmol/1 EDTA, $20 \mathrm{mmol} / 1$ dithiothreitol, 7.5\% (wt/vol) SDS, and $50 \%$ sucrose) were subjected to SDS-polyacrylamide gel electrophoresis, followed by Western blotting for the detection of total AMPK $\alpha 1$ and AMPK $\alpha 2$, phosphorylation of AMPK and ACC by applying antibodies against AMPK $\alpha 1$, AMPK $\alpha 2$, phospho-AMPK $\alpha$ (Thr172) and phospho-ACC (Ser79), according to the manufacturer's instructions.

These sample buffer-containing cardiomyocyte lysates (20 $\mu \mathrm{g}$ protein) were also used for the detection of the relative amounts of the substrate transporters CD36 and GLUT4 upon electrophoresis and Western Blotting. Mouse monoclonal anti-CD36 antibody 1258 and sheep polyclonal anti-GLUT4 antiserum, respectively, were used for the detection of these transporters according to manufacturer's instructions.

\section{AMPKa1 and AMPKa2 activity in cardiomyocytes}

Cardiomyocyte lysates $\left(75 \mu \mathrm{g}\right.$ protein) were incubated at $4{ }^{\circ} \mathrm{C}$ for $1 \mathrm{~h}$ on a rotating wheel with $40 \mu \mathrm{l}$ of protein G-sepharose covalently conjugated to $1 \mu \mathrm{g}$ of AMPK $\alpha 1$ or AMPKa2 antibody. The sepharose beads were washed twice with lysis buffer containing $0.5 \mathrm{~mol} / \mathrm{l} \mathrm{NaCl}$ and twice with wash buffer $(50 \mathrm{mmol} / \mathrm{l}$ Tris $\cdot \mathrm{HCl}, \mathrm{pH} 7.5$, 
$0.1 \mathrm{mmol} / 1 \mathrm{EGTA}$, and $0.1 \%$ 2-mercaptoethanol). Phospho-incorporation into the SAMS peptide was then measured in a total assay volume of $50 \mu 1$ consisting of 50 $\mathrm{mmol} / 1 \mathrm{Tris} \cdot \mathrm{HCl}, \mathrm{pH}$ 7.5, $0.1 \mathrm{mmol} / 1$ EGTA, 0.1\% 2-mercaptoethanol, $10 \mathrm{mmol} / \mathrm{l}$ magnesium acetate, $0.2 \mathrm{mmol} / 1 \mathrm{SAMS}$ peptide, $0.2 \mathrm{mmol} / 1 \mathrm{AMP}, 0.2 \mathrm{mmol} / 1 \mathrm{ATP}$ and $2 \mu \mathrm{Ci}\left[{ }^{32} \mathrm{P}\right] \mathrm{ATP}$. The assays were carried out at $30^{\circ} \mathrm{C}$ and after $20 \mathrm{~min}, 25 \mu \mathrm{l}$ of the reaction mixture was spotted onto p 81 membranes. The papers were washed four times for $15 \mathrm{~min}$ with $1 \%$ phosphoric acid, once with acetone and dried. The radioactivity was measured by scintillation counting.

\section{Phosphocreatine, creatine and adenosine phosphate contents in cardiomyocytes}

Pellets of cardiomyocytes were obtained by a pulse centrifugation of pre-incubated cell suspensions whereafter supernatants were removed. Cell pellets were freeze dried followed by extraction with $1.3 \mathrm{M}$ perchloric acid and neutralization with $1 \mathrm{M}$ $\mathrm{KHCO}_{3}$. Thereafter, the cellular contents of phosphocreatine, creatine, ATP, ADP and AMP were determined by high-performance liquid chromatography as described previously [36].

\section{Palmitate and deoxyglucose uptake into cardiomyocytes}

To study palmitate and deoxyglucose uptake, $0.5 \mathrm{ml}$ of a mixture of [1$\left.{ }^{14} \mathrm{C}\right]$ palmitate/BSA complex and $\left[1-{ }^{3} \mathrm{H}\right]$ deoxyglucose was added to pre-incubated cell suspensions at the start of the incubations with a final concentration of 100 $\mu \mathrm{mol} / 1$ palmitate and $100 \mu \mathrm{mol} / 1$ deoxyglucose with a corresponding palmitate/BSA ratio of 0.3 [5]. Cellular uptake of ${ }^{14} \mathrm{C}$-palmitate (3-min incubation) and ${ }^{3} \mathrm{H}$ deoxyglucose (3-min incubation) was determined upon washing the cells two times for $2 \mathrm{~min}$ at $45 \mathrm{~g}$ in an ice-cold stop solution containing $0.2 \mathrm{mmol} / \mathrm{l}$ phloretin. The radioactivity of the cell pellets was measured by scintillation counting.

\section{Palmitate oxidation in cardiomyocytes}

To study palmitate oxidation, $0.5 \mathrm{ml}$ of a mixture of $\left[1-{ }^{14} \mathrm{C}\right]$ palmitate/BSA complex was added to pre-incubated cell suspensions at the start of the incubations with a final concentration of $100 \mu \mathrm{mol} / 1$ palmitate with a corresponding palmitate/BSA ratio of 0.3 [5]. The oxidation of palmitate (20-min incubation) into $\mathrm{CO}_{2}$ was determined after addition of perchloric acid (final concentration $0.5 \mathrm{M}$ ) to cell suspensions. Production of ${ }^{14} \mathrm{CO}_{2}$ was measured after base trapping [37].

\section{Sarcolemmal CD36 and GLUT4 content of cardiomyocytes}

Directly after isolation, cell suspensions of cardiomyocytes were plated in laminincoated $(20 \mu \mathrm{g} / \mathrm{ml}) 35 \mathrm{~mm}$ culture plates. After $1 \mathrm{~h}$ the cells were incubated with 
$0.35 \%$ DMSO $(\mathrm{Ctrl})$ or $1 \mu \mathrm{mol} / 1$ oligomycin for $20 \mathrm{~min}$ at $37^{\circ} \mathrm{C}$. As previously described [38], cells were biotinylated with the cell-permeable reagent sulfo-NHSLC-biotin in bicarbonate medium at a final concentration of $1 \mathrm{mg} / \mathrm{ml}$ for $45 \mathrm{~min}$ at $4^{\circ} \mathrm{C}$. Cells were treated with ice-cold glycine in bicarbonate medium $(100 \mathrm{mM})$. After a brief wash with ice-cold bicarbonate medium, cells were lysed by scraping in $250 \mu 1$ lysis buffer. The lysates were incubated on ice for $1 \mathrm{~h}$, and centrifuges for $10 \mathrm{~min}$ at $13,000 \mathrm{~g}$ at $4^{\circ} \mathrm{C}$. A $15 \mu \mathrm{l}$ supernatant sample was used as total lystate sample for Western Blotting, and $150 \mu \mathrm{l}$ was then incubated overnight with streptavidin beads. Samples were briefly centrifuged, and the beads were washed twice with lysis buffer. The biotinylated proteins were eluted by incubation of the streptavidin beads for $5 \mathrm{~min}$ at $95^{\circ} \mathrm{C}$ in sample buffer. Samples were subjected to SDS-polyacrylamide gel electrophoresis, followed by Western Blotting for the detection of CD36 and GLUT4, as previously described.

\section{Data presentation and statistics}

All data are presented as means \pm S.E.M. for the indicated number of cardiomyocyte preparations. Statistical difference between means was analyzed by the paired Student's t test. $\mathrm{P}$ values $\leq 0.05$ were considered significant.

\section{Results}

\section{AMPK dynamics in WT and AMPK KD cardiomyocytes: confirmation of the AMPK KD phenotype}

Total expression of AMPK $\alpha 1$ and AMPK $\alpha 2$ were not significantly different between WT and AMPK KD cardiomyocytes treated without or with oligomycin, AICAR or dipyridamole (Fig. 4.1A). AMPK-Thr172 phosphorylation in quiescent cardiomyocytes (referred to as basal/control) was not significantly altered in AMPK KD cardiomyocytes (Fig. 4.1A). Oligomycin markedly increased the phosphorylation of AMPK, i.e., by 5.0-fold $( \pm 0.6 ; \mathrm{n}=5, \mathrm{P}<0.05)$ in wild-type (WT) cardiomyocytes, which increase was modestly reduced (to 3.4-fold $\pm 0.5 ; n=5$, $\mathrm{P}<0.05)$ in oligomycin-treated AMPK KD cardiomyocytes. Hence, the mutant $\alpha$ subunit in AMPK KD cardiomyocytes retains the ability to be phosphorylated at Thr172, as observed in the presence of oligomycin, albeit to a lesser extent. AICAR treatment resulted in a modest $(1.5$-fold $\pm 0.2 ; \mathrm{n}=5, \mathrm{P}<0.05)$ increase in AMPKThr172 phosphorylation in WT cardiomyocytes, which was reduced to 1.3 -fold ( \pm $0.1 ; \mathrm{n}=5, \mathrm{P}<0.05$ ) in AMPK KD cardiomyocytes (Fig. 4.1A). In contrast, dipyridamole had no effect on AMPK-Thr172 phosphorylation, neither in WT nor in AMPK KD cardiomyocytes.

With respect to AMPK's major target ACC, treatment of WT cardiomyocytes with oligomycin (6.4-fold $\pm 0.9 ; \mathrm{n}=5, \mathrm{P}<0.05)$ or $\operatorname{AICAR}(5.5$-fold $\pm 1.1 ; \mathrm{n}=5, \mathrm{P}<0.05)$ 
A

WT

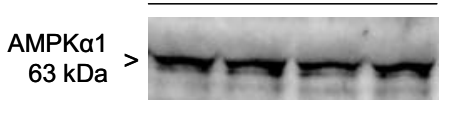
AMPKa2
$63 \mathrm{kDa}$
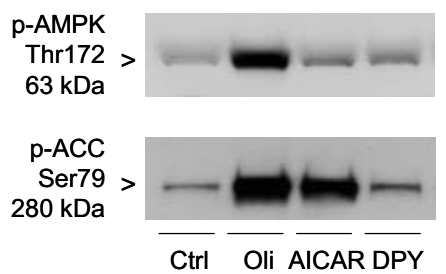

AMPK KD
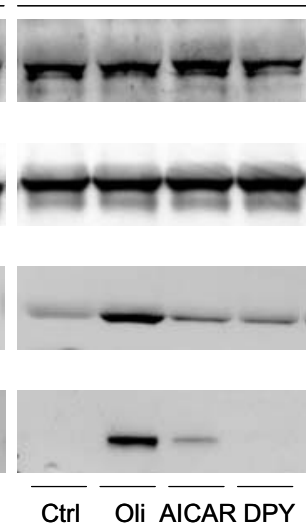

$\mathrm{B}$

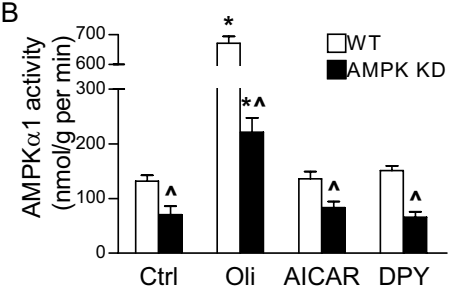

$\mathrm{C}$

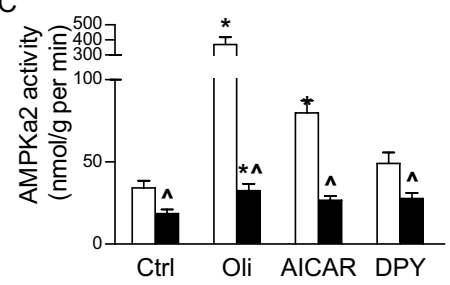

Figure 4.1 Influence of contraction-mimetic stimuli on phosphorylation of AMPK, ACC, and on AMPK $\alpha 1$ and $\alpha 2$ expression and activity in cardiomyocytes from WT and AMPK KD mice WT (口) and AMPK KD cardiomyocytes (-) were incubated for $20 \mathrm{~min}$ in the absence (Ctrl) or presence of $1 \mu \mathrm{mol} / 1$ oligomycin (Oli), $2 \mathrm{mmol} / 1$ 5-aminoimidazole-4-carboxamide ribonucleoside (AICAR) or $100 \mu \mathrm{mol} / 1$ dipyridamole (DPY), whereafter AMPK $\alpha 1$, AMPK $\alpha 2$, phospho-AMPK (Thr172), phospho-acetyl-CoA carboxylase (ACC; Ser79) (panel A), and the activity of AMPK $\alpha 1$ (panel B) and AMPK $\alpha 2$ (panel C) were determined. A representative Western Blot is presented out of 5 experiments with different cardiomyocyte preparations. Data are means \pm S.E.M. for 5-6 experiments carried out with different cardiomyocyte preparations. ${ }^{*}$ Significantly different from $\mathrm{Ctrl}(\mathrm{P}<0.05)$; $\wedge$ significantly different from WT $(\mathrm{P}<0.05)$.

but not dipyridamole, increased its phosphorylation at Ser79, in agreement with our previous observations in rat cardiomyocytes [7, 32]. Under all conditions, Ser79 phosphorylation of ACC was decreased in AMPK KD cardiomyocytes (Fig. 4.1A). Under basal conditions, this decrease was total, whereas during oligomycin $(-81 \% \pm$ $1, \mathrm{n}=5 ; \mathrm{P}<0.05)$ or AICAR treatment $(-88 \% \pm 6 ; \mathrm{n}=5, \mathrm{P}<0.05)$ this decrease was near-total. These observations confirm the phenotype of the AMPK KD cardiomyocytes in that AMPK's activity towards ACC is greatly reduced. The discrepancy between the modest AMPK-Thr172 phosphorylation and the potent 
ACC-Ser79 phosphorylation upon AICAR treatment of WT cardiomyocytes (Fig. 4.1A) may suggest that AMPK-independent mechanisms could contribute to AICAR-induced ACC-Ser79 phosphorylation. However, the large reduction in AICAR-induced ACC phosphorylation in AMPK KD cardiomyocytes indicates that AMPK is mainly responsible for ACC phosphorylation upon AICAR treatment. Phosphorylation of ACC by AMPK is the resultant of combined $\alpha 1$ and $\alpha 2$ activity. AMPK $\alpha 1$ activity was reduced during basal conditions in AMPK KD cardiomyocytes by $46 \%$ compared to WT cardiomyocytes (Fig. 4.1B). Treatment with oligomycin increased AMPK $\alpha 1$ activity by 5.1-fold in WT cardiomyocytes. In AMPK KD cardiomyocytes, oligomycin-induced AMPK $\alpha 1$ activity was reduced by $67 \%$, but still 1.7-fold above basal AMPKal activity in WT cardiomyocytes. AICAR and dipyridamole did not change AMPK $\alpha 1$ activity, neither in WT nor in AMPK KD cardiomyocytes compared to the basal state (Fig. 4.1B). Hence, these measurements confirmed that overexpression of the kinase-dead AMPK $\alpha 2$ mutant markedly reduced the AMPK $\alpha 1$ activity [14], as observed under basal conditions and after oligomycin treatment of cardiomyocytes.

During basal conditions, AMPK $\alpha 2$ activity was reduced by $46 \%$ in AMPK KD cardiomyocytes (Fig. 4.1C). Oligomycin increased AMPK $\alpha 2$ activity by 10.8 -fold in WT cardiomyocytes. This increase was almost completely blunted in AMPK KD cardiomyocytes, so that AMPK $\alpha 2$ activity upon oligomycin treatment was lower than in WT cardiomyocytes under basal conditions. AICAR treatment increased AMPK $\alpha 2$ activity by 2.3 -fold in WT cardiomyocytes, which effect was completely blunted in AMPK KD cardiomyocytes. Dipyridamole did not change AMPKa2 activity in WT nor in AMPK KD cardiomyocytes (Fig. 4.1C).

Integrating the findings concerning activation of both $\alpha$-isoforms in cardiomyocytes demonstrates that oligomycin treatment induces both $\alpha 1$ and $\alpha 2$ activity of AMPK, whereas AICAR only induces AMPK $\alpha 2$ activity. Furthermore, all the oligomycin and AICAR-induced signaling responses involving AMPK were largely absent in AMPK KD cardiomyocytes.

\section{Expression of CD36 and GLUT4 in WT and AMPK KD cardiomyocytes}

Expression of CD36 and GLUT4 were not significantly different between WT and AMPK KD cardiomyocytes (Fig. 4.2), indicating that the cardiac transport capacity for LCFA and glucose is not altered due to the dominant-negative overexpression of mutant AMPK $\alpha 2$. 


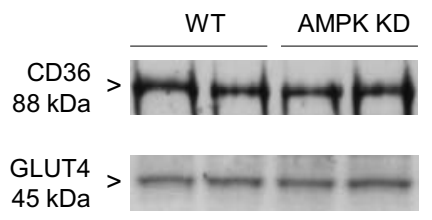

Figure 4.2 Total GLUT4 and CD36 expression in cardiomyocytes from WT and AMPK KD mice

Protein expression of fatty acid translocase/CD36 (CD36; $88 \mathrm{kDa})$ and glucose transporter 4 (GLUT4; $45 \mathrm{kDa}$ ) were detected by Western Blotting in lysates of different WT and AMPK KD cardiomyocyte preparations $(\mathrm{n}=5)$. A representative Western Blot is presented.

\section{Contents of phosphocreatine, creatine and adenosine phosphates in WT and AMPK KD cardiomyocytes}

Basal phosphocreatine content in cardiomyocytes was not significantly different between WT and AMPK KD mice (Table 4.1). Treatment with oligomycin, AICAR or dipyridamole did not significantly change the phosphocreatine contents neither in WT nor in AMPK KD cardiomyocytes. During basal conditions and after treatment with AICAR and dipyridamole, creatine levels were similar in WT and AMPK KD cardiomyocytes. Treatment of cardiomyocytes with oligomycin significantly increased the creatine content in both mouse groups at the expense of phosphocreatine.

The intracellular contents of ATP, ADP AMP were not significant different between WT and AMPK KD cardiomyocytes under control conditions or treated with AICAR or dipyridamole. Oligomycin treatment significantly decreased the ATP content and concomitantly increased the AMP and ADP content in WT and AMPK KD cardiomyocytes, in agreement with the inhibiting action of this compound on the $\mathrm{F}_{1} \mathrm{~F}_{0}$-ATPase. These effects were slightly larger in AMPK KD cardiomyocytes (Table 4.1), indicating modest problems with ATP homeostasis in the hearts of these transgenic animals under increased metabolic demands. ZMP levels were not detectable in cardiomyocytes during basal, oligomycin and dipyridamole treatments, and were increased after AICAR stimulation similarly in WT and AMPK KD cardiomyocytes (data not shown).Taken together, the energy reserve of AMPK KD cardiomyocytes is in almost all instances not different from that of WT cardiomyocytes under basal conditions, as well as in the presence of contraction-mimetic stimuli. Hence, the viability of these cells is not affected by the inactivation of AMPK. Moreover, energy demanding processes, such as CD36 and GLUT4 translocation to the sarcolemma, presenting the underlying events for increased LCFA and glucose uptake in the presence of the applied stimuli, remain operable in AMPK KD cardiomyocytes. 
Table 4.1 Influence of contraction-mimetic stimuli on intracellular contents of high-energy phosphates in cardiomyocytes from WT and AMPK KD mice

\begin{tabular}{lcc}
\hline Parameter & \multicolumn{1}{c}{ WT } & AMPK KD \\
\hline PCr & & \\
Ctrl & $116.2 \pm 16.8$ & $171.3 \pm 29.2$ \\
Oli & $78.5 \pm 9.70$ & $107.8 \pm 9.77$ \\
AICAR & $109.5 \pm 34.7$ & $128.0 \pm 26.3$ \\
DPY & $116.7 \pm 13.0$ & $173.5 \pm 35.6$ \\
& & \\
Cr & & \\
Ctrl & $3.0 \pm 0.6$ & $3.7 \pm 0.7$ \\
Oli & $22.2 \pm 3.2^{*}$ & $17.4 \pm 2.7^{*}$ \\
AICAR & $6.6 \pm 0.6$ & $5.1 \pm 0.3$ \\
DPY & $5.1 \pm 1.1$ & $4.4 \pm 0.6$ \\
& & \\
ATP & & \\
Ctrl & $18.5 \pm 2.0$ & $17.4 \pm 2.5$ \\
Oli & $7.7 \pm 1.5^{*}$ & $5.0 \pm 0.4^{* \wedge}$ \\
AICAR & $18.8 \pm 6.4$ & $17.2 \pm 2.6$ \\
DPY & $15.3 \pm 1.7$ & $15.3 \pm 4.3$ \\
& & \\
ADP & & $3.5 \pm 0.6$ \\
Ctrl & $3.2 \pm 0.4$ & $5.5 \pm 0.8^{* \wedge}$ \\
Oli & $7.3 \pm 1.5^{*}$ & $3.7 \pm 0.4$ \\
AICAR & $3.2 \pm 1.0$ & $4.0 \pm 0.6$ \\
DPY & $3.2 \pm 0.7$ & \\
& & $0.5 \pm 0.1$ \\
AMP & & $2.8 \pm 0.5^{* \wedge}$ \\
Ctrl & $0.5 \pm 0.1$ & $0.5 \pm 0.1$ \\
Oli & $1.5 \pm 0.3^{*}$ & \\
AICAR & $0.5 \pm 0.1$ & $0.6 \pm 0.1$ \\
DPY & $0.7 \pm 0.1$ & \\
\hline & &
\end{tabular}

WT and AMPK KD cardiomyocytes were incubated for $20 \mathrm{~min}$ in the absence (Ctrl) or presence of 1 $\mu \mathrm{mol} / \mathrm{l}$ Oligomycin (Oli), $2 \mathrm{mmol} / 1$ 5-aminoimidazole-4-carboxamide ribonucleoside (AICAR) or 100 $\mu \mathrm{mol} / 1$ dipyridamole (DPY), after which intracellular levels of phosphocreatine (PCr), creatine (Cr), ATP, ADP and AMP were determined. Values ( $\mu \mathrm{mol} / \mathrm{g}$ dry mass) are means \pm S.E.M. from 5 experiments carried out with different cardiomyocyte preparations. *Significantly different from Ctrl $(\mathrm{P}<0.05)$; ^significantly different from WT $(\mathrm{P}<0.05)$.

Even in oligomycin-treated AMPK KD cardiomyocytes, which display a modestly larger drop in ATP content compared with their WT counterparts, this further reduction in ATP is not limiting for CD36 and GLUT4 translocation, because we also observed stimulation of substrate uptake in WT cardiomyocytes treated with 5 $\mu \mathrm{M}$ oligomycin, reducing the ATP content to below $5 \mu \mathrm{mol} / \mathrm{g}$ dry mass (data not shown). In case of impaired metabolic responses (see below) in AMPK KD cardiomyocytes upon treatment with oligomycin, AICAR or dipyridamole, these impairments cannot be attributed to the inability of these cells to mobilize CD36 and GLUT4. 


\section{CD36-mediated palmitate and GLUT4-mediated deoxyglucose uptake into WT and AMPK KD cardiomyocytes}

In WT cardiomyocytes, treatment with oligomycin, AICAR or dipyridamole enhanced LCFA uptake by 1.6-fold, 1.6-fold or 1.5-fold, respectively (Fig. 4.3A). Deoxyglucose uptake into WT cardiomyocytes was enhanced by 3.2-fold or 1.8fold, respectively, whereas dipyridamole treatment lowered deoxyglucose uptake ($48 \%$; Fig. 4.3A). The effects of AICAR or dipyridamole on LCFA uptake and that of AICAR on deoxyglucose uptake were non-additive to those of oligomycin (Fig. 4.3A), indicating that all three pharmacological stimuli use the same mechanism to stimulate the uptake of both substrates into WT cardiomyocytes.

In order to investigate if this mechanism includes a translocation of CD36 and GLUT4 from intracellular stores to the sarcolemma, as established in rat cardiomyocytes using subcellular fractionation [7], we used a cell surface biotinylation assay. Oligomycin treatment resulted in an increase in sarcolemmal contents of CD36 and GLUT4, amounting to 1.9- and 3.3-fold, respectively, whereas the total cellular content of both transporters did not change as a result of this treatment (Fig. 4.3B). These increases in cell surface substrate transporter content closely paralleled the oligomycin-induced increases in substrate uptake (Fig. 4.3A), indicating that CD36 and GLUT4 translocation are responsible for stimulation of LCFA and deoxyglucose uptake upon treatment of cardiomyocytes with this compound. In combination of the non-additive effects of the three stimuli on substrate uptake, it is concluded that, besides oligomycin, also AICAR induces CD36 and GLUT4 translocation, and that dipyridamole selectively induces the translocation of CD36.

Palmitate uptake into quiescent cardiomyocytes was not significantly different between WT and AMPK KD cardiomyocytes (Fig. 4.3C). In addition, basal deoxyglucose uptake was similar between WT and AMPK KD cardiomyocytes (Fig. 4.3D). Together, these observations indicate that AMPK activity is not required for substrate uptake into quiescent cardiomyocytes. Treatment of WT cardiomyocytes with oligomycin and AICAR increased palmitate uptake by 1.9fold and 1.6-fold, respectively, and deoxyglucose uptake by 2.6-fold and 1.6-fold, respectively, all of which effects were completely inhibited in AMPK KD cardiomyocytes (Fig. 4.3C and 4.3D). Dipyridamole significantly increased palmitate uptake into both WT and AMPK KD cardiomyocytes by 1.7-fold and 1.6fold, respectively (Fig. 4.3C). In contrast, dipyridamole reduced deoxyglucose uptake into WT cardiomyocytes (-50\%) and AMPK KD cardiomyocytes (-52\%; Fig. 4.3D), in agreement with earlier observations in cardiomyocytes from rat [32] and mouse [6]. 


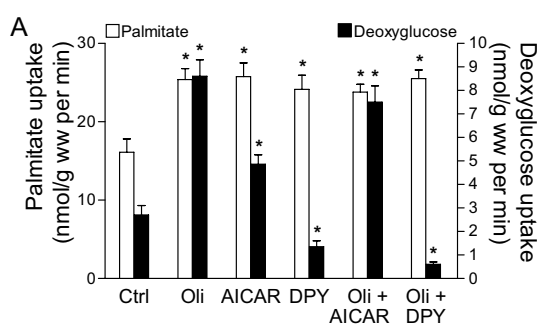

B
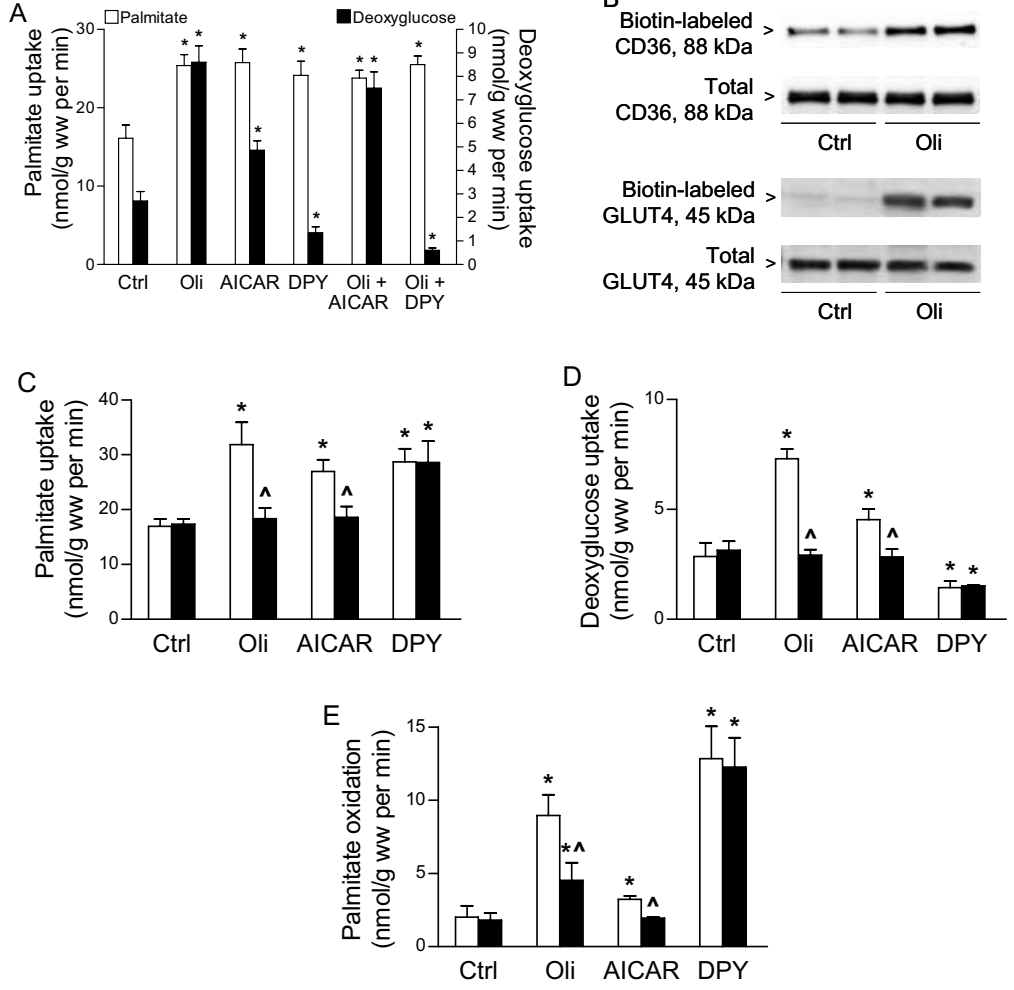

Figure 4.3 Influence of contraction-mimetic stimuli on CD36 and GLUT4-mediated palmitate and deoxyglucose uptake, respectively, and on palmitate oxidation in cardiomyocytes from WT and AMPK KD mice

Panel A: Different cardiomyocytes preparations $(\mathrm{n}=4)$ were incubated for $20 \mathrm{~min}$ in the absence (Ctrl) or presence of $1 \mu \mathrm{mol} / 1$ oligomycin (Oli) $2 \mathrm{mmol} / \mathrm{l} 5$-aminoimidazole-4-carboxamide ribonucleoside (AICAR), $100 \mu \mathrm{mol} / 1$ dipyridamole (DPY), or in the combinations indicated, whereafter uptake rates of ${ }^{14} \mathrm{C}$-palmitate (口) and ${ }^{3} \mathrm{H}$-deoxyglucose (a) were measured. Panel B: Different cardiomyocytes preparations ( $\mathrm{n}=5)$ were incubated for $20 \mathrm{~min}$ in the absence (Ctrl) or presence of $1 \mu \mathrm{mol} / \mathrm{l}$ oligomycin (Oli), whereafter biotin-labeled (cell surface) fatty acid translocase/CD36 (CD36) and total cellular CD36 (upper panel) and biotin-labeled (cell surface) glucose transporter 4 (GLUT4) and total cellular GLUT4 were determined. A representative Western Blot is displayed. Panels C, D and E: WT ( $\square$ ) and AMPK KD cardiomyocytes ( $\square$ ) were incubated for $20 \mathrm{~min}$ in the absence (Ctrl) or presence of $1 \mu \mathrm{mol} / \mathrm{l}$ Oli, $2 \mathrm{mmol} / \mathrm{l}$ AICAR or $100 \mu \mathrm{mol} / 1 \mathrm{DPY}$ whereafter uptake rates of ${ }^{14} \mathrm{C}$-palmitate (panel C) and ${ }^{3} \mathrm{H}$ deoxyglucose (panel D), as well as rates of ${ }^{14} \mathrm{C}$-palmitate oxidation (measured as ${ }^{14} \mathrm{CO}_{2}$ production; panel E) were measured. With respect to measurement of substrate uptake (panels $\mathrm{C}$ and $\mathrm{D}$ ), data are means \pm S.E.M. for 6-8 experiments carried out with different cardiomyocyte preparations, and with respect to measurement of palmitate oxidation, data are means \pm S.E.M. for 5 experiments. *Significantly different from $\mathrm{Ctrl}(\mathrm{P}<0.05)$; ${ }^{\wedge}$ significantly different from WT $(\mathrm{P}<0.05)$. 
Taken together, these results indicate that AMPK activity regulates oligomycin and AICAR-induced CD36 translocation/palmitate uptake and GLUT4 translocation/deoxyglucose uptake. However, AMPK is not involved in the substrate-uptake effects of dipyridamole.

\section{Palmitate oxidation in WT and AMPK KD cardiomyocytes}

Rates of basal palmitate oxidation were similar in AMPK KD cardiomyocytes and WT cardiomyocytes (Fig. 4.3E). Upon oligomycin or AICAR treatment, palmitate oxidation was significantly increased in WT cardiomyocytes by 4.5-fold and 1.6fold, respectively, and in AMPK KD cardiomyocytes these effects were reduced by $49 \%$ or completely blunted, respectively. Dipyridamole-induced palmitate oxidation was increased by 6.3-fold in WT cardiomyocytes and by 6.7-fold in AMPK KD cardiomyocytes (Fig. 4.3E). Hence, AMPK regulates AICAR-induced palmitate oxidation entirely, and oligomycin-induced palmitate oxidation largely, but is not involved in dipyridamole-induced palmitate oxidation.

\section{AMPK activation in WT versus AMPK KD, AMPKa2 KO and LKB1 $\mathrm{KO}$ cardiomyocytes treated with oligomycin}

In case of each of the three genetically manipulated mouse models, cardiomyocytes from WT littermates were taken as control. In cardiomyocytes from all three control mouse strains, oligomycin treatment induced a $>5$-fold increase in AMPK-Thr172 and ACC-79 phosphorylation (Fig. 4.4A), in agreement with data from Fig. 4.1. As also displayed in Fig. 4.1, oligomycin-induced Thr172 phosphorylation of the KD mutant of AMPK was only modestly (32\%) decreased compared to WT. In contrast, in AMPKa2 KO and LKB1 KO cardiomyocytes oligomycin-induced Thr172 phosphorylation was markedly reduced or completely abolished, respectively (Fig. 4.4A). When regarding oligomycin-induced ACC-Ser79 phosphorylation in cardiomyocytes from the three genetically manipulated models, this is largely reduced in AMPK KD (by $81 \% \pm 1 ; n=4$ ) and AMPK $\alpha 2 \mathrm{KO}$ (by $71 \% \pm 12 ; n=4$ ) cardiomyocytes, and almost completely absent in LKB1 KO cardiomyocytes. Hence, in AMPK $\alpha 2 \mathrm{KO}$ cardiomyocytes AMPK activation is largely reduced but not completely absent due to the residual presence of AMPK $\alpha 1$, and in LKB1 KO cardiomyocytes AMPK signaling is almost entirely blunted.

\section{Palmitate and deoxyglucose uptake into WT versus AMPK KD, AMPKa2 KO and LKB1 KO cardiomyocytes after oligomycin stimulation}

In all three mouse models (AMPK KD, AMPK $\alpha 2 \mathrm{KO}$ and LKB1 KO), basal palmitate and deoxyglucose uptake rates into cardiomyocytes from genetically 
A

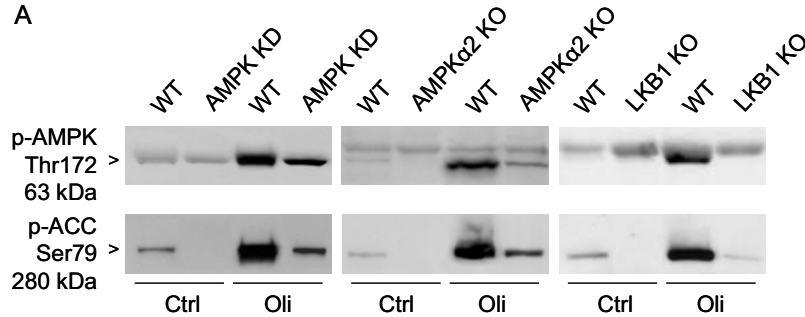

$\mathrm{B}$

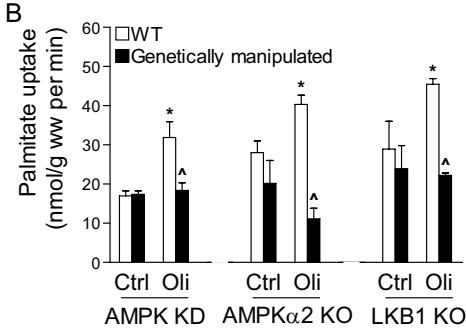

C

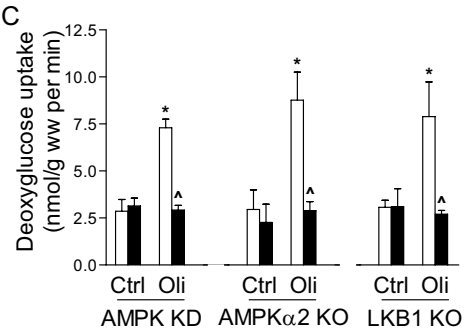

Figure 4.4 Influence of oligomycin on phosphorylation of AMPK and ACC in cardiomyocytes and on palmitate and deoxyglucose uptake into cardiomyocytes from WT, AMPK KD,

AMPKa2 KO and LKB1 KO mice

Cardiomyocytes from WT ( $\square$ ) and genetically manipulated mice (ø) were incubated for $20 \mathrm{~min}$ in the absence (Ctrl) or presence of $1 \mu \mathrm{mol} / 1$ oligomycin (Oli), whereafter phospho-AMPK (Thr172), phospho-acetyl-CoA carboxylase (ACC; Ser79; panel A), and uptake rates of ${ }^{14} \mathrm{C}$-palmitate (panel B) and ${ }^{3} \mathrm{H}$-deoxyglucose (panel C) were determined. A representative Western Blot is presented out of 4-5 experiments with cardiomyocytes from each of the genetically manipulated mice models and their WT littermates. Note that the upper band in the p-AMPK Blot likely represents albumin, which is present abundantly in the cardiomyocyte lysates. Albumin, like AMPK, has a molecular mass of $\sim 60 \mathrm{kDa}$. Data are means \pm S.E.M. for 3-8 experiments carried out with different cardiomyocyte preparations.

*Significantly different from $\mathrm{Ctrl}(\mathrm{P}<0.05)$; ${ }^{\wedge}$ significantly different from WT $(\mathrm{P}<0.05)$.

manipulated mice did not differ from the uptake rates into cardiomyocytes from WT mice (Fig. 4.4B and 4.4C). Oligomycin treatment resulted in similar increases in palmitate uptake into cardiomyocytes from WT littermates from each of the three genetically manipulated models, amounting to 1.9-fold, 1.4-fold and 1.6-fold, respectively (Fig. 4.4B). Also the oligomycin-induced increases in deoxyglucose uptake into WT cardiomyocytes from all three models were in a similar range, i.e., by 2.6-fold, 3.0-fold and 2.6-fold respectively (Fig. 4.4C). Both oligomycininduced palmitate and deoxyglucose uptake into cardiomyocytes were completely abrogated in cardiomyocytes from all three genetically manipulated mouse models. 


\section{Discussion}

Until now, the evidence for the involvement of AMPK in contraction-induced LCFA and glucose uptake into the heart was only based on association between AMPK activation by different stimuli and their stimulating action on LCFA uptake into cardiomyocytes [7], while there is no information about the involvement of LKB1. Using mouse models deficient for AMPK and LKB1, we sought to obtain direct evidence whether, or not, the LKB1 - AMPK signaling axis is involved in regulation of cardiac substrate uptake by oligomycin, AICAR or dipyridamole, i.e., agents that induce CD36 translocation in a contraction-mimetic manner. Using these genetically engineered mouse models, the following novel findings have been made. (i) Oligomycin and AICAR-stimulated LCFA uptake and oxidation, and glucose uptake into cardiomyocytes are almost completely dependent on AMPK. (ii) Oligomycin-stimulated LCFA and glucose uptake into cardiomyocytes is dependent on the presence of LKB1 and AMPKa2. (iii) In contrast, AMPK is not involved in dipyridamole-stimulated LCFA uptake and oxidation by cardiomyocytes. Collectively, our findings reveal that cardiac substrate utilization induced by contraction-mimetic stimuli is dependent on signaling through LKB1 and AMPK $\alpha 2$. In addition, an unknown pathway, independent of AMPK $\alpha 2$, can stimulate LCFA but not glucose utilization.

\section{Involvement of AMPK in induction of LCFA and glucose uptake and LCFA oxidation by oligomycin or AICAR}

Based on their ability to induce CD36 and GLUT4 translocation in a contractionmimetic manner, oligomycin and AICAR were used to investigate the involvement of AMPK in contraction-induced substrate utilization in the heart. In wild-type cardiomyocytes, oligomycin and AICAR displayed differential actions towards activation of each of the $\alpha$-isoforms of AMPK. Both oligomycin and AICAR induce the activation of AMPK $\alpha 2$, but only oligomycin additionally induces $\alpha 1$ activation. Because both compounds stimulate uptake of LCFA and glucose and LCFA oxidation, $\alpha 2$ activation seems to be sufficient for these metabolic effects (Fig. 4.5). Moreover, the degree of $\alpha 2$ activation is proportional with the degree of stimulation of glucose uptake and LCFA oxidation, with oligomycin having the larger effect in comparison to AICAR. For LCFA uptake this is less obvious, but in earlier studies oligomycin-induced LCFA uptake into cardiomyocytes was markedly larger than that induced by AICAR [7].

$\mathrm{AMPK} \mathrm{KD}$ and $\mathrm{AMPK} \alpha 2 \mathrm{KO}$ mice were used to investigate the overall and isoform-specific involvement of AMPK in regulation of cardiac substrate utilization. First, we confirmed that in AMPK KD cardiomyocytes oligomycin/AICAR-induced activation of both $\alpha 1$ and $\alpha 2$ isoforms was at least 


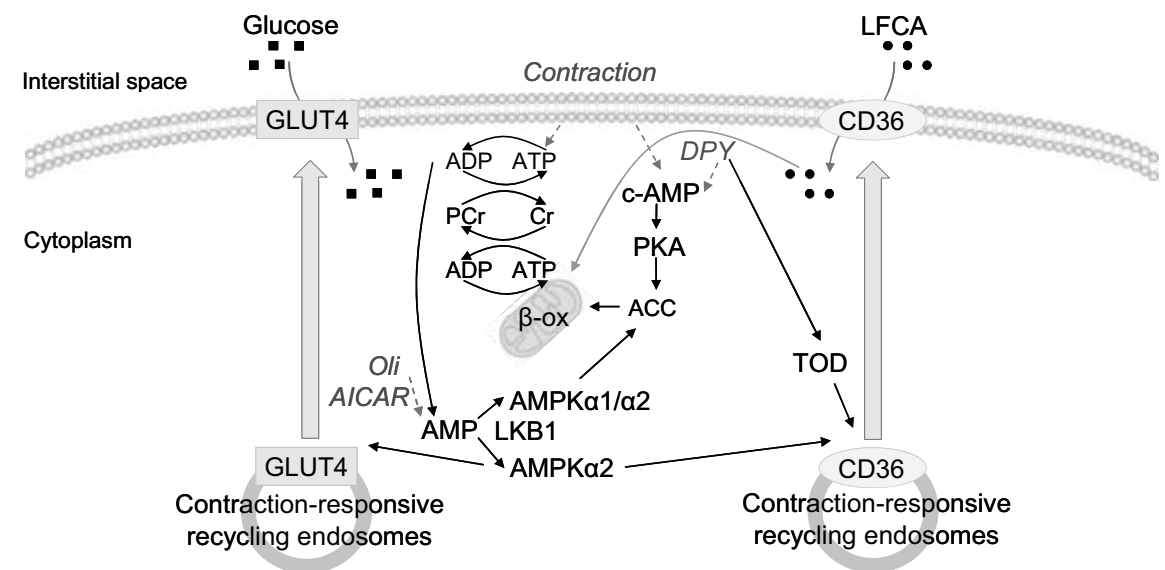

Figure 4.5 Hypothetical scheme of the involvement of AMPKa1/a2 and LKB1 in stimulation of LCFA and glucose uptake and LCFA oxidation by contraction and contraction-mimetic agents Under basal conditions, the majority of the glucose transporter 4 (GLUT4) and $\sim 50 \%$ of fatty acid translocase/CD36 (CD36) is present in intracellular stores (recycling endosomes) with the remaining portion of both transporters at the sarcolemma. The onset of contraction results in elevation of intracellular AMP and cyclic-AMP (c-AMP) levels. Elevation of AMP stimulates LKB1-mediated phosphorylation of the AMPK isoforms $\alpha 1$ and $\alpha 2$. Elevation of c-AMP results in activation of protein kinase A (PKA). Both activated AMPK $\alpha 1 / \alpha 2$ and PKA directly phosphorylate acetyl-CoA carboxylase (ACC), resulting in increased mitochondrial $\beta$-oxidation ( $\beta$-ox) of long-chain fatty acids (LCFA). AMPK $\alpha 2$, but not $\alpha 1$ or PKA, is also involved in contraction-induced uptake of LCFA and glucose, specifically, AMP-induced LKB1-mediated activation of AMPK $\alpha 2$ results in vesicle-mediated translocation of CD36 and GLUT4 from the recycling endosomes to the sarcolemma. Treatment of cardiomyocytes with oligomycin (Oli) results in elevation of AMP and subsequent AMPK $\alpha 1 / \alpha 2$ activation, and finally in CD36 and GLUT4 translocation from contraction-responsive recycling endosomal subcompartments, as well as stimulation of $\beta$-ox. Treatment of cardiomyocytes with 5aminoimidazole-4-carboxamide ribonucleoside (AICAR) results in activation of AMPK $\alpha 2$, and thereafter in CD36 and GLUT4 translocation from contraction-responsive recycling endosomes, as well as stimulation of $\beta$-ox. Treatment of cardiomyocytes with dipyridamole (DPY) results in elevation of cAMP and subsequent activation of PKA and ACC, and finally in increased $\beta$-ox. Separately, dipyridamole activates an unknown protein kinase (hypothetical target of dipyridamole; TOD) downstream of AMPK $\alpha 2$ at the signaling branch specifically leading to CD36 translocation from contraction-responsive recycling endosomes.

greatly reduced, and that in both AMPK KD and AMPK $\alpha 2 \mathrm{KO}$ cardiomyocytes oligomycin/AICAR-induced overall AMPK activation was completely absent. When considering cardiac substrate utilization, almost all effects of oligomycin and AICAR on LCFA uptake and oxidation and glucose uptake in AMPK KD cardiomyocytes were blunted, indicating that $\alpha 1$ and/or $\alpha 2$ activation are necessary in these processes. The only metabolic response that was not completely absent in 
AMPK KD cardiomyocytes is oligomycin-induced LCFA oxidation, which could be explained by the residual $\alpha 1$ activation/ACC phosphorylation in the presence of oligomycin. This residual $\alpha 1$ activation was not sufficient to sustain oligomycininduced LCFA and glucose uptake. This finding, in combination with the observation that $\alpha 2$ activation is sufficient to allow AICAR-induced LCFA and glucose uptake, suggests that solely $\alpha 2$ activation is involved in the enhanced uptake of both LCFA and glucose into the heart. This notion is confirmed by the observation that in AMPK $\alpha 2 \mathrm{KO}$ cardiomyocytes oligomycin-induced LCFA and glucose uptake are entirely blunted. Together, the combined data obtained with cardiomyocytes from AMPK KD and AMPK $\alpha 2$ KO mice demonstrate that (i) $\alpha 2$, but not $\alpha 1$ activation results in stimulation of cardiac LCFA and glucose uptake through translocation of CD36 and GLUT4 translocation, respectively, and that (ii) both $\alpha 1$ and $\alpha 2$ activity are involved in stimulation of LCFA oxidation, with $\alpha 2$ having the largest contribution.

\section{LKB1 is the upstream kinase involved in AMPK-mediated myocardial LCFA and glucose uptake}

LKB1 has been proven to be the main kinase upstream of AMPK in the heart [39]. The involvement of LKB1 in AMPK-dependent substrate utilization in the heart has not been investigated. The present study, in which we observed that the stimulatory effects of oligomycin on LCFA and glucose uptake were lost in LKB1 KO cardiomyocytes, shows for the first time the full dependence of oligomycin-induced LCFA and glucose uptake into cardiomyocytes on LKB1 activity. Hence, the LKB1 - AMPK $\alpha 2$ axis is necessary for stimulation of LCFA and glucose uptake into the heart upon stimulation with agents that induce the translocation of both CD36 and GLUT4 in a non-additive manner to contraction.

\section{Dipyridamole-stimulated LCFA uptake and oxidation in cardiomyocytes is independent of AMPK}

Upon establishment that the phosphodiesterase inhibitor dipyridamole stimulated LCFA uptake into cardiomyocytes [40], we discovered that the underlying mechanism involved a translocation of CD36 to the sarcolemma. Surprisingly, the similarly effects of dipyridamole on LCFA uptake and CD36 translocation were unrelated to elevation of intracellular cyclic AMP/GMP since other phosphodiesterase inhibitors failed to increase LCFA uptake [41]. In addition, dipyridamole was identified to stimulate LCFA uptake in a non-additive manner to contraction. However, in contrast to oligomycin and AICAR, dipyridamole treatment did not induce AMPK activation, eluding to the notion that this compound interacts with the AMPK signal transduction pathway downstream of 
AMPK [6, 32]. Accordingly, in the present study we found no effect of dipyridamole on AMPK-Thr172 and ACC-Ser79 phosphorylation, nor on $\alpha 1$ and $\alpha 2$ activity. Moreover, we have previously shown that dipyridamole's ability to induce CD36 translocation was not accompanied by an induction of GLUT4 translocation in cardiomyocytes [6, 32]. In agreement, in the present study dipyridamole stimulated glucose uptake neither in wild-type cardiomyocytes nor in cardiomyocytes from AMPK KD mice. In AMPK KD cardiomyocytes, dipyridamole retained its stimulatory action on LCFA uptake, adding further evidence to the notion that dipyridamole activates a protein kinase downstream of AMPK specifically leading to CD36 translocation. The retention of dipyridamolestimulated LCFA uptake in AMPK KD cardiomyocytes also illustrates that the subcellular translocation machinery is not negatively affected by the large reduction in AMPK activity.

Besides LCFA uptake, LCFA oxidation is retained in dipyridamole-stimulated AMPK KD cardiomyocytes. It should be noted that the stimulation of LCFA oxidation by dipyridamole (5.2-fold) greatly exceeds its stimulatory action on LCFA uptake (1.7-fold), indicating that dipyridamole, just like contraction/oligomycin, redirects the incoming LCFA efficiently into mitochondrial $\beta$-oxidation. Unlike the non-involvement of the cyclic AMP-elevating action of dipyridamole in stimulation of LCFA uptake, the elevation of intracellular cyclic AMP levels is definitely involved in dipyridamole's stimulation of LCFA oxidation in cardiomyocytes, because also other phosphodiesterase inhibitors or cellpermeable cyclic AMP analogs were shown to redirect the incoming LCFA efficiently towards mitochondrial $\beta$-oxidation [41]. Hence, the combined ability of dipyridamole to activate a kinase downstream of AMPK and to induce cyclic AMPdependent signaling perfectly mimics the combined ability of contraction/oligomycin to increase simultaneously the activity of AMPK and ACC. Just like with contraction/oligomycin, the mechanism by which dipyridamole treatment stimulates $\beta$-oxidation may include activation of ACC. Namely, dipyridamole's stimulatory action on cyclic AMP can be related to earlier observations that cyclic-AMP-activated protein kinase A phosphorylates purified ACC in in vitro kinase assays [42, 43]. However, unlike contraction/oligomycin, this is not associated with phosphorylation of ACC at Ser79 (see Fig. 4.1A). Possibly, dipyridamole treatment enhances phosphorylation of ACC at Ser77 and Ser1200, just like protein kinase A did in in vitro kinase assays [42]. In view that the combined evidence from previous work $[6,32]$ and the present study indicates that dipyridamole acts in an AMPK-independent manner to alter LCFA but not glucose utilization, it appears that other signaling components involved in stimulating LCFA uptake and oxidation remain to be identified. 


\section{Conclusions}

The onset of contractions results in a rapid rise in the concentration of a number of second messengers in cardiac myocytes, such as AMP, cyclic AMP, $\mathrm{Ca}^{2+}$ and reactive oxygen species [10]. Together these second messengers activate a complex network of signaling events. The present study demonstrates that AMP-mediated AMPK $\alpha 2$ activation in a LKB1-dependent manner is necessary for stimulating LCFA and glucose uptake into the heart by oligomycin and AICAR. We expect that the involvement of LKB1 and AMPK $\alpha 2$ in stimulation of substrate uptake using both agents can be extrapolated to contraction based on the ability of both oligomycin and AICAR to stimulate CD36 and GLUT4 translocation in a nonadditive manner to contraction [7].

However, this does not imply that the LKB1 - AMPK $\alpha 2$ axis is the only signaling pathway involved in contraction-induced substrate utilization in the heart. We have recently found evidence for the involvement of protein kinase D in contractioninduced glucose uptake, a process that was shown to be completely independent of AMPK signaling [44]. Thus, it appears that contraction-induced GLUT4 translocation may depend on the simultaneous input of two distinct pathways, i.e, the LKB1 - AMPK axis and protein kinase D signaling, similar to what has been shown for insulin-induced GLUT4 translocation, i.e., the insulin receptor substrate phosphatidylinositol-3-kinase - protein kinase B axis and the CAP/Cbl pathway [45]. Likewise, contraction-induced CD36 translocation might therefore also be codependent on a signaling pathway that is complementary but independent of AMPK. Finally, the LKB1 - AMPK $\alpha 2$ axis could be an attractive target for therapy in cardiac diseases with decreased energy reserves.

\section{Acknowledgements}

The authors gratefully acknowledge Ms Rogayah Carroll and Prof. dr. David Severson (University of Calgary, Canada) for their expert help to optimize the technique of isolating mouse cardiomyocytes. Prof. dr. Morris Birnbaum (University of Pennsylvania, USA) is thanked for providing founder AMPK KD mice. Founder LKB1 KO mice were kindly provide by dr. Kei Sakamoto (University of Dundee, UK). We gratefully thank Prof. dr. Grahame Hardie (University of Dundee, UK) for the AMPK $\alpha 1$ and AMPK $\alpha 2$ antibodies and the SAMS peptide. We also wish to thank Mr. J. Willems for helping with the illustrations.

This study was supported by the Netherlands Organisation for Health Research and Development (ZonMw grant nr. 40-00812-98-03075), the European Community (Integrated Project LSHM-CT-2004-005272, Exgenesis), the Danish Medical Research Council, the Lundbeck Foundation, the Danish Ministry of Food, 
Agriculture and Fisheries, the Fonds National de la Recherche Scientifique et Médicale (Belgium) and the Actions de Recherche Concertées (Belgium), the Canadian Institutes of Health Research, the Natural Sciences and Engineering Research Council of Canada, the Heart and Stroke Foundation of Ontario, the Canada Research Chair program. L. Bertrand is Research Associate of the Fonds National de la Recherche Scientifique, Belgium. A. Bonen is the Canada Research Chair in Metabolism and Health. J.F.C. Glatz is Netherlands Heart Foundation Professor of Cardiac Metabolism. 


\section{References}

1 Stanley WC, Recchia FA and Lopaschuk GD 2005 Myocardial substrate metabolism in the normal and failing heart. Physiol Rev 85: 1093-1129

2 Belke DD, Larsen TS, Lopaschuk GD and Severson DL 1999 Glucose and fatty acid metabolism in the isolated working mouse heart. Am J Physiol 277: R1210-1217

3 Zorzano A, Sevilla L, Camps M, Becker C, Meyer J, Kammermeier H, Munoz P, Guma A, Testar X, Palacin M, Blasi J and Fischer Y 1997 Regulation of glucose transport, and glucose transporters expression and trafficking in the heart: studies in cardiac myocytes. Am J Cardiol 80: 65A-76A

4 Bonen A, Chabowski A, Luiken JJ and Glatz JF 2007 Is membrane transport of FFA mediated by lipid, protein, or both? Mechanisms and regulation of protein-mediated cellular fatty acid uptake: molecular, biochemical, and physiological evidence. Physiology (Bethesda) 22: 15-29

5 Luiken JJ, van Nieuwenhoven FA, America G, van der Vusse GJ and Glatz JF 1997 Uptake and metabolism of palmitate by isolated cardiac myocytes from adult rats: involvement of sarcolemmal proteins. J Lipid Res 38: 745-758

6 Habets DD, Coumans WA, Voshol PJ, den Boer MA, Febbraio M, Bonen A, Glatz JF and Luiken JJ 2007 AMPK-mediated increase in myocardial long-chain fatty acid uptake critically depends on sarcolemmal CD36. Biochem Biophys Res Commun 355: 204-210

7 Luiken JJ, Coort SL, Willems J, Coumans WA, Bonen A, van der Vusse GJ and Glatz JF 2003 Contraction-induced fatty acid translocase/CD36 translocation in rat cardiac myocytes is mediated through AMP-activated protein kinase signaling. Diabetes 52: 1627-1634

8 Luiken JJ, Willems J, van der Vusse GJ and Glatz JF 2001 Electrostimulation enhances FAT/CD36mediated long-chain fatty acid uptake by isolated rat cardiac myocytes. Am J Physiol Endocrinol Metab 281: E704-712

9 Rose AJ and Richter EA 2005 Skeletal muscle glucose uptake during exercise: how is it regulated? Physiology (Bethesda) 20: 260-270

10 Luiken JJ, Coort SL, Koonen DP, Bonen A and Glatz JF 2004 Signalling components involved in contraction-inducible substrate uptake into cardiac myocytes. Proc Nutr Soc 63: 251-258

11 Hardie DG, Hawley SA and Scott JW 2006 AMP-activated protein kinase--development of the energy sensor concept. J Physiol 574: 7-15

12 Stapleton D, Mitchelhill KI, Gao G, Widmer J, Michell BJ, Teh T, House CM, Fernandez CS, Cox T, Witters LA and Kemp BE 1996 Mammalian AMP-activated protein kinase subfamily. J Biol Chem 271: 611-614

13 Xing Y, Musi N, Fujii N, Zou L, Luptak I, Hirshman MF, Goodyear LJ and Tian R 2003 Glucose metabolism and energy homeostasis in mouse hearts overexpressing dominant negative alpha2 subunit of AMP-activated protein kinase. J Biol Chem 278: 28372-28377

14 Russell RR, 3rd, Li J, Coven DL, Pypaert M, Zechner C, Palmeri M, Giordano FJ, Mu J, Birnbaum MJ and Young LH 2004 AMP-activated protein kinase mediates ischemic glucose uptake and prevents postischemic cardiac dysfunction, apoptosis, and injury. J Clin Invest 114: 495-503

15 Carvajal K, Zarrinpashneh E, Szarszoi O, Joubert F, Athea Y, Mateo P, Gillet B, Vaulont S, Viollet B, Bigard X, Bertrand L, Ventura-Clapier R and Hoerter JA 2007 Dual cardiac contractile effects of the alpha2-AMPK deletion in low-flow ischemia and reperfusion. Am J Physiol Heart Circ Physiol 292: H3136-3147

16 Mu J, Brozinick JT, Jr., Valladares O, Bucan M and Birnbaum MJ 2001 A role for AMP-activated protein kinase in contraction- and hypoxia-regulated glucose transport in skeletal muscle. Mol Cell 7: 1085-1094

17 Fujii N, Hirshman MF, Kane EM, Ho RC, Peter LE, Seifert MM and Goodyear LJ 2005 AMP-activated protein kinase alpha2 activity is not essential for contraction- and hyperosmolarity-induced glucose transport in skeletal muscle. J Biol Chem 280: 39033-39041

18 Jorgensen SB, Viollet B, Andreelli F, Frosig C, Birk JB, Schjerling P, Vaulont S, Richter EA and Wojtaszewski JF 2004 Knockout of the alpha2 but not alpha1 5'-AMP-activated protein kinase isoform abolishes 5-aminoimidazole-4-carboxamide-1-beta-4-ribofuranosidebut not contraction-induced glucose uptake in skeletal muscle. J Biol Chem 279: 1070-1079 
19 Barnes BR, Marklund S, Steiler TL, Walter M, Hjalm G, Amarger V, Mahlapuu M, Leng Y, Johansson C, Galuska D, Lindgren K, Abrink M, Stapleton D, Zierath JR and Andersson L 2004 The 5'-AMPactivated protein kinase gamma3 isoform has a key role in carbohydrate and lipid metabolism in glycolytic skeletal muscle. J Biol Chem 279: 38441-38447

20 Jensen TE, Rose AJ, Jorgensen SB, Brandt N, Schjerling P, Wojtaszewski JF and Richter EA 2007 Possible CaMKK-dependent regulation of AMPK phosphorylation and glucose uptake at the onset of mild tetanic skeletal muscle contraction. Am J Physiol Endocrinol Metab 292: E1308-1317

21 Hawley SA, Pan DA, Mustard KJ, Ross L, Bain J, Edelman AM, Frenguelli BG and Hardie DG 2005 Calmodulin-dependent protein kinase kinase-beta is an alternative upstream kinase for AMP-activated protein kinase. Cell Metab 2: 9-19

22 Sakamoto K, Goransson O, Hardie DG and Alessi DR 2004 Activity of LKB1 and AMPK-related kinases in skeletal muscle: effects of contraction, phenformin, and AICAR. Am J Physiol Endocrinol Metab 287: E310-317

23 Hawley SA, Boudeau J, Reid JL, Mustard KJ, Udd L, Makela TP, Alessi DR and Hardie DG 2003 Complexes between the LKB1 tumor suppressor, STRAD alpha/beta and MO25 alpha/beta are upstream kinases in the AMP-activated protein kinase cascade. $J$ Biol 2: 28

24 Witczak CA, Fujii N, Hirshman MF and Goodyear LJ 2007 Ca2+/calmodulin-dependent protein kinase kinase-alpha regulates skeletal muscle glucose uptake independent of AMP-activated protein kinase and Akt activation. Diabetes 56: 1403-1409

25 Sakamoto K, McCarthy A, Smith D, Green KA, Grahame Hardie D, Ashworth A and Alessi DR 2005 Deficiency of LKB1 in skeletal muscle prevents AMPK activation and glucose uptake during contraction. Embo J 24: 1810-1820

26 Thomson DM, Brown JD, Fillmore N, Condon BM, Kim HJ, Barrow JR and Winder WW 2007 LKB1 and the Regulation of Malonyl-CoA and Fatty Acid Oxidation in Muscle. Am J Physiol Endocrinol Metab

27 Russell RR, 3rd, Bergeron R, Shulman GI and Young LH 1999 Translocation of myocardial GLUT-4 and increased glucose uptake through activation of AMPK by AICAR. Am J Physiol 277: H643-649

28 Hayashi T, Hirshman MF, Kurth EJ, Winder WW and Goodyear LJ 1998 Evidence for 5' AMPactivated protein kinase mediation of the effect of muscle contraction on glucose transport. Diabetes 47: 1369-1373

29 Marsin AS, Bertrand L, Rider MH, Deprez J, Beauloye C, Vincent MF, Van den Berghe G, Carling D and Hue L 2000 Phosphorylation and activation of heart PFK-2 by AMPK has a role in the stimulation of glycolysis during ischaemia. Curr Biol 10: 1247-1255

30 Chabowski A, Coort SL, Calles-Escandon J, Tandon NN, Glatz JF, Luiken JJ and Bonen A 2005 The subcellular compartmentation of fatty acid transporters is regulated differently by insulin and by AICAR. FEBS Lett 579: 2428-2432

31 Bertrand L, Ginion A, Beauloye C, Hebert AD, Guigas B, Hue L and Vanoverschelde JL 2006 AMPK activation restores the stimulation of glucose uptake in an in vitro model of insulin-resistant cardiomyocytes via the activation of protein kinase B. Am J Physiol Heart Circ Physiol 291: H239-250

32 Luiken JJ, Coort SL, Willems J, Coumans WA, Bonen A and Glatz JF 2004 Dipyridamole alters cardiac substrate preference by inducing translocation of FAT/CD36, but not that of GLUT4. Mol Pharmacol 65: 639-645

33 Zarrinpashneh E, Carjaval K, Beauloye C, Ginion A, Mateo P, Pouleur AC, Horman S, Vaulont S, Hoerter J, Viollet B, Hue L, Vanoverschelde JL and Bertrand L 2006 Role of the alpha2-isoform of AMP-activated protein kinase in the metabolic response of the heart to no-flow ischemia. Am J Physiol Heart Circ Physiol 291: H2875-2883

34 Viollet B, Andreelli F, Jorgensen SB, Perrin C, Geloen A, Flamez D, Mu J, Lenzner C, Baud O, Bennoun M, Gomas E, Nicolas G, Wojtaszewski JF, Kahn A, Carling D, Schuit FC, Birnbaum MJ, Richter EA, Burcelin R and Vaulont S 2003 The AMP-activated protein kinase alpha2 catalytic subunit controls whole-body insulin sensitivity. J Clin Invest 111: 91-98

35 Carroll R, Carley AN, Dyck JR and Severson DL 2005 Metabolic effects of insulin on cardiomyocytes from control and diabetic db/db mouse hearts. Am J Physiol Endocrinol Metab 288: E900-906 
36 Prinzen FW, Van der Vusse GJ, Arts T, Roemen TH, Coumans WA and Reneman RS 1984 Accumulation of nonesterified fatty acids in ischemic canine myocardium. Am J Physiol 247: H264-272

37 Glatz JF, Jacobs AE and Veerkamp JH 1984 Fatty acid oxidation in human and rat heart. Comparison of cell-free and cellular systems. Biochim Biophys Acta 794: 454-465

38 van Oort MM, van Doorn JM, Bonen A, Glatz JF, van der Horst DJ, Rodenburg KW and Luiken JJ 2008 Insulin-induced translocation of CD36 to the plasma membrane is reversible and shows similarity to that of GLUT4. Biochim Biophys Acta 1781: 61-71

39 Sakamoto K, Zarrinpashneh E, Budas GR, Pouleur AC, Dutta A, Prescott AR, Vanoverschelde JL, Ashworth A, Jovanovic A, Alessi DR and Bertrand L 2006 Deficiency of LKB1 in heart prevents ischemia-mediated activation of AMPKalpha2 but not AMPKalpha1. Am J Physiol Endocrinol Metab 290: E780-788

40 Abdel-aleem S, El-Guindy N, Sallam TI, Hughes GC and Lowe JE 1999 Stimulation of long-chain fatty acid uptake by dipyridamole in isolated myocytes. J Cardiovasc Pharmacol 33: 43-48

41 Luiken JJ, Willems J, Coort SL, Coumans WA, Bonen A, Van Der Vusse GJ and Glatz JF 2002 Effects of cAMP modulators on long-chain fatty-acid uptake and utilization by electrically stimulated rat cardiac myocytes. Biochem J 367: 881-887

42 Davies SP, Sim AT and Hardie DG 1990 Location and function of three sites phosphorylated on rat acetyl-CoA carboxylase by the AMP-activated protein kinase. Eur J Biochem 187: 183-190

43 Dyck JR, Kudo N, Barr AJ, Davies SP, Hardie DG and Lopaschuk GD 1999 Phosphorylation control of cardiac acetyl-CoA carboxylase by cAMP-dependent protein kinase and 5'-AMP activated protein kinase. Eur J Biochem 262: 184-190

44 Luiken JJ, Vertommen D, Coort SL, Habets DD, El Hasnaoui M, Pelsers MM, Viollet B, Bonen A, Hue L, Rider MH and Glatz JF 2008 Identification of protein kinase D as a novel contraction-activated kinase linked to GLUT4-mediated glucose uptake, independent of AMPK. Cell Signal 20: 543-556

45 Hou JC and Pessin JE 2007 Ins (endocytosis) and outs (exocytosis) of GLUT4 trafficking. Curr Opin Cell Biol 19: 466-473 
88 


\section{CHAPTER 5}

\section{AICAR stimulates long-chain fatty acid uptake and oxidation in mouse heart independent of CD36}

Daphna D.J. Habets ${ }^{1}$, Arend Bonen ${ }^{2}$, Peter J. Voshol ${ }^{3}$, Jan F.C. Glatz ${ }^{1}$ and Joost J.F.P. Luiken ${ }^{1}$

${ }^{1}$ Department of Molecular Genetics, Cardiovascular Research Institute Maastricht (CARIM), Maastricht University, the Netherlands

${ }^{2}$ Department of Human Health and Nutritional Sciences, Guelph University, Guelph, Ontario, Canada

${ }^{3}$ Department of Endocrinology and Diabetes, Leiden University Medical Center, Leiden, the Netherlands 


\section{Abstract}

Cardiac long-chain fatty acid (LCFA) uptake is facilitated by a number of sarcolemmal fatty acid transporters, namely fatty acid translocase/CD36 (CD36), plasma membrane fatty acid-binding protein (FABPpm), and two isoforms of the fatty acid-transport protein family (FATP1 and FATP6). 5-aminoimidazole-4carboxamide ribonucleoside (AICAR) is an insulin-sensitizing therapeutic agent through its ability to activate AMP-activated protein kinase (AMPK). In this study cardiomyocytes from CD36 knockout mice were used to compare the effects of AICAR on LCFA transporters distribution and LCFA utilization with that of oligomycin, another AMPK-activating agent. In CD36 knockout cardiomyocytes the effects of oligomycin, but not AICAR, on LCFA uptake and oxidation were reduced. In WT cardiomyocytes, oligomycin induced surface appearance of CD36 but not of other LCFA transporters, whereas AICAR had no effect on any transporter distribution in WT or CD36 knockout cardiomyocytes. It is concluded by default that in CD36 knockout cardiomyocytes LCFA transporters other than CD36 are involved in AICAR stimulated LCFA uptake, but that in murine cardiomyocytes these other LCFA transporters do not mediate this event by a translocation mechanism. Moreover, species and tissue specific aspects of these observations are discussed. 


\section{Introduction}

Cardiac tissue acquires most of its metabolic energy from major substrates, glucose and long-chain fatty acids (LCFA). Compared with glucose, LCFA is the preferred substrate consumed by the heart, contributing $\sim 70 \%$ of ATP when supplied at physiological levels $[1,2]$. It is now well-documented that LCFA uptake in many tissues, including skeletal muscle and the heart, is facilitated by membraneassociated LCFA transporters. Several LCFA transporters are expressed in these muscles, including fatty acid translocase/CD36 (CD36), plasma membrane fatty acid-binding protein (FABPpm), and isoforms of the fatty acid-transport protein family (FATP1, FATP4 and FATP6) [3, 4]. Although the mechanism of proteinmediated LCFA transport across the plasma membrane is incompletely understood, there is strong evidence for the involvement of both CD36 and FABPpm in this process. Furthermore, LCFA uptake is regulated by the reversible translocation of CD36 and FABPpm from intracellular storage pools to the sarcolemma. It has been suggested that these LCFA transporters act in concert but the exact mechanism is not yet known [5]. A vesicle-mediated process has not been observed for FATP1 [6, 7] while for FATP6 this remains unknown.

In heart and skeletal muscle, contraction and insulin are the two main physiological stimuli inducing CD36-mediated LCFA uptake and glucose transporter 4 (GLUT4)mediated glucose uptake $[6,8,9]$. A key player in the regulation of LCFA metabolism [8] is AMP-activated protein kinase (AMPK) similar to that established for glucose metabolism [10]. Generally, AMPK activation results in activation of catabolic pathways (LCFA and glucose oxidation), and de-activation of anabolic pathways (LCFA and glucose storage) [10]. AMPK is activated in response to increased AMP levels during cellular contractions but also in response to different pharmacological agents, e.g., oligomycin and 5-aminoimidazole-4-carboxamide ribonucleoside (AICAR) [8]. Oligomycin is a $\mathrm{F}_{1} \mathrm{~F}_{0}$-ATPase inhibitor leading to an increased AMP/ATP ratio and finally increased AMPK activity [11, 12]. AICAR, a cell-permeable analog of adenosine is taken up into cells and metabolized by adenosine kinase to form ZMP, the monophosphorylated derivate that mimics the effect of AMP on AMPK activity [13-15]. The advantage of AICAR over oligomycin is that ATP depletion by oligomycin could have toxic effects, depending on the dose and duration of treatment (see chapter 2), while AICAR has been used as an insulin sensitizing agent [13, 15-17].

Oligomycin and AICAR have been used in many studies to investigate the regulatory mechanism of energy metabolism in heart and skeletal muscle. Both agents increase LCFA uptake and oxidation in cardiomyocytes. The oligomycininduced increase in LCFA uptake is CD36 dependent as has been established by using sulfo- $N$-succinimidyl oleate (SSO), a specific inhibitor of CD36, in studies with cardiomyocytes and by using cardiomyocytes from CD36 knockout (CD36 
KO) mice $[8,18]$. AICAR increases the abundance of CD36 and FABPpm at the sarcolemma at the cost of its intracellular storage resulting in an increased LCFA uptake rate into rat cardiomyocytes [7]. The AICAR-induced increase in LCFA uptake was completely blocked by SSO incubations in rat cardiomyocytes [7, 8]. In addition, in skeletal muscle of CD36 KO mice the increase in LCFA uptake and oxidation by AICAR treatment is almost fully inhibited [6]. This suggests that either FABPpm translocation is not involved in stimulation of LCFA uptake by AICAR, or the contribution of FABPpm to stimulation of AICAR-induced LCFA uptake is CD36 dependent. Since CD36 and FABPpm co-immunoprecipitate [5] it could be speculated that these transporters act in concert to mediate LCFA uptake.

We sought to investigate whether in mouse cardiomyocytes CD36 fulfills a similar role in AICAR-stimulated LCFA uptake as has been observed in oligomycinstimulated LCFA uptake. For this, cardiomyocytes from CD36 KO mice were used to study the role of CD36 in the stimulation of LCFA uptake and oxidation by AICAR.

\section{Materials and methods}

\section{Materials}

$\left[1-{ }^{14} \mathrm{C}\right]$ palmitic acid was obtained from GE Healthcare (Piscataway, NJ, USA). AICAR, BSA (fraction V, essentially fatty acid free), phloretin, DMSO and oligomycin were obtained from Sigma (St. Louis, MO). Liberase blendzyme 1 was purchased from Roche Diagnostics (Indianapolis, IN). The antibody directed against phosphorylated ACC was from Upstate (Dundee, UK) and anti-phosphoAMPK from Cell Signalling (Danvers, MA). An antibody directed against CD36 was obtained from Chemicon International Inc. (Temecula, USA) and FATP1 from Santa Cruz Biotechnology Inc. (Santa Cruz, USA). Anti-FABPpm was a gift from Dr. J. Calles-Escandon, Wake Forest University School of Medicine \& Baptist Medical Center, Winston-Salem NC. The antibody for FATP6 was kindly provided by Dr. A. Stahl, Palo Alto Medical Foundation and Stanford University School of Medicine, Palo Alto, California.

\section{Animals}

CD36 KO mice were generated by targeted homologous recombination and crossed back eight times to the C57B1/6 background. WT and CD36 KO mice were bred at TNO Quality of Life, Leiden, the Netherlands. The Experimental Animal Committee of Maastricht University gave approval for all experiments involving animals. 


\section{Isolation and pre-incubation of mouse cardiomyocytes}

Adult mouse cardiomyocytes (male mice 2-3 months of age) were isolated using a Langendorff perfusion system according to the procedure described by Severson et al. [19], which has been described previously [18]. After $30 \mathrm{~min}$ of recovery, suspensions of cardiomyocytes $(2.0 \mathrm{ml} ; 5-10 \mathrm{mg}$ wet mass $/ \mathrm{ml})$ were pre-incubated in capped 20-ml incubation vials either with $0.35 \%$ dimethyl sulfoxide (DMSO;Ctrl), $1 \mu \mathrm{mol} / 1$ oligomycin or $2 \mathrm{mmol} / 1 \mathrm{AICAR}$ for $20 \mathrm{~min}$ at $37^{\circ} \mathrm{C}$ under continuous shaking. At the applied concentrations of oligomycin and AICAR, LCFA uptake rates were found to be maximally stimulated (data not shown).

\section{Phosphorylation of AMPK and ACC in cardiomyocytes}

Pellets of stimulated cell suspensions were dissolved in sample buffer and subjected to SDS-polyacrylamide gel electrophoresis, followed by Western blotting to determine the phosphorylation of AMPK and ACC by applying antibodies against phospho-AMPK $\alpha$ (Thr172) and phospho-ACC (Ser79), respectively according to the manufacturer's instructions.

\section{Palmitate uptake in cardiomyocytes}

To study palmitate uptake, $0.5 \mathrm{ml}$ of $\left[1-{ }^{14} \mathrm{C}\right]$ palmitate/BSA complex was added to pre-incubated cell suspensions at the start of the incubations with a final concentration of $100 \mu \mathrm{mol} / 1$ palmitate with a corresponding palmitate/BSA ratio of 0.3. Cellular uptake of ${ }^{14} \mathrm{C}$-palmitate (3-min incubation) was determined upon washing the cells two times for $2 \mathrm{~min}$ at $45 \mathrm{~g}$ in an ice-cold stop solution containing $0.2 \mathrm{mmol} / 1$ phloretin. The radioactivity of the cell pellets was measured by scintillation counting.

\section{Palmitate oxidation into cardiomyocytes}

To study palmitate oxidation, $0.5 \mathrm{ml}$ of a mixture of $\left[1-{ }^{14} \mathrm{C}\right]$ palmitate/BSA complex was added to pre-incubated cell suspensions at the start of the incubations with a final concentration of $100 \mu \mathrm{mol} / 1$ palmitate with a corresponding palmitate/BSA ratio of 0.3 [20]. The oxidation of palmitate (20-min incubation) into $\mathrm{CO}_{2}$ was determined after addition of perchloric acid (final concentration $0.5 \mathrm{M}$ ) to cell suspensions. Production of ${ }^{14} \mathrm{CO}_{2}$ was measured after base trapping.

\section{Sarcolemmal CD36, FABPpm, FATP1 and FATP6 content of cardiomyocytes}

Directly after isolation, cell suspensions of cardiomyocytes were plated in laminincoated $(20 \mu \mathrm{g} / \mathrm{ml}) 35 \mathrm{~mm}$ culture plates. After $1 \mathrm{~h}$ the cells were incubated with $0.35 \%$ DMSO (Ctrl), $1 \mu \mathrm{mol} / 1$ oligomycin or $2 \mathrm{mmol} / 1 \mathrm{AICAR}$ for $20 \mathrm{~min}$ at $37^{\circ} \mathrm{C}$. 
As previously described [21], cells were biotinylated with the cell-permeable reagent sulfo-NHS-LC-biotin in bicarbonate medium at a final concentration of 1 $\mathrm{mg} / \mathrm{ml}$ for $45 \mathrm{~min}$ at $4^{\circ} \mathrm{C}$. Cells were treated with ice-cold glycine in bicarbonate medium $(100 \mathrm{mM})$. After a brief wash with ice-cold bicarbonate medium, cells were lysed by scraping in $250 \mu 1$ lysis buffer. The lysates were incubated on ice for $1 \mathrm{~h}$, and centrifuged for $10 \mathrm{~min}$ at $13,000 \mathrm{~g}$ at $4{ }^{\circ} \mathrm{C}$. A $15 \mu 1$ supernatant sample was used as total lysate sample for Western Blotting, and $150 \mu 1$ was then incubated overnight with streptavidin beads. Samples were briefly centrifuged, and the beads were washed twice with lysis buffer. The biotinylated proteins were eluted by incubation of the streptavidin beads for $5 \mathrm{~min}$ at $95^{\circ} \mathrm{C}$ in sample buffer. Samples were subjected to SDS-polyacrylamide gel electrophoresis, followed by Western Blotting for the detection of CD36, FABPpm, FATP1, FATP6 and caveolin-3 by applying mouse monoclonal anti-CD36 antibody 1258, a rabbit polyclonal antiFABPpm antiserum, a goat polyclonal anti-FATP1 antiserum and rabbit antiFATP6 antiserum, respectively, according to the manufacturer's instructions.

\section{Data presentation and statistics}

All data are presented as means \pm S.E.M. for the indicated number of cardiomyocyte preparations. Statistical difference between means was analyzed by the paired Student's t test. P values $\leq 0.05$ were considered significant.

\section{Results}

\section{Effects of oligomycin and AICAR on the contraction signaling cascade in cardiomyocytes from WT and CD36 KO mice}

Activation of AMPK was assessed by determining phosphorylation of the specific threonine residue (Thr172) at the $\alpha$-subunit of this heterotrimeric enzyme, and by the phosphorylation of its main substrate acetyl-CoA carboxylase (ACC; Ser79). Oligomycin-treatment of cardiomyocytes increased the degree of phosphorylation of both AMPK and ACC by 4.1-fold $( \pm 0.6 ; n=4, P<0.05)$ and 5.9-fold $( \pm 0.6 ; n=4$, $\mathrm{P}<0.05)$, respectively, in WT cardiomyocytes as well as in CD36 KO cardiomyocytes (to 3.9-fold \pm 0.2 and 5.5-fold $\pm 0.4 ; \mathrm{n}=4, \mathrm{P}<0.05$, respectively; Fig. 5.1). Although, AMPK was modestly phosphorylated by 1.2 -fold $( \pm 0.2 ; n=4$, $\mathrm{P}<0.05)$ in WT and by 1.3 -fold $( \pm 0.2 ; \mathrm{n}=4, \mathrm{P}<0.05)$ in $\mathrm{CD} 36 \mathrm{KO}$ cardiomyocytes after AICAR treatment, phosphorylation of ACC was elevated by 4.4 -fold $( \pm 0.5$; $\mathrm{n}=4, \mathrm{P}<0.05)$ and 4.2 -fold $( \pm 0.4 ; \mathrm{n}=4, \mathrm{P}<0.05)$ in WT cardiomyocytes and in CD36 $\mathrm{KO}$ cardiomyocytes (Fig. 5.1), respectively. This indicates that AMPK signalling is markedly activated during AICAR-treatment. Taken together, in CD36 KO cardiomyocytes AMPK signaling is not impaired. 


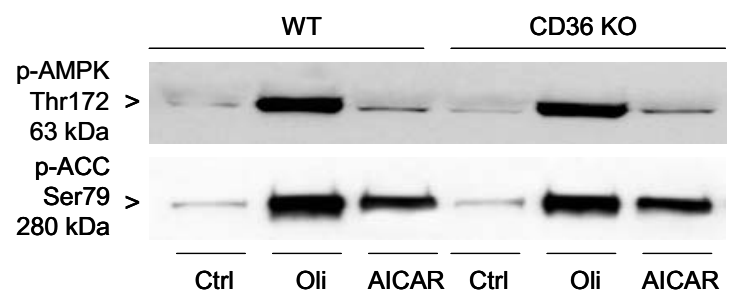

Figure 5.1 Effect of oligomycin and AICAR stimulation on the contraction signaling cascade in cardiomyocytes from WT and CD36 KO mice

Cardiomyocytes from WT mice and CD36 KO mice were incubated for $20 \mathrm{~min}$ in the absence (Ctrl) or presence of $15 \mu \mathrm{mol} / \mathrm{l}$ oligomycin (Oli) or $2 \mathrm{mmol} / \mathrm{l} 5$-aminoimidazole-4-carboxamide ribonucleoside (AICAR). Phosphorylation of AMP-activated protein kinase (AMPK)-Thr172 and of acetyl-CoA carboxylase (ACC)-Ser79 was determined by Western Blotting. From each sample, $20 \mu \mathrm{g}$ of myocytes wet mass was taken for electrophoresis. Western Blotting with antibodies against caveolin-3 and $\beta$-actin further confirmed no differences in protein amount per lane (data not shown). A representative Western Blot is presented out of 4 experiments with different cardiomyocyte preparations.

\section{Effects of oligomycin and AICAR on palmitate uptake into cardiomyocytes from WT and CD36 KO mice}

Palmitate uptake in quiescent cardiomyocytes (referred to as basal/control uptake) was not significantly different between WT and CD36 KO cardiomyocytes (Fig. 5.2A). Stimulation of WT cardiomyocytes with oligomycin markedly enhanced palmitate uptake by 2.5 -fold, but caused a merely modest increase in palmitate uptake (1.3-fold) in CD36 KO cardiomyocytes (Fig. 5.2A). In contrast, stimulation of palmitate uptake in cardiomyocytes by AICAR was not significantly different in WT cardiomyocytes (1.9-fold) compared to CD36 KO cardiomyocytes (2.1-fold; Fig. 5.2A). Thus, it appears that AICAR-stimulated LCFA uptake in cardiomyocytes was not changed due to knockout of $\mathrm{CD} 36$, while oligomycin stimulated LCFA uptake was largely reduced.

\section{Effects of oligomycin and AICAR on palmitate oxidation in cardiomyocytes from WT and CD36 KO mice}

Under basal conditions, palmitate oxidation in cardiomyocytes was not significantly different between WT and CD36 KO cardiomyocytes (Fig. 5.2B). Oligomycin significantly stimulated palmitate oxidation in WT cardiomyocytes by 3.6 -fold, also the 2.5-fold stimulation in CD36 KO cardiomyocytes was found to be significant, although, this increase was significantly lower compared to WT cardiomyocytes (Fig. 5.2B). However, AICAR-stimulated palmitate oxidation was not changed in 
WT (1.7-fold increase) compared to CD36 KO cardiomyocytes (1.8-fold increase; Fig. 5.2B). Thus, cardiomyocyte CD36 ablation does not alter AICAR-stimulated LCFA oxidation while oligomycin stimulated LCFA oxidation was reduced.
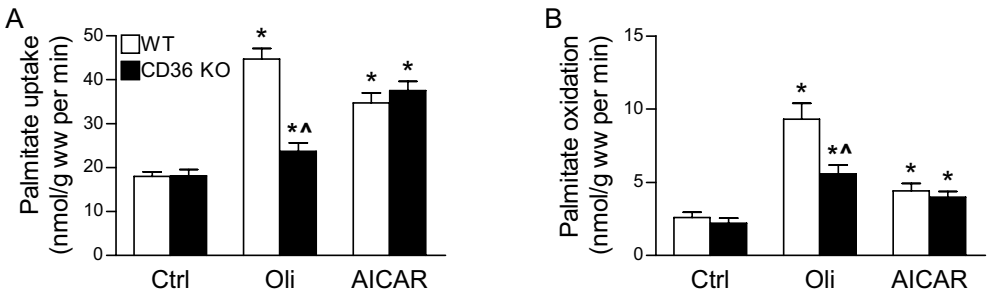

Figure 5.2 Effect of oligomycin and AICAR stimulation on LCFA uptake and oxidation in cardiomyocytes from WT and CD36 KO mice

Cardiomyocytes from WT mice ( $\square$ ) and CD36 KO mice (-) were incubated for $20 \mathrm{~min}$ in the absence (Ctrl) or presence of $15 \mu \mathrm{mol} / 1$ oligomycin (Oli) or $2 \mathrm{mmol} / 1$-aminoimidazole-4-carboxamide ribonucleoside (AICAR) where after uptake rates (panel A) and oxidation rates (panel B) of palmitate were measured. Values are means \pm S.E.M. for 5-7 animals per group. ${ }^{*}$ Significantly different from $\mathrm{Ctrl}(\mathrm{P}<0.05)$; ^significantly different from $\mathrm{WT}(\mathrm{P}<0.05)$.

\section{Sarcolemmal content of fatty acid transporters after oligomycin and AICAR stimulation of cardiomyocytes from WT and CD36 KO mice}

We explored the possible translocation of all LCFA transporters upon oligomycin and AICAR treatment by using cell surface biotinylation assay. First, we confirmed the phenotype of the CD36 KO cardiomyocytes: expression of CD36 was not detectable in these cardiomyocytes. Then, we confirmed that oligomycin treatment of WT cardiomyocytes resulted in an increase in the sarcolemmal content of CD36, amounting to 1.9 -fold $( \pm 0.3 ; \mathrm{n}=5, \mathrm{P}<0.05$; Fig. $5.3 \mathrm{~A})$. We made the surprising observation that AICAR treatment did not increase CD36 present at the sarcolemma in WT cardiomyocytes $(1.1 \pm 0.3 ; \mathrm{n}=5, \mathrm{P}>0.05$; Fig. 5.3A). The total protein expression of FABPpm (Fig. 5.3B) and FATP6 (Fig. 5.3D) was similar in WT and CD36 KO cardiomyocytes, while FATP1 (Fig. 5.3C) total protein expression was greater in CD36 KO cardiomyocytes (to 1.5 -fold $\pm 0.2 ; n=5, \mathrm{P}<0.05$ ) compared to WT mice, in agreement with earlier studies in heart and muscle of CD36 KO mice $[6,18,22]$. However, oligomycin and AICAR did not change the sarcolemmal content of FATP1 in WT nor in CD36 KO cardiomyocytes (Fig. 5.3C). The contents of FABPpm and FATP6 at the sarcolemmal were not changed, in WT and CD36 KO cardiomyocytes, under basal conditions or when stimulated with 
oligomycin or AICAR (Fig. 5.3B and 5.3D). This indicates that both stimuli did not alter the subcellular distribution of FABPpm, FATP1 and FATP6 in mouse heart.

A

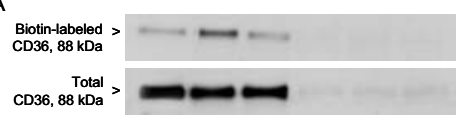

B

Biotin-labeled

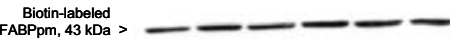

Total
FABPpm, $43 \mathrm{kDa}$
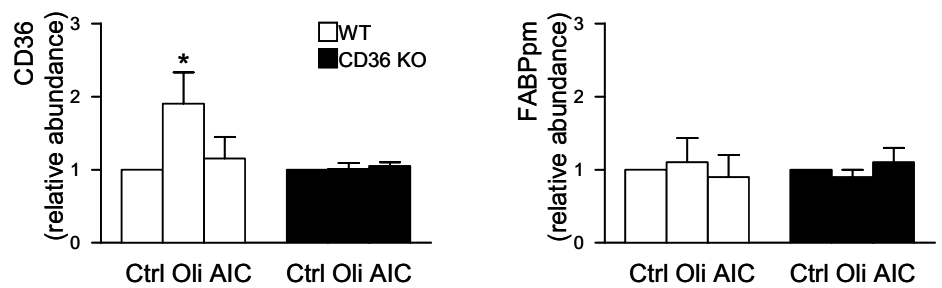

C

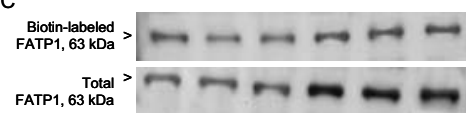

D Biotin-labeled FATP6, $70 \mathrm{kDa}$ >

Total
FATP6, $70 \mathrm{kDa}$
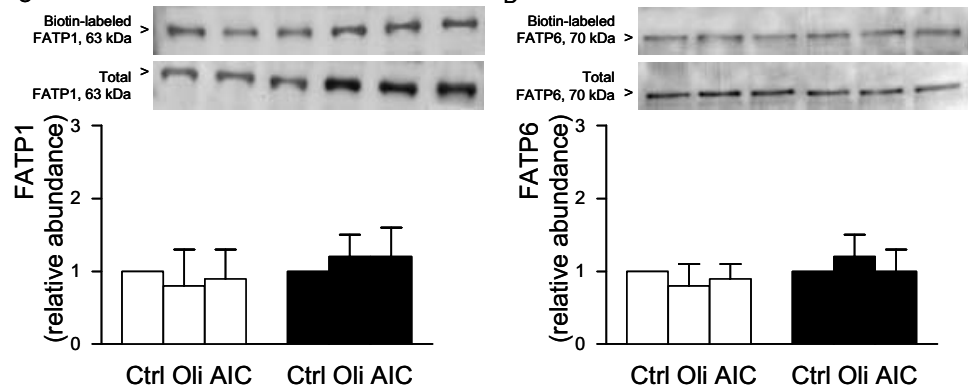

Figure 5.3 Effect of oligomycin and AICAR stimulation on sarcolemmal and total contents of LCFA transporters in cardiomyocytes from WT and CD36 KO mice

Cardiomyocytes from WT mice ( $\square$ ) and CD36 KO mice ( $\square)$ were incubated for 20 min in the absence (Ctrl) or presence of $1 \mu \mathrm{mol} / 1$ oligomycin (Oli) or $2 \mathrm{mmol} / 1$ 5-aminoimidazole-4-carboxamide ribonucleoside (AIC), whereafter biotin-labeled (cell surface) fatty acid translocase/ CD36 (CD36), plasma membrane fatty acid-binding protein (FABPpm), fatty acid-transport protein 1 and 6 (FATP1 and FATP6), and total cellular CD36, FABPpm, FATP1 and FATP6 were determined by Western Blotting followed by densitometry (relative abundance Ctrl set at 1). Representative Western Blots are presented out of 5 experiments with different cardiomyocyte preparations. *Significantly different from Ctrl $(\mathrm{P}<0.05)$

\section{Discussion}

In this study we observed for the first time that short-term, i.e., within minutes, stimulated LCFA uptake does not always correlate with increased CD36 and/or other LCFA transporter abundance at the sarcolemma. Oligomycin (15 min 
incubations) elevates sarcolemmal CD36 content concomitant with LCFA uptake and oxidation rates. However, in response to AICAR (15 minutes incubations) the abundance of CD36 at the sarcolemma was not changed while LCFA uptake and oxidation rates were increased. Direct evidence that CD36 is not involved in AICAR-stimulated LCFA uptake and oxidation was provided by using CD36 KO mice in this study. We attempted to unravel the mechanism as a result of which AICAR was able to induce LCFA uptake by determining whether the sarcolemmal presence of other LCFA transporters is altered during AICAR stimulation. In the present study, FABPpm, FATP1 and FATP6 were expressed at the sarcolemma of cardiomyocytes. However, the sarcolemmal expression was not altered after AICAR treatment neither in WT nor in CD36 KO cardiomyocytes. These current observations are in contrast with earlier studies in rat cardiomyocytes and mouse skeletal muscle in which we have demonstrated that AICAR induces the translocation of CD36 and FABPpm to the sarcolemma concomitant with elevated LCFA metabolism $[6,7]$. This leads us to speculate about the possible mechanisms explaining redundancy of AICAR-stimulated LCFA uptake and oxidation rates in isolated cardiomyocytes from CD36 $\mathrm{KO}$ mice.

It is possible that LCFA uptake is not only regulated by translocation of LCFA transporters from intracellular compartments to the sarcolemmal, but also by stimulation of the intrinsic activity of these transporters at the sarcolemma. The increase in intrinsic activity could be due to post-translational modifications and possibly by phosphorylation of LCFA transporters at the sarcolemma. In CD36 KO cardiomyocytes the AICAR-mediated transporter activation event then must include modifications of either FABPpm, FATP1 and/or FATP6. However, while posttranslational modifications and phosphorylation of CD36 have been described in the literature [23-25] this is presently unknown for the other LCFA transporters.

Another possibility is that LCFA transporters reposition to specialized regions of the sacrolemma to be able to increase the uptake rates of LCFA. It has been shown in cell lines that CD36 is not homogenous distributed over the sarcolemma but that it is clustered in specific regions of the sarcolemma. Examples of these specialized regions at the sarcolemma are caveolae. Caveolae are invaginations of the sarcolemma consisting of caveolin, cholesterol, and glycosphingolipids, and are enriched with membrane receptors and signaling molecules [26]. It has been observed that caveolae are involved in the CD36-mediated LCFA uptake process in adipocytes [27, 28]. In addition, it has been shown that the major component caveolae in muscle, namely caveolin-3, colocalizes with CD36 in human skeletal muscle [29]. This suggests that the translocation of LCFA transporters to the sarcolemma is not the only regulatory step in LCFA uptake and that their targeting to caveolae could provide another level of regulation for LCFA transport. However, it has not been investigated yet whether FABPpm, FATP1 and FATP6 are located 
in caveolae of cardiomyocytes and whether AICAR can influence their shuttling between caveolae and non-caveolae plasma membrane regions.

Furthermore, this study shows that the regulation of LCFA uptake is not only different between species, i.e., rat and mouse, but also between muscles, i.e., heart and skeletal muscle. Earlier studies showed that the effect of AICAR on LCFA uptake rate was dependent on CD36, because of the sensitivity to inhibition by the specific CD36 inhibitor, SSO in rat cardiomyocytes [7, 8]. Furthermore, in rat cardiomyocytes AICAR induced the translocation of CD36 from the intracellular storage pool to the plasma membrane [7]. In these studies the incubation conditions were exactly the same. Thus, AICAR-stimulated LCFA uptake appears differently regulated in rat and mouse hearts. Even comparing LCFA uptake in mouse tissues showed different results. In skeletal muscle of CD36 KO mice the effect of AICAR on LCFA uptake was almost fully prevented [6], while in the present study CD36 knockout in cardiomyocytes did not inhibit LCFA uptake and oxidation. This indicates that information about the regulation of substrate utilization can not always be extrapolated from one tissue to another and not from one species to another.

To conclude, not only translocation but also activity and localization of transporters on the sarcolemma could be involved in the regulation of LCFA uptake and oxidation. The present study illustrates that unraveling the activation, interactions, and localization of LCFA transporters on the sarcolemma is of interest in the perspective to regulate LCFA metabolism.

\section{Acknowledgements}

The authors gratefully acknowledge Ms Rogayah Carroll and Prof. dr. David Severson (University of Calgary, Canada) for their expert help to optimize the technique of isolating mouse cardiomyocytes. This study was supported by the Netherlands Organisation for Health Research and Development (ZonMw grant nr. 40-00812-98-03075), the European Community (Integrated Project LSHM-CT2004-005272, Exgenesis), and the Canadian Institutes of Health Research, the Natural Sciences and Engineering Research Council of Canada, the Heart and Stroke Foundation of Ontario, the Canada Research Chair program. J.F.C. Glatz is Netherlands Heart Foundation Professor of Cardiac Metabolism. A. Bonen is the Canada Research Chair in Metabolism and Health. 


\section{References}

1 Belke DD, Larsen TS, Lopaschuk GD and Severson DL 1999 Glucose and fatty acid metabolism in the isolated working mouse heart. Am J Physiol 277: R1210-1217

2 Stanley WC, Recchia FA and Lopaschuk GD 2005 Myocardial substrate metabolism in the normal and failing heart. Physiol Rev 85: 1093-1129

3 Bonen A, Chabowski A, Luiken JJ and Glatz JF 2007 Is membrane transport of FFA mediated by lipid, protein, or both? Mechanisms and regulation of protein-mediated cellular fatty acid uptake: molecular, biochemical, and physiological evidence. Physiology (Bethesda) 22: 15-29

4 Glatz JF, Bonen A, Ouwens DM and Luiken JJ 2006 Regulation of sarcolemmal transport of substrates in the healthy and diseased heart. Cardiovasc Drugs Ther 20: 471-476

5 Chabowski A, Gorski J, Luiken JJ, Glatz JF and Bonen A 2007 Evidence for concerted action of FAT/CD36 and FABPpm to increase fatty acid transport across the plasma membrane. Prostaglandins Leukot Essent Fatty Acids 77: 345-353

6 Bonen A, Han XX, Habets DD, Febbraio M, Glatz JF and Luiken JJ 2007 A null mutation in skeletal muscle FAT/CD36 reveals its essential role in insulin- and AICAR-stimulated fatty acid metabolism. Am J Physiol Endocrinol Metab 292: E1740-1749

7 Chabowski A, Coort SL, Calles-Escandon J, Tandon NN, Glatz JF, Luiken JJ and Bonen A 2005 The subcellular compartmentation of fatty acid transporters is regulated differently by insulin and by AICAR. FEBS Lett 579: 2428-2432

8 Luiken JJ, Coort SL, Willems J, Coumans WA, Bonen A, van der Vusse GJ and Glatz JF 2003 Contraction-induced fatty acid translocase/CD36 translocation in rat cardiac myocytes is mediated through AMP-activated protein kinase signaling. Diabetes 52: 1627-1634

9 Luiken JJ, Koonen DP, Willems J, Zorzano A, Becker C, Fischer Y, Tandon NN, Van Der Vusse GJ, Bonen A and Glatz JF 2002 Insulin stimulates long-chain fatty acid utilization by rat cardiac myocytes through cellular redistribution of FAT/CD36. Diabetes 51: 3113-3119

10 Hardie DG, Hawley SA and Scott JW 2006 AMP-activated protein kinase--development of the energy sensor concept. $J$ Physiol 574: 7-15

11 Bertrand L, Ginion A, Beauloye C, Hebert AD, Guigas B, Hue L and Vanoverschelde JL 2006 AMPK activation restores the stimulation of glucose uptake in an in vitro model of insulin-resistant cardiomyocytes via the activation of protein kinase B. Am J Physiol Heart Circ Physiol 291: H239-250

12 Marsin AS, Bertrand L, Rider MH, Deprez J, Beauloye C, Vincent MF, Van den Berghe G, Carling D and Hue L 2000 Phosphorylation and activation of heart PFK-2 by AMPK has a role in the stimulation of glycolysis during ischaemia. Curr Biol 10: 1247-1255

13 Bergeron R, Russell RR, 3rd, Young LH, Ren JM, Marcucci M, Lee A and Shulman GI 1999 Effect of AMPK activation on muscle glucose metabolism in conscious rats. Am J Physiol 276: E938-944

14 Hayashi T, Hirshman MF, Kurth EJ, Winder WW and Goodyear LJ 1998 Evidence for 5' AMPactivated protein kinase mediation of the effect of muscle contraction on glucose transport. Diabetes 47: 1369-1373

15 Merrill GF, Kurth EJ, Hardie DG and Winder WW 1997 AICA riboside increases AMP-activated protein kinase, fatty acid oxidation, and glucose uptake in rat muscle. Am J Physiol 273: E1107-1112

16 Ye JM, Dzamko N, Hoy AJ, Iglesias MA, Kemp B and Kraegen E 2006 Rosiglitazone treatment enhances acute AMP-activated protein kinase-mediated muscle and adipose tissue glucose uptake in high-fat-fed rats. Diabetes 55: 2797-2804

17 Musi N 2006 AMP-activated protein kinase and type 2 diabetes. Curr Med Chem 13: 583-589

18 Habets DD, Coumans WA, Voshol PJ, den Boer MA, Febbraio M, Bonen A, Glatz JF and Luiken JJ 2007 AMPK-mediated increase in myocardial long-chain fatty acid uptake critically depends on sarcolemmal CD36. Biochem Biophys Res Commun 355: 204-210

19 Carroll R, Carley AN, Dyck JR and Severson DL 2005 Metabolic effects of insulin on cardiomyocytes from control and diabetic db/db mouse hearts. Am J Physiol Endocrinol Metab 288: E900-906

20 Luiken JJ, van Nieuwenhoven FA, America G, van der Vusse GJ and Glatz JF 1997 Uptake and metabolism of palmitate by isolated cardiac myocytes from adult rats: involvement of sarcolemmal proteins. J Lipid Res 38: 745-758 
21 van Oort MM, van Doorn JM, Bonen A, Glatz JF, van der Horst DJ, Rodenburg KW and Luiken JJ 2008 Insulin-induced translocation of CD36 to the plasma membrane is reversible and shows similarity to that of GLUT4. Biochim Biophys Acta 1781: 61-71

22 Yang J, Sambandam N, Han X, Gross RW, Courtois M, Kovacs A, Febbraio M, Finck BN and Kelly DP 2007 CD36 deficiency rescues lipotoxic cardiomyopathy. Circ Res 100: 1208-1217

23 Asch AS, Liu I, Briccetti FM, Barnwell JW, Kwakye-Berko F, Dokun A, Goldberger J and Pernambuco M 1993 Analysis of CD36 binding domains: ligand specificity controlled by dephosphorylation of an ectodomain. Science 262: 1436-1440

24 Hatmi M, Gavaret JM, Elalamy I, Vargaftig BB and Jacquemin C 1996 Evidence for cAMP-dependent platelet ectoprotein kinase activity that phosphorylates platelet glycoprotein IV (CD36). J Biol Chem 271: 24776-24780

25 Tao N, Wagner SJ and Lublin DM 1996 CD36 is palmitoylated on both N- and C-terminal cytoplasmic tails. J Biol Chem 271: 22315-22320

26 Pohl J, Ring A, Ehehalt R, Herrmann T and Stremmel W 2004 New concepts of cellular fatty acid uptake: role of fatty acid transport proteins and of caveolae. Proc Nutr Soc 63: 259-262

27 Pohl J, Ring A, Ehehalt R, Schulze-Bergkamen H, Schad A, Verkade P and Stremmel W 2004 Longchain fatty acid uptake into adipocytes depends on lipid raft function. Biochemistry 43: 4179-4187

28 Pohl J, Ring A, Korkmaz U, Ehehalt R and Stremmel W 2005 FAT/CD36-mediated long-chain fatty acid uptake in adipocytes requires plasma membrane rafts. Mol Biol Cell 16: 24-31

29 Vistisen B, Roepstorff K, Roepstorff C, Bonen A, van Deurs B and Kiens B 2004 Sarcolemmal FAT/CD36 in human skeletal muscle colocalizes with caveolin-3 and is more abundant in type 1 than in type 2 fibers. J Lipid Res 45: 603-609 
102 | 


\title{
CHAPTER 6
}

\author{
Munc18c is not rate-limiting for \\ glucose and long-chain fatty acid \\ uptake in the heart
}

Daphna D.J. Habets ${ }^{1}$, Debbie C. Thurmond ${ }^{2}$, Will A. Coumans ${ }^{1}$, Arend Bonen ${ }^{3}$, Jan F.C. Glatz ${ }^{1}$ and Joost J.F.P. Luiken ${ }^{1}$

${ }^{1}$ Department of Molecular Genetics, Cardiovascular Research Institute Maastricht (CARIM), Maastricht University, the Netherlands

${ }^{2}$ Department of Biochemistry and Molecular Biology, Center for Diabetes Research, Indiana University School of Medicine, Indianapolis, Indiana, USA

${ }^{3}$ Department of Human Health and Nutritional Sciences, Guelph University, Guelph, Ontario, Canada

Submitted 


\section{Abstract}

The role of soluble $N$-ethylmaleimide-sensitive factor attachment protein receptor (SNARE)- and SNARE-associated proteins have not yet been assessed in regulation of cardiac glucose uptake, nor in the regulation of long-chain fatty acid (LCFA) uptake in any tissue. Munc18c is a SNARE-associated protein that regulates glucose transporter translocation in skeletal muscle and adipose tissue. Using cardiomyocytes from Munc $18 \mathrm{c}^{-/+}$mice (with $56 \%$ reduction of Munc18c protein expression), we investigated whether this syntaxin4-associated protein is involved in regulation of cardiac substrate uptake. Basal, insulin- and oligomycin (an AMPactivated protein kinase-activating agent)-stimulated glucose and LCFA uptake was not altered significantly in Munc $18 \mathrm{c}^{-/+}$cardiomyocytes compared to wild-type cells. We conclude, therefore, that Munc18c is not rate-limiting for cardiac substrate uptake, neither under basal conditions nor when maximal stimulated metabolically. 


\section{Introduction}

In the heart, long-chain fatty acids (LCFA) and glucose are the predominant substrates. Glucose is mainly taken up into cardiomyocytes via glucose transporter 4 (GLUT4), and LCFA largely via fatty acid translocase/CD36 (CD36) [1]. Both transporters recycle between intracellular stores and the sarcolemma, and can be induced to translocate to the sarcolemma by several physiological stimuli, such as an increase in circulating concentrations of insulin [2], and an increase in contractile activity [3]. Hence, both the translocation of GLUT4 and CD36 appear to be similarly regulated. This similarity also applies to the signaling components activated by each of these stimuli. Insulin recruits both GLUT4 and CD36 via activation of the phosphatidylinositol-3-kinase - protein kinase B (PKB)/Akt axis, and contraction recruits these transporters via activation of the LKB1 - AMPactivated protein kinase (AMPK) axis [2, 3].

The translocation of GLUT4 and CD36 to the sarcolemma in response to physiological stimuli occurs by vesicular trafficking $[2,3]$, but for the heart there is little information on the routes involved. However, much more information is available for GLUT4 translocation in adipocytes [4], and to a lesser extent in skeletal muscle [5], upon insulin stimulation. This work revealed that GLUT4 translocation is a vesicle-mediated exocytotic process, obeying principles of the soluble $N$-ethylmaleimide-sensitive factor attachment protein receptor (SNARE) hypothesis. Accordingly, in vesicular trafficking events a unique vesicle SNARE (vSNARE) specifically recognizes and interacts with a cognate target SNARE (tSNARE) localized at the target membrane. This specific vSNARE - tSNARE recognition ensures that transport vesicles do not fuse randomly with subcellular membrane compartments, but deliver their cargo at the appropriate intracellular address. Cardiomyocytes contain multiple types of SNARE proteins [6], which include the vSNARE vesicle-associated membrane protein-2 (VAMP2) and the tSNAREs soluble NSF-attachment protein-23 (SNAP23) and syntaxin4, which were found to be involved in insulin-induced GLUT4 translocation in adipocytes and skeletal muscle [7].

Besides SNARE proteins, a number of accessory proteins have been shown to be important in formation of the SNARE complex [7]. One of these accessory proteins is Munc18c, which belongs to a family of Sec1p-like/Munc18 proteins. Munc18c forms a complex with syntaxin4 [8], and is known to be involved in several trafficking processes including GLUT4 translocation, as has been shown in cell lines [9] and in skeletal muscle from heterozygous Munc18c mice [10]. Driven by the lack of information about the role of SNAREs and accessory proteins in GLUT4 translocation in the heart and in CD36 translocation in any tissue, we sought to investigate (i) whether in the heart Munc18c fulfills a similar role in insulinstimulated GLUT4 translocation, as has been observed in adipose tissue and in 
skeletal muscle, and (ii) whether this role can be extended to AMPK-stimulated GLUT4 translocation, and/or to (iii) insulin- and contraction-induced CD36 translocation. Because homozygous Munc18c mice are not viable [10, 11], we used heterozygous Munc18c mice to study the potential effects of partial ablation of this protein in the stimulation of glucose and LCFA uptake into cardiomyocytes by insulin and by oligomycin, an AMPK-activating contraction-mimetic agent.

\section{Materials and methods}

\section{Materials}

$\left[1-{ }^{14} \mathrm{C}\right]$ palmitic acid and 2-deoxy-D-[1- $\left.{ }^{3} \mathrm{H}\right]$ glucose were obtained from GE Healthcare (Piscataway, NJ, USA). BSA (fraction V, essentially fatty acid free), phloretin, oligomycin, insulin and DMSO were obtained from Sigma (St. Louis, MO). Liberase blendzyme 1 was purchased from Roche Diagnostics (Indianapolis, IN). The rabbit anti-Munc18c antibody was generated as previously described [9]. The antibody directed against phosphorylated ACC was obtained from Upstate (Dundee, UK), anti-GAPDH, anti-phospho-PKB and anti-phospho-AMPK from Cell Signalling (Danvers, MA). Antibodies directed against CD36 and GLUT4 were obtained from Chemicon International Inc. (Temecula, USA).

\section{Animals}

Munc $18 \mathrm{c}^{-/+}$mice on the C57B1/6 background were generated as previously described [10]. The Experimental Animal Committee of Maastricht University gave approval for all experiments involving animals.

\section{Isolation and pre-incubation of mouse cardiomyocytes}

Adult mouse cardiomyocytes (male mice 2-3 months of age) were isolated using a Langendorff perfusion system as described previously [12]. Suspensions of cardiomyocytes $(2.0 \mathrm{ml} ; 5-10 \mathrm{mg}$ wet mass $/ \mathrm{ml}$; viability $60-80 \%)$ were preincubated in capped $20-\mathrm{ml}$ incubation vials either with $0.35 \%$ dimethyl sulfoxide (DMSO; Ctrl), $1 \mu \mathrm{mol} / 1$ oligomycin or $100 \mathrm{nmol} / 1$ insulin for $20 \mathrm{~min}$ at $37^{\circ} \mathrm{C}$ under continuous shaking. Previously we have shown that oligomycin, a mitochondrial $\mathrm{F}_{1} \mathrm{~F}_{0}$-ATPase inhibitor, stimulates LCFA uptake in a non-additive manner to contractions, indicating that oligomycin activates the same signaling cascade as contractions [3].

\section{Phosphorylation of AMPK, ACC, PKB and total expression of Munc18c, GADPH, CD36 and GLUT4 in cardiomyocytes}

Pellets of stimulated cell suspensions were dissolved in sample buffer, as previously described [12], and subjected to SDS-polyacrylamide gel electrophoresis, followed 
by Western Blotting for the detection of Munc18c [9], GAPDH, of phosphoAMPK $\alpha$ (Thr172), phospho-ACC (Ser79), phospho-PKB (Ser473), and of total GLUT4 and CD36 expression levels by applying the antibodies according to the manufacturer's instructions.

\section{Deoxyglucose and palmitate uptake into cardiomyocytes}

To study the rate of deoxyglucose and palmitate uptake, $0.5 \mathrm{ml}$ of a mixture of [1-

$\left.{ }^{3} \mathrm{H}\right]$ deoxyglucose and $\left[1-{ }^{14} \mathrm{C}\right]$ palmitate/BSA complex was added to pre-incubated cell suspensions at the start of the incubations with a final concentration of 100 $\mu \mathrm{mol} / \mathrm{l}$ deoxyglucose and $100 \mu \mathrm{mol} / 1$ palmitate with a corresponding palmitate/bovine serum albumin (BSA) ratio of 0.3 . Cellular uptake of ${ }^{3} \mathrm{H}$ deoxyglucose (3-min incubation) and ${ }^{14} \mathrm{C}$-palmitate (3-min incubation) was determined upon washing the cells, and measuring the radioactivity of the cell pellets [13].

\section{Data presentation and statistics}

All data are presented as means \pm S.E.M. for the indicated number of cardiomyocyte preparations. Statistical difference between means was analyzed by the paired Student's $t$ test. $P$ values $\leq 0.05$ were considered significant.

\section{Results}

\section{Munc18c expression in WT and Munc18c $\mathrm{c}^{-/+}$cardiomyocytes}

Quantification of Western Blots showed Munc18c to be reduced in Munc18c $\mathrm{c}^{-/+}$ cardiomyocytes by $56 \%( \pm 0.6 ; \mathrm{n}=5, \mathrm{P}<0.05$; Fig. $6.1 \mathrm{~A})$, in agreement with the previously observed $50 \%$ reduction in heart homogenates of these mice [10]. The loading control; glyceraldehyde-3-phosphate dehydrogenase (GAPDH) expression was similar in WT and Munc18c $\mathrm{c}^{-/+}$cardiomyocytes (Fig. 6.1A).

\section{Effects of oligomycin and insulin on signal transduction pathways in WT and Munc18c $\mathrm{c}^{-/+}$cardiomyocytes}

Activation of AMPK was assessed by determining phosphorylation of the specific threonine residue (Thr172) at the $\alpha$-subunit of this heterotrimeric enzyme, and by the phosphorylation of its main substrate acetyl-CoA carboxylase (ACC; Ser79). AMPK-Thr172 and ACC-Ser79 phosphorylation in quiescent cardiomyocytes (referred to as Ctrl) was similar in WT and Munc18 $\mathrm{c}^{-/+}$cardiomyocytes. Oligomycin-treatment of cardiomyocytes increased the degree of phosphorylation of both AMPK by 5.9-fold $( \pm 0.5 ; \mathrm{n}=4, \mathrm{P}<0.05)$ and ACC by 7.5 -fold $( \pm 0.5 ; \mathrm{n}=4$, $\mathrm{P}<0.05)$, respectively, in WT cardiomyocytes as well as in Munc18 $\mathrm{c}^{-/+}$ 


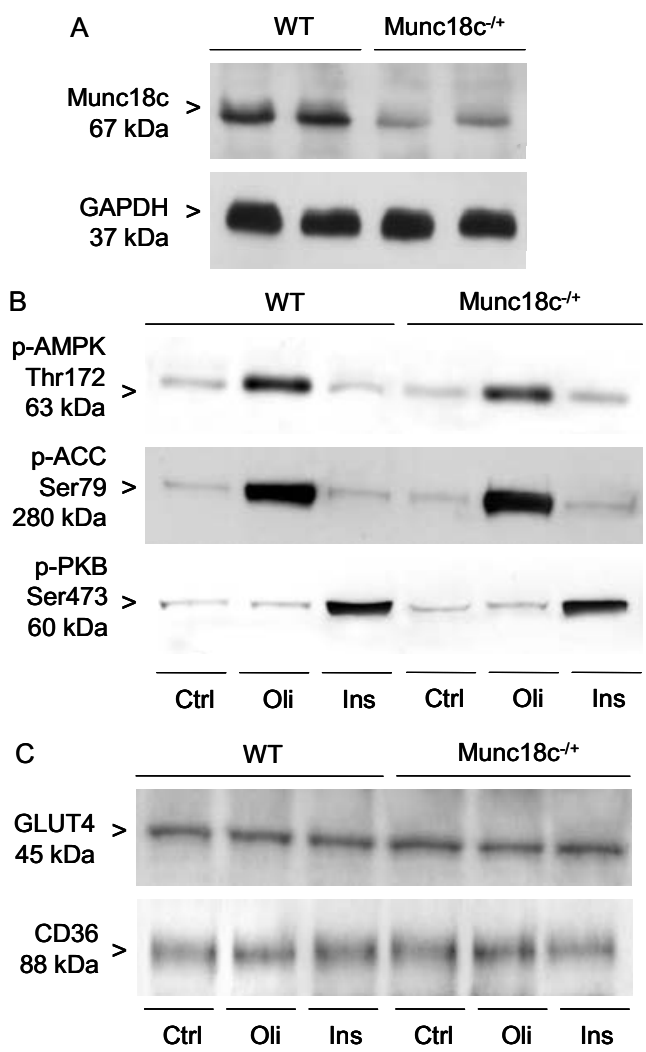

Fig. 6.1 Munc18c expression in cardiomyocytes from WT and Munc $18 \mathrm{c}^{-1+}$ mice and the effects of oligomycin and insulin treatment on phosphorylation of AMPK, ACC, PKB, and on total expression of CD36 and GLUT4

WT and Munc18 $\mathrm{c}^{-1+}$ cardiomyocytes were used to determine Munc18c and glyceraldehydes-3phosphate dehydrogenase (GAPDH; loading control) expression (panel A), and after incubation for 20 min in the absence (Ctrl) or presence of $1 \mu \mathrm{mol} / 1$ oligomycin (Oli) or $100 \mathrm{nmol} / 1$ insulin (Ins) phosphoAMP-activated protein kinase (AMPK;Thr172), phospho-acetyl-CoA carboxylase (ACC;Ser79), phospho-protein kinase B (PKB; Ser473; panel B), and total expression of glucose transporter 4 (GLUT4) and fatty acid translocase/CD36 (CD36; panel C) were determined by Western Blotting. A representative Western Blot is presented out of 5 experiments with different cardiomyocyte preparations.

cardiomyocytes (to 5.3-fold \pm 0.4 and 7.9 -fold \pm 0.6 ; $=4, \mathrm{P}<0.05$, respectively) (Fig. 6.1B). Stimulation of cardiomyocytes with insulin did not alter the phosphorylation state of AMPK and ACC, neither in WT cardiomyocytes nor in Munc18c ${ }^{-/+}$cardiomyocytes (Fig. 6.1B). 
Activation of the insulin signaling pathway was determined by phosphorylation of PKB (Ser473). In quiescent cardiomyocytes, phosphorylation of PKB was similar in WT and Munc18c $\mathrm{c}^{-/+}$cardiomyocytes. Treatment of WT cardiomyocytes with insulin (4.3-fold $\pm 0.5 ; \mathrm{n}=5, \mathrm{P}<0.05)$ but not oligomycin, increased the phosphorylation of PKB (Fig. 6.1B). This increase after insulin treatment was similar in Munc18c $\mathrm{c}^{-/+}$cardiomyocytes (4.1-fold $\left.\pm 0.4 ; \mathrm{n}=5, \mathrm{P}<0.05\right)$. Hence, activation of signal transduction pathways normally leading to increased myocardial substrate uptake are not disrupted in Munc18 $\mathrm{c}^{-/+}$cardiomyocytes.

\section{Expression of GLUT4 and CD36 in WT and Munc18c $\mathrm{c}^{-/+}$ cardiomyocytes}

Total expression of GLUT4 and CD36 was not significantly different between WT and Munc18 $\mathrm{c}^{-/+}$cardiomyocytes (Fig. 6.1C), nor after incubation with oligomycin or insulin. This indicates that the cardiac transport capacity for LCFA and glucose is not altered due to heterozygous knockout of Munc18c.

\section{Oligomycin- and insulin-stimulated deoxyglucose and palmitate uptake into WT and Munc18c $\mathrm{c}^{-/+}$cardiomyocytes}

Deoxyglucose uptake into quiescent cardiomyocytes was similar between WT and Munc18 $\mathrm{c}^{-/+}$cardiomyocytes (Fig. 6.2A). Oligomycin treatment increased deoxyglucose by 3.4-fold in WT and by 2.9 -fold in Munc $18 \mathrm{c}^{-/+}$cardiomyocytes. Insulin enhanced the deoxyglucose uptake by 5.8 -fold and 6.1-fold into WT and Munc $18 \mathrm{c}^{-/+}$cardiomyocytes, respectively.
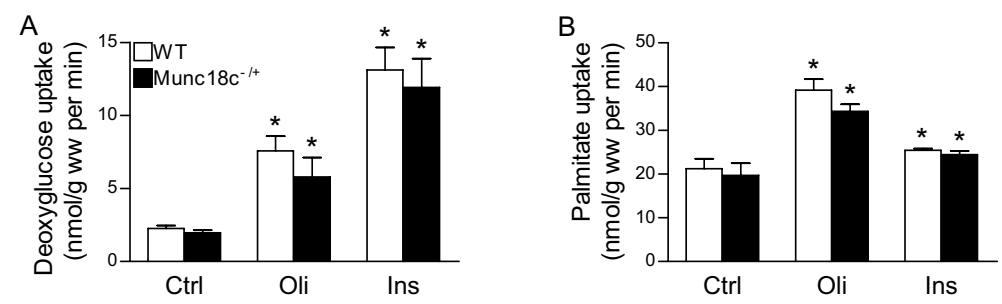

Fig. 6.2 Effects of oligomycin and insulin stimulation on deoxyglucose and palmitate uptake into cardiomyocytes from WT and Munc $18 \mathrm{c}^{-/+}$mice

WT ( $\square$ ) and Munc1 $8 \mathrm{c}^{-/ /}$cardiomyocytes ( $\square$ ) were incubated for $20 \mathrm{~min}$ in the absence (Ctrl) or presence of $1 \mu \mathrm{mol} / \mathrm{l}$ oligomycin (Oli) or $100 \mathrm{nmol} / \mathrm{l}$ insulin (Ins) whereafter uptake rates of ${ }^{3} \mathrm{H}$-deoxyglucose (panel A) and ${ }^{14} \mathrm{C}$-palmitate (panel B) were measured. Data are means \pm S.E.M. for 10 experiments carried out with different cardiomyocyte preparations. *Significantly different from $\mathrm{Ctrl}(\mathrm{P}<0.05)$. 
Palmitate uptake into quiescent cardiomyocytes was not significantly different between WT and Munc18 $\mathrm{c}^{-/+}$cardiomyocytes (Fig. 6.2B). Treatment of WT and Munc $18 \mathrm{c}^{-/+}$cardiomyocytes with oligomycin increased palmitate uptake by 1.9 -fold and 1.7-fold, respectively. In addition, there was no significant difference in insulininduced palmitate uptake into WT (1.2-fold increase) and $\mathrm{Munc} 18 \mathrm{c}^{-/+}$ cardiomyocytes (1.2-fold increase). Taken together, WT and Munc18c $\mathrm{c}^{-/+}$ cardiomyocytes, in the absence or presence of a stimulus, showed no significant differences in deoxyglucose and palmitate uptake rates.

\section{Discussion}

The SNARE-associated protein Munc18c is on the steadily growing list of proteins found to be involved in insulin-stimulated GLUT4 translocation, as established in adipocytes and skeletal muscle [14]. Whether Munc18c fulfils a similar role in insulin-induced GLUT4 translocation in the heart is not known. It is also of interest to study whether Munc18c is involved in CD36 translocation, because differences in the regulation of the translocation of CD36 relative to GLUT4 would disclose targets for modulation of the substrate preference of the heart [1]. Using cardiomyocytes from heterozygous Munc18c knockout mice, we made the following observations: (i) basal, oligomycin- or insulin-induced glucose uptake rates were not altered by partial Munc18c deletion, nor were (ii) basal, oligomycinor insulin-induced LCFA uptake rates. Together, these findings suggest that Munc18c is not rate-limiting for basal and stimulus-induced cardiac substrate uptake.

The lack of effect upon insulin signaling (PKB-Ser473 phosphorylation) in cardiomyocytes here in heterozygous Munc18c mice is consistent with that lack of effect in skeletal muscle, supporting the concept that Munc18c plays a more direct role in modulating SNARE protein machinery at the plasma membrane in exocytosis events. With respect to the regulation of glucose uptake through GLUT4 translocation, the heterozygous Munc18c mice display significantly impaired skeletal muscle insulin-stimulated GLUT4 translocation [10]. Obviously, the unimpaired glucose uptake rate into insulin-treated cardiomyocytes with 56\% reduced Munc18c content, as obtained in this study, contrasts markedly with the effects in skeletal muscle. There are two explanations for this discrepancy: (i) Munc18c is obligatorily involved in insulin-stimulated GLUT4 translocation in muscle, but not in heart, or (ii) Munc18c is redundantly present in heart, but not in skeletal muscle, so that a partial reduction in its content is not rate-limiting for glucose flux under maximal conditions. We speculate that the latter option is more likely. Notably, in heart and muscle glucose uptake is similarly regulated by signaling cascades inducing GLUT4 translocation from endosomal and preendosomal stores to the sarcolemma $[15,16]$. Moreover, besides Munc18c, 
components of the SNARE complex involved in insulin-induced fusion of GLUT4containing transport vesicles with the sarcolemma, as found in muscle [17], including VAMP2, syntaxin4 and SNAP23, are also present in heart [6]. When taken in consideration that this redundancy hypothesis cannot be explained by the degree of Munc18c expression in heart versus muscle, being of similar magnitude $[6,17]$, a higher activation state of Munc18c in heart versus muscle may be compatible with a functional redundancy in the heart. This might be related to the permanent contractile state of the heart resulting in the permanent elevation of second messengers which could be involved in Munc18c activation. The recent finding that tyrosine phosphorylation of Munc18c facilitates vesicle exocytosis [18], might elude to the notion that in the heart tyrosine phosphorylation of Munc18c is chronically upregulated. Alternatively, the ratio of Munc18c expression to expression of the other components of the SNARE complex could be different in heart versus muscle. In this instance, either one of the proteins VAMP2, syntaxin4 or SNAP23 could display a lower expression level in heart compared to muscle, so that these proteins, and thus not Munc18c, are rate-limiting for SNARE complex formation in heart.

Concerning regulation of LCFA uptake via CD36 translocation, no studies have yet been undertaken to examine the involvement of SNARE- or SNARE-associated proteins in this process. The inability of partial Munc18c deletion to alter LCFA uptake into quiescent and stimulated cardiomyocytes leads us to speculate that (i) Munc18c is not involved in the regulation of LCFA uptake, or (ii) Munc18c is not rate-limiting for LCFA uptake. As above we propose that the latter possibility is more likely, since the regulation of glucose uptake and LCFA uptake are very similar with respect to localization of intracellular compartments and involvement of signaling cascades. Taken together, Munc18c is not rate-limiting for uptake of both glucose and LCFA into cardiomyocytes, neither under basal nor under maximal metabolic demands.

\section{Acknowledgements}

This study was supported by the Netherlands Organisation for Health Research and Development (ZonMw grant nr. 40-00812-98-03075), the European Community (Integrated Project LSHM-CT-2004-005272, Exgenesis), the National Institutes of Health (DK67912 to D.C.T.) and the Canadian Institutes of Health Research, the Natural Sciences and Engineering Research Council of Canada, the Heart and Stroke Foundation of Ontario, the Canada Research Chair program. A. Bonen is the Canada Research Chair in Metabolism and Health. J.F.C. Glatz is Netherlands Heart Foundation Professor of Cardiac Metabolism. 


\section{References}

1 Glatz JF, Bonen A, Ouwens DM and Luiken JJ 2006 Regulation of sarcolemmal transport of substrates in the healthy and diseased heart. Cardiovasc Drugs Ther 20: 471-476

2 Luiken JJ, Koonen DP, Willems J, Zorzano A, Becker C, Fischer Y, Tandon NN, Van Der Vusse GJ, Bonen A and Glatz JF 2002 Insulin stimulates long-chain fatty acid utilization by rat cardiac myocytes through cellular redistribution of FAT/CD36. Diabetes 51: 3113-3119

3 Luiken JJ, Coort SL, Willems J, Coumans WA, Bonen A, van der Vusse GJ and Glatz JF 2003 Contraction-induced fatty acid translocase/CD36 translocation in rat cardiac myocytes is mediated through AMP-activated protein kinase signaling. Diabetes 52: 1627-1634

4 Watson RT and Pessin JE 2007 GLUT4 translocation: the last 200 nanometers. Cell Signal 19: 22092217

5 Rudich A and Klip A 2003 Push/pull mechanisms of GLUT4 traffic in muscle cells. Acta Physiol Scand 178: 297-308

6 Peters CG, Miller DF and Giovannucci DR 2006 Identification, localization and interaction of SNARE proteins in atrial cardiac myocytes. J Mol Cell Cardiol 40: 361-374

7 Ishiki M and Klip A 2005 Minireview: recent developments in the regulation of glucose transporter-4 traffic: new signals, locations, and partners. Endocrinology 146: 5071-5078

8 Hata Y, Slaughter CA and Sudhof TC 1993 Synaptic vesicle fusion complex contains unc-18 homologue bound to syntaxin. Nature 366: 347-351

9 Thurmond DC, Ceresa BP, Okada S, Elmendorf JS, Coker K and Pessin JE 1998 Regulation of insulinstimulated GLUT4 translocation by Munc18c in 3T3L1 adipocytes. J Biol Chem 273: 33876-33883

10 Oh E, Spurlin BA, Pessin JE and Thurmond DC 2005 Munc18c heterozygous knockout mice display increased susceptibility for severe glucose intolerance. Diabetes 54: 638-647

11 Kanda H, Tamori Y, Shinoda H, Yoshikawa M, Sakaue M, Udagawa J, Otani H, Tashiro F, Miyazaki J and Kasuga M 2005 Adipocytes from Munc18c-null mice show increased sensitivity to insulinstimulated GLUT4 externalization. J Clin Invest 115: 291-301

12 Habets DD, Coumans WA, Voshol PJ, den Boer MA, Febbraio M, Bonen A, Glatz JF and Luiken JJ 2007 AMPK-mediated increase in myocardial long-chain fatty acid uptake critically depends on sarcolemmal CD36. Biochem Biophys Res Commun 355: 204-210

13 Luiken JJ, van Nieuwenhoven FA, America G, van der Vusse GJ and Glatz JF 1997 Uptake and metabolism of palmitate by isolated cardiac myocytes from adult rats: involvement of sarcolemmal proteins. J Lipid Res 38: 745-758

14 Thurmond DC and Pessin JE 2001 Molecular machinery involved in the insulin-regulated fusion of GLUT4-containing vesicles with the plasma membrane (review). Mol Membr Biol 18: 237-245

15 Zorzano A, Sevilla L, Camps M, Becker C, Meyer J, Kammermeier H, Munoz P, Guma A, Testar X, Palacin M, Blasi J and Fischer Y 1997 Regulation of glucose transport, and glucose transporters expression and trafficking in the heart: studies in cardiac myocytes. Am J Cardiol 80: 65A-76A

16 Martin S, Slot JW and James DE 1999 GLUT4 trafficking in insulin-sensitive cells. A morphological review. Cell Biochem Biophys 30: 89-113

17 St-Denis JF and Cushman SW 1998 Role of SNARE's in the GLUT4 translocation response to insulin in adipose cells and muscle. J Basic Clin Physiol Pharmacol 9: 153-165

18 Oh E and Thurmond DC 2006 The stimulus-induced tyrosine phosphorylation of Munc18c facilitates vesicle exocytosis. J Biol Chem 281: 17624-17634 


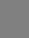

\section{CHAPTER 7}

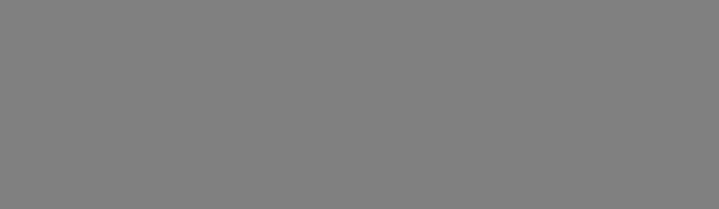

(n)

\section{General discussion \\ General discussion




\section{Introduction}

In this chapter the most important findings of this thesis will be discussed in a broader perspective and in relation to the newest literature. Next to the studies described in this thesis I have also contributed to other investigations. The conclusions of these studies will also be discussed in this chapter.

In the heart there is a very finely tuned balance between long-chain fatty acid (LCFA) and glucose utilization, of which LCFA is the predominant substrate for ATP production necessary to sustain mechanical performance [2]. In many conditions, e.g., fasted state, fed state or during increased workload, the heart is a highly flexible metabolic organ in which many regulatory processes are involved to maintain energy homeostasis. In general, the aim of this thesis was to further unravel the regulation of cellular substrate utilization in the healthy heart. In the studies described in this thesis we used isolated cardiomyocytes from various genetically manipulated mouse models. Isolated cells from mice with altered expression of relevant signaling and trafficking genes involved in stimulus-induced translocation of LCFA and glucose transporters provide direct evidence for their role in cardiac substrate regulation under healthy conditions. Subsequently, the role of these regulatory signaling and trafficking pathways was studied in pathological conditions, as in cardiomyocytes from rats on a high-fat diet. Understanding the regulation of cardiac substrate utilization under healthy and pathological conditions could be promising to identify novel therapies aimed at restoring cardiac substrate balance of the diseased heart [84], e.g., diabetic cardiomyopathy, in which the substrate balance is disrupted as observed in cardiomyocytes from rats on a high-fat $\operatorname{diet}[85]$.

\section{Lessons from cardiac metabolism in the healthy heart}

The uptake of both LCFA and glucose is regulated by the sarcolemmal content of specific transport proteins, e.g., fatty acid translocase/CD36 (CD36) (see chapter 3) and GLUT4, respectively. These transporters are not only present at the sarcolemma, but also in intracellular storage compartments [14]. The recruitment of these transporters to the sarcolemma is regulated by signal transduction cascades. Regulatory key players in stimulated cardiac energy metabolism have been unraveled in the last few years [6]. Others have explored the role of AMP-activated protein kinase (AMPK), calmodulin-dependent protein kinase kinase (CaMKK), AS160, and protein kinase C (PKC) isoforms but only in contraction-stimulated GLUT4-mediated glucose uptake in skeletal muscle [86]. During my thesis work, the roles of most of these metabolic regulatory proteins have been examined in the heart and also in contraction-stimulated CD36-mediated LCFA uptake. 


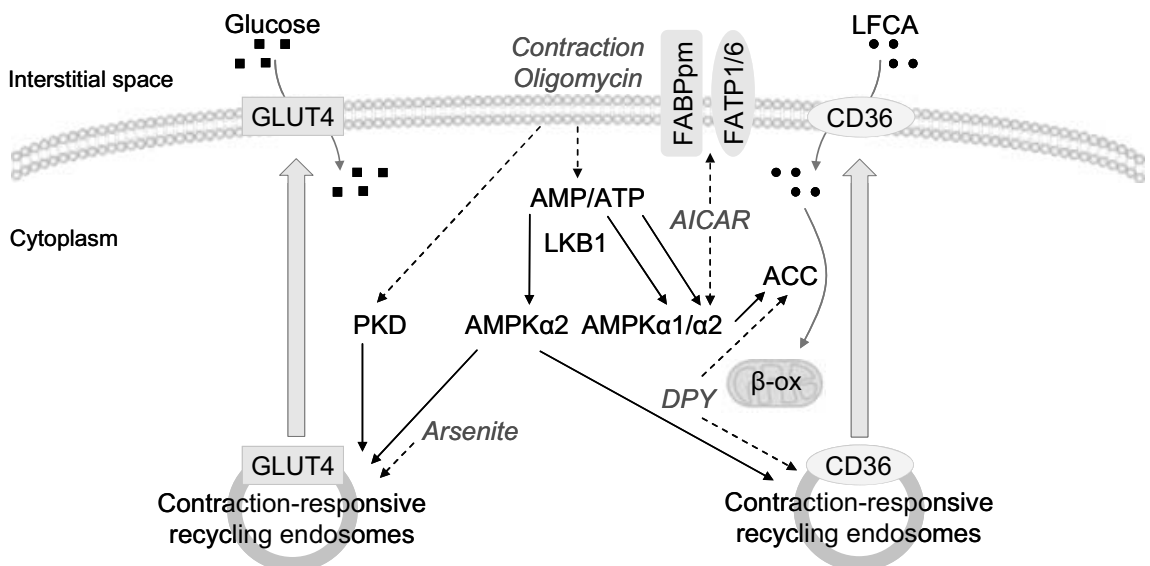

Fig. 7.1 Hypothetical scheme of the involvement of contraction signal transduction pathways in stimulation of cardiac substrate utilization

Under basal conditions, the majority of the glucose transporter 4 (GLUT4), fatty acid translocase/CD36 (CD36), and plasma membrane fatty acid-binding protein (FABPpm) are present in both intracellular storage compartments (recycling endosomes) and at the sarcolemma. For fatty acid transporter 1 and 6 (FATP1 and FATP6) the subcellular distribution is largely unknown. The onset of contraction results in elevation of the intracellular AMP/ATP ratio. Elevation of AMP stimulates LKB1-mediated activation of the AMP-activated protein kinase (AMPK) subunits $\alpha 1$ and $\alpha 2$. Activated AMPK $\alpha 1 / \alpha 2$ directly phosphorylates acetyl-CoA carboxylase (ACC), resulting in increased mitochondrial $\beta$-oxidation ( $\beta$-ox) of long-chain fatty acids (LCFA). AMPK $\alpha 2$, but not $\alpha 1$, is also involved in contraction-induced uptake of LCFA and glucose. Specifically, AMP-induced LKB1-mediated activation of AMPKo2 results in vesicle-mediated translocation of CD36 and GLUT4 from the recycling endosomes to the sarcolemma. As during contractions, oligomycin (Oli) results in elevation of AMP and subsequent AMPK $\alpha 1 / \alpha 2$ activation, and finally stimulates LCFA and glucose uptake by CD36 and GLUT4 translocation from contraction-responsive recycling endosomes, respectively, as well as stimulation of $\beta$-ox. Independent of AMPK, activation of protein kinase D (PKD) by contraction and oligomycin results in GLUT4mediated glucose uptake. Treatment of cardiomyocytes with 5-aminoimidazole-4-carboxamide ribonucleoside (AICAR) results in activation of AMPK $\alpha 2$, whereafter LCFA and glucose uptake are stimulated, as well as stimulation of LCFA $\beta$-ox. AICAR stimulates GLUT4-mediated glucose uptake although the regulation for the stimulated LCFA uptake is independent of CD36 and is possibly regulated via other LCFA transporters, i.e., FABPpm and/or FATP1/6. Treatment of cardiomyocytes with dipyridamole (DPY) results in activation of ACC, and finally in increased $\beta$-ox. Dipyridamole stimulates LCFA uptake by an unknown protein kinase downstream of AMPK $\alpha 2$ at the signaling branch specifically leading to CD36 translocation from contraction-responsive recycling endosomes. On the other hand, arsenite treatment selectively elevates GLUT4-mediated glucose uptake, but not LCFA uptake. 


\section{AMPK and upstream kinases; LBK1 and CaMKK}

The critical role of AMPK as an energy sensor in the heart and other tissues has been extensively reviewed [87]. The AMPK signaling cascade has been highly conserved through evolution, to turn off ATP-consuming processes whilst activating ATP-generating pathways. Although activation of AMPK by the binding of AMP to its regulatory $\gamma$ subunit represents the classical mode of regulation, it is becoming clear that also several potential upstream kinases of AMPK are involved. The first identified upstream kinase was the tumor suppressor LKB1. AMP binding to AMPK promotes phosphorylation by LKB1 [65] as LKB1 activity is not increased during contraction [71]. Furthermore, evidence is provided that CaMKK$\alpha$ and $-\beta$, especially the latter, also activates AMPK [88]. Thus, calcium signaling may also have a role in activating AMPK in muscle during contractions. A last potential upstream kinase is transforming growth factor- $\beta$-activated kinase-1 (Tak1), which activates the SNF1 complex (the yeast orthologue of AMPK) when expressed in $S$. cerevisiae, and also activates AMPK in cell free assays [89]. The physiologically relevance of this kinase remains unclear at present.

Previously, the importance of AMPK activity and upstream kinases in the maintenance of energy levels in skeletal muscle was explored in different AMPK transgenic and knockout mouse models. In skeletal muscle of these mice 5aminoimidazole-4-carboxamide ribonucleoside (AICAR)-induced increase in glucose uptake was completely blocked, however, stimulated glucose uptake by contraction was not affected $[90,91]$ or partly reduced [92] in these mice. Whether CaMKK regulates contraction-stimulated glucose uptake in muscle via AMPK activation mains controversial [69, 93]. In LKB1 null mice, contraction and AICAR-stimulated glucose uptake by muscle were reduced [72], as was LCFA oxidation [94]. Hence, these conflicting results cast doubt on the role of AMPK and upstream kinases in contraction-induced glucose uptake in skeletal muscle. In chapter 4 it has been shown that AMPK is a regulatory kinase for cardiac substrate uptake. Chapter 4 describes a study with different genetically manipulated mouse models to investigate the regulatory role of AMPK in cardiac energy metabolism stimulated by contraction-mimetic agents (see chapter 2). In the heart of AMPK kinase-dead, AMPK $\alpha 2$ knockout, and LKB1 knockout mice, in which AMPKa1 activity was still present or compensated, both the contraction-induced increase in LCFA and glucose uptake were completely blocked. This indicates that AMPK has a more important role in the regulation of substrate uptake in the heart than in skeletal muscle. Since cardiac LCFA oxidation was only partly reduced it appears that the regulation of LCFA uptake and oxidation are not entirely similar. The results from this study suggest that AMPK $\alpha 1$ and AMPK $\alpha 2$ activity is involved in the upregulation of LCFA oxidation while a change in LCFA uptake is only 
regulated by AMPK $\alpha 2$ activity (Fig. 7.1). Whether CaMKKs are responsible for the residual, LKB1-independent activity of AMPK $\alpha 1$ is not completely resolved.

\section{Downstream targets of AMPK; AS160 and PKC AS160}

An interesting novel target of AMPK is the rab GTPase-activating protein AS160, which is involved in contraction-stimulated glucose uptake in skeletal muscle [95]. Phosphorylated AS160 inhibits its ability to activate GTPase and therefore results in GTP loading of its cognate Rab protein. GTP-loaded Rab may subsequently allow GLUT4 storage vesicles to dock and fuse with the plasma membrane [96]. Recently it has been shown that insulin-stimulated glucose uptake requires the phosphorylation of AS160 in cardiomyocytes [97] as has previously been shown in skeletal muscle [98]. Moreover, insulin-induced AS160 phosphorylation is additive to contraction-induced AS160 phosphorylation. These observations indicate that insulin signaling and contraction pathways meet at the level of AS160. The role of AS160 in contraction-induced CD36 translocation has not been investigated yet.

\section{PKC}

Another kinase that is activated by both insulin and contraction is PKC- $\zeta$. It is firmly established that, at least in skeletal muscle, phosphatidylinositol-3-kinasemediated PKC- $\zeta$ activation is necessary for insulin-induced GLUT4 translocation [99-101]. Subsequently, we have shown that PKC- $\zeta$ is also important in insulininduced glucose uptake (Fig. 7.2A) and LCFA uptake in the heart (Fig. 7.2B). Moreover, in the heart $\mathrm{PKC}-\zeta$ is already fully active under basal conditions and not further stimulated by insulin (Fig. 7.2C), indicating that its role in insulinstimulated uptake of both LCFA and glucose is permissive rather than regulatory (Luiken et al. submitted). With respect to the role of $\mathrm{PKC}-\zeta$ in contraction-induced AMPK-mediated substrate uptake the stimulatory effect of the AMPK activating agent AICAR on GLUT4 translocation and glucose uptake were blocked by pretreatment of muscle cells with myristoylated $\mathrm{PKC}-\zeta$ pseudosubstrate [99]. The role of PKC- $\zeta$ in insulin-induced substrate uptake converges with that in contractioninduced substrate uptake, namely treadmill exercise activates $\mathrm{PKC}-\zeta$ in skeletal muscle, and insulin even increases this effect [99]. It remains to be established whether PKC is involved in contraction-induced CD36 translocation in muscle tissues. 

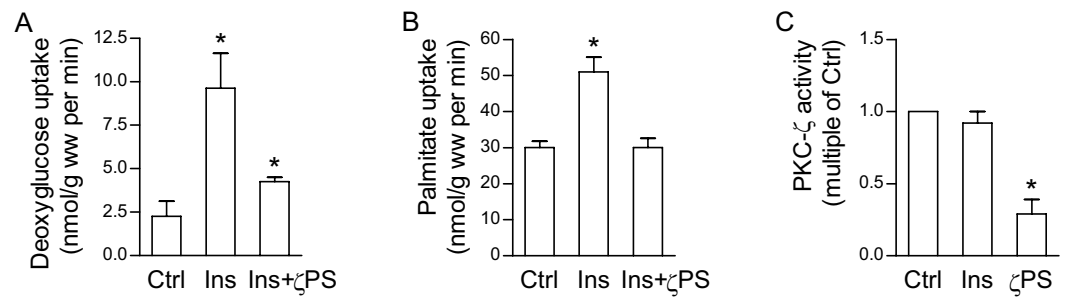

Fig. 7.2 Influence of a PKC- $\zeta$ inhibitors on insulin-induced deoxyglucose and palmitate uptake, and $\mathrm{PKC}-\zeta$ activity in rat cardiomyocytes

Isolated rat cardiomyocytes were pre-incubated for $60 \mathrm{~min}$ at $37^{\circ} \mathrm{C}$ without additions $(\mathrm{Ctrl})$ or with 50 $\mu \mathrm{mol} / 1$ myristoylated PKC- $\zeta$ pseudosubstrate ( $\zeta \mathrm{PS})$. Thereafter, cardiomyocytes were treated without or with $100 \mathrm{nmol} / \mathrm{l}$ insulin (Ins) for $15 \mathrm{~min}$ at $37^{\circ} \mathrm{C}$. Finally, initial uptake rates of ${ }^{3} \mathrm{H}$-deoxyglucose (panel A) and ${ }^{14} \mathrm{C}$-palmitate (panel B) were measured. For the assessment of PKC- $\zeta$ activity, pre-incubated cardiomyocytes, as described above, were lysed and used for immunoprecipitations, whereafter PKC- $\zeta$ activity was measured by incorporation of $\left[\gamma-{ }^{32} \mathrm{P}\right]$-ATP into a PKC-target peptide (panel C). Data are means \pm S.E.M. for 4-5 experiments carried out with different cardiomyocyte preparations.

*Significantly different from $\mathrm{Ctrl}(\mathrm{P}<0.05)$. Submitted by Luiken et al.

\section{AMPK independent signaling; PKD}

Independent of AMPK, we recently showed that another pathway is involved in cardiac substrate metabolism, i.e., contraction-activated protein kinase D (PKD) [70]. A pharmacological blockade of PKD is associated with inhibition of contraction-stimulated GLUT4 translocation and glucose uptake (Fig. 7.3A), suggesting that PKD could also be involved in stimulation of cardiac substrate uptake upon an increase in contractile activity. This finding is only based on a pharmacological approach by using rather non-specific PKC/PKD inhibitors. We will investigate PKD knockout mice from Fielitz et al. [102] to verify these pharmacological findings, namely that the use of isolated cardiomyocytes from these mice could provide direct evidence for the regulatory role of PKD in cardiac substrate uptake. Because contraction activates both AMPK and PKD simultaneously, we have investigated isolated cardiomyocytes from AMPK 22 knockout mice whether or not these enzymes operate within the same signal cascade (Fig. 7.3B) [70]. Since both AMPK ablation and blockade of PKD inhibits contraction-induced glucose uptake, this indicates that contraction-induced GLUT4 translocation would require the input of two parallel pathways, i.e., AMPK signaling and PKD signaling, either of which is necessary to move GLUT4 to the sarcolemma in the contracting heart. This dual signaling input is not a novel concept in the regulation of cellular glucose uptake, because also insulin-induced GLUT4 translocation has been established to depend on simultaneous and parallel 
activation of phosphatidylinositol-3-kinase, and of subsequent protein kinase B/Akt signaling axis, and a pathway beginning with the phosphorylation of the adaptor protein $\mathrm{Cbl}$ by the insulin receptor and resulting in activation of a small GTPbinding protein TC10 (as described in chapter 1; insulin signaling pathway) [103]. It is currently unknown, whether PKD is also involved in contraction-induced CD36 translocation and subsequent LCFA uptake. Furthermore, upstream and downstream components in PKD signaling involved in contraction-induced transporter translocation have not yet been identified. One possibility to explain contraction-induced PKD activation could be via reactive oxygen species (ROS). ROS is a by-product of oxidative phosphorylation, and ROS levels increase upon increased contractile activity. Moreover, radical-induced ROS production has been shown to increase glucose uptake in muscle [77-79]. A likely downstream kinase of PKD in the regulation of cardiac energy metabolism is phosphatidylinositol-4kinase since it is a physiological substrate of PKD and it is present in GLUT4containing vesicles $[104,105]$ in which it regulates vesicle transport [106].
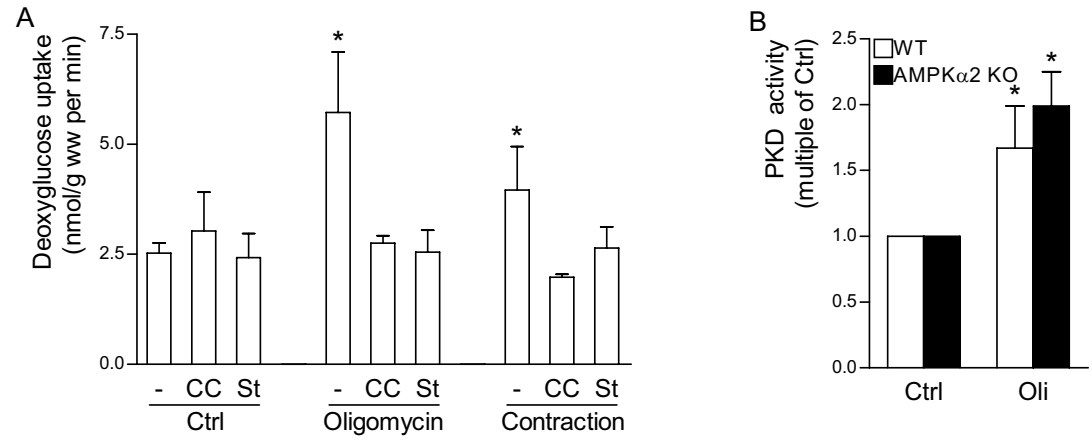

Fig. 7.3 Effect of PKC/PKD inhibitors on oligomycin/contraction-stimulated deoxyglucose uptake, and the effect of oligomycin on PKD activity in cardiomyocytes

Isolated rat cardiomyocytes were pre-incubated for $15 \mathrm{~min}$ at $37^{\circ} \mathrm{C}$ without additions (-) or with protein kinase C/D (PKC/PKD) inhibitors, i.e., $2 \mu \mathrm{mol} / 1$ calphostin-C (CC) or $1 \mu \mathrm{mol} / 1$ staurosporine (St). Thereafter, cardiomyocytes were incubated in the absence (Ctrl) or presence of $1 \mu \mathrm{mol} / \mathrm{l}$ oligomycin stimulation or electrical stimulation at $200 \mathrm{~V} / 4 \mathrm{~Hz}$ (Contraction) for $15 \mathrm{~min}$ at $37^{\circ} \mathrm{C}$. Finally, initial rates of ${ }^{3} \mathrm{H}$-deoxyglucose were measured (panel A). Isolated cardiomyocytes from WT ( $\square$ ) and AMPactivated protein kinase 22 (AMPKa2) KO mice $(-)$ were treated for 20 min at $37^{\circ} \mathrm{C}$ without $(\mathrm{Ctrl})$ or with $1 \mu \mathrm{mol} / 1$ oligomycin (Oli). Upon PKD immunoprecipitations of lysed cardiomyocytes, PKD activity was measured by incorporation of $\left[\gamma_{-}{ }^{32} \mathrm{P}\right]$-ATP into syntide-2 (panel B). PKD activity in nonstimulated cardiomyocytes from AMPK $\alpha 2 \mathrm{KO}$ mice was not significantly different from that in nonstimulated cardiomyocytes in WT mice. Data are means \pm S.E.M. (panel A) or expressed relative to Ctrl \pm S.E.M. (panel B) for 4-5 experiments carried out with different cardiomyocyte preparations.

*Significantly different from $\mathrm{Ctrl}(\mathrm{P}<0.05)$. Taken from [70]. 


\section{Merging of signaling pathways}

Taken together, the proteins involved in the insulin-induced transporter translocation machinery and in the contraction-induced transporter translocation machinery can be divided into two classes: (i) proteins that are specific to either machinery so as to ensure that insulin-responsive compartments are activated to mobilize transporter-containing vesicles in response to insulin (e.g., protein kinase $\mathrm{B} / \mathrm{Akt}$ ) and contraction-responsive compartments in response to contraction (e.g., AMPK and/or PKD), and (ii) proteins that are common to both machineries, likely because of their general involvement in vesicle budding and translocation. In this respect, inhibition of AS160 appears necessary for activation of GLUT4 vesicles to translocate to the plasma membrane, and the function of $\mathrm{PKC}-\zeta$ appears to be remodeling of the actin cytoskeleton, which is the transport route for the GLUT4containing vesicles. Both, the activation of GLUT4 vesicles and their transport along the actin cytoskeleton are general preconditions to increase sarcolemmal GLUT4 and glucose uptake in response to insulin or increased workload. Therefore, both signaling pathways might converge at the level of GLUT4 translocation and interact with the same regulatory elements. Future studies should investigate whether this trafficking machinery is also involved in CD36 translocation.

\section{AMPK in diabetic cardiomyopathy}

Because the AMPK system is a major regulator of energy balance at both cellular and whole body level, its role in metabolic disorders needs to be considered. The role of AMPK in the etiology of these diseases is currently unclear. Interestingly, it has recently been reported that the activation of AMPK during exercise is reduced in obese and type 2 diabetic humans [107]. In contrast, the role of AMPK activation in the treatment of metabolic disorders is well established. Drugs that activate AMPK (metformin and thiazolidinediones) are now commonly used for the treatment of type 2 diabetes [108, 109]. These drugs improve the glucose disposal rate which is the main defect in type 2 diabetes. Also LCFA metabolism is altered in type 2 diabetes and there is a tight association between excessive LCFA uptake and the development of cardiomyopathy [110]. A possible mechanism is that triacylglycerol (TAG) accumulation as occurs in the diabetic heart interferes with the insulin signaling pathway, finally leading to the inhibition of GLUT4 translocation. This suggests that inhibition of TAG storage could restore the insulininduced GLUT4-mediated glucose uptake. Therefore, the stimulatory effect on LCFA utilization by AMPK activation could be effective in the treatment of cardiomyopathy.

Recent studies support that AMPK activation can restore glucose uptake in insulin resistance $[54,111,112]$. A possible explanation is that lipid storage is decreased 
by elevating AMPK-mediated LCFA oxidation. This then shuttles LCFA away from the TAG pool towards LCFA oxidation and prevents the formation of toxic LCFA metabolites which are in dynamic equilibrium with this TAG pool. This approach, however, has some disadvantage because LCFA present a less efficient substrate for ATP production as they require more oxygen for their oxidation compared to glucose. Moreover, AMPK not only enhances LCFA oxidation but also appears to act on LCFA uptake. Because in the diabetic heart LCFA uptake rates exceed LCFA oxidation rates [2, 113], AMPK activation may exert less therapeutic benefits. Moreover, because in diabetes and obesity the circulating serum lipid levels are increased, this could further worsen lipid accumulation. Remarkably, in chapter 4 distinctive roles of the AMPK $\alpha 1$ and AMPK $\alpha 2$ subunits in LCFA uptake and oxidation have been described. AMPK $\alpha 2$ has been suggested to be involved in LCFA uptake and oxidation while AMPK $\alpha 1$ seems only involved in LCFA oxidation (Fig. 7.1). Therefore, identifying targets that lead to activation of AMPK $\alpha 1$ but not of AMPK $\alpha 2$ could be of therapeutical interest. Different physiological, pathophysiological and pharmacological activators of AMPK are known although till now no specific target for one of the two AMPK isoforms has been identified. Recently a new compound, A-769662 has been shown to activate both AMPK $\alpha 1$ and $\alpha 2[114,115]$. Furthermore, A-769662 was found to elicit an increase on whole-body fatty acid oxidation, and simultaneously a decrease in the plasma TAG concentration [116], suggesting that this compound, and possibly also other AMPK activators, may be useful for the treatment of diabetes. However, the therapeutic value of A-769662 to restore cardiac LCFA utilization in metabolic diseases is expected to be limited since it activates both $\alpha$-subunits of AMPK.

\section{CD36 in diabetic cardiomyopathy}

In case of diabetes the heart suffers from impaired glucose uptake and relies almost completely on LCFA [113, 117, 118]. CD36 is the main LCFA transporter responsible for LCFA influx, and in different animal models, the involvement of CD36 in cardiomyopathy has been described. Therefore, different strategies are discussed to normalize increased CD36-mediated LCFA uptake.

Sarcolemmal abundance of CD36 has been found to be involved in the changes of cardiac metabolism in the diabetic heart, as observed in obese Zucker rats [119]. A different rat model for obesity and insulin resistance that is more comparable with the human life-style is high-fat diet-fed rats. In a study with rats fed a high-fat diet we have shown that elevated LCFA uptake was CD36 dependent because: (i) the content of CD36 at the sarcolemma was increased already under basal conditions (Fig. 7.4A), and (ii) in the presence of sulfo- $N$-succinimidyl oleate (SSO), a specific inhibitor of CD36 (see chapter 3), LCFA uptake was reduced to a similar rate as observed in cardiomyocytes from rats fed a low-fat diet (Fig. 7.4E) [85]. 
Furthermore, these rats developed cardiac contractile dysfunction associated with increased abundance of CD36 at the sarcolemma. Thus, the permanent presence of CD36 at the sarcolemma resulted in enhanced rates of LCFA uptake and myocardial TAG accumulation, and this contributes to the development of diabetic cardiomyopathy. This suggests that CD36 is involved in the development of cardiomyopathy and that novel therapeutic strategies aimed at reducing CD36mediated LCFA uptake show promise for the prevention or treatment of cardiac dysfunction related to metabolic diseases such as obesity and diabetes.
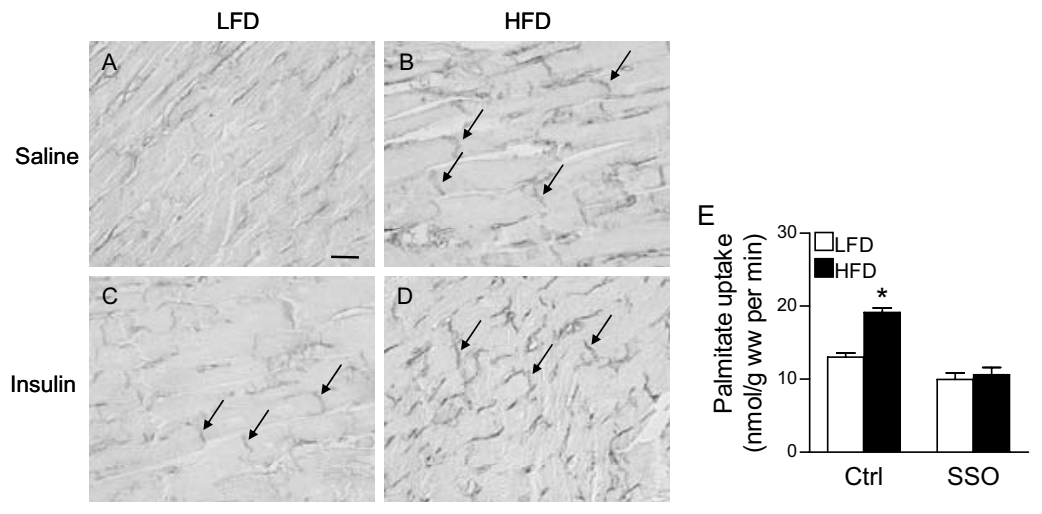

Fig. 7.4 Subcellular localization of fatty acid translocase/CD36, and palmitate uptake in cardiomyocytes from LFD-fed rats and HFD-fed rats

Immunohistochemical staining for fatty acid translocase/CD36 localization of left ventricle tissue sections from rats fed a low-fat diet (LFD; panel A an C) or high-fat diet (HFD; panel B and D) for 8 weeks. Rats received an intraperitoneal injection of saline (panel A and B) or insulin (panel C and D) $30 \mathrm{~min}$ before sacrifice. Photographs are representative of two independent experiments performed on three rats per experimental group. Arrows indicate intercalated discs. Scale bar indicates $25 \mu \mathrm{m}$. Isolated cardiomyocytes from LFD-fed ( $\square$ ) and HFD-fed ( $\square$ ) rats were pre-incubated for $30 \mathrm{~min}$ at room temperature without (Ctrl) or with $0.4 \mathrm{mmol} / \mathrm{l}$ sulfo- $N$-succinimidyl oleate (SSO), thereafter $14 \mathrm{C}$ palmitate uptake rates were measured (panel E). Data are means \pm S.E.M. for 8 experiments carried out with different cardiomyocyte preparations. *Significantly different from $\mathrm{Ctrl}(\mathrm{P}<0.05)$. Taken from [85].

In hearts from diabetic mice, the elevated LCFA influx is also accompanied by a relocation of CD36 to the sarcolemma [120]. Also in skeletal muscle biopsies from obese and type-2 diabetic subjects CD36 was found to be relocated to the sarcolemma [121]. All these studies show that the increase in the CD36 functional pool is not due to increased total expression, but rather to a permanent relocation of CD36 to the sarcolemma. This then suggests that not only CD36 but also the 
machinery regulating its translocation most likely is a common critical factor in the etiology of diabetic cardiomyopathy, and therefore not only CD36 but also its trafficking machinery are important targets in restoring substrate balance. Future investigations aimed at disclosing the mechanism underlying the permanent relocation of CD36 to the sarcolemma could reveal novel therapeutic targets in this trafficking machinery.

Proof-of-principle studies have started in which CD36 ablation reverses myocardial lipid accumulation and thereby improves cardiac function. In hearts from CD36 knockout mice [122] and in hearts from aged CD36-deficient mice [123] changes in LCFA metabolism, i.e., decrease in TAG storage, have been shown to restore cardiac performance. Therefore, a possible mechanism to rescue cardiac dysfunction observed in cardiomyopathy is inhibition of CD36. CD36-mediated cellular LCFA influx can be specifically inhibited with sulfo- $N$-succinimidyl esters of LCFA, e.g., SSO, which covalently binds to CD36 (see chapter 3). Although for in vivo administration SSO is not yet appropriate. The most important reason for this is that it does not only inhibit CD36 in the heart but also in other cell types, where CD36 performs a function unrelated to LCFA uptake (e.g., uptake of oxidized low-density lipoproteins in macrophages and trombospondin binding in platelets) [124]. Therefore, a cardiospecific strategy to inhibit CD36 could be a more effective approach. Studies in cells from various mammalian tissues yielded differential expression of proteins involved in trafficking, i.e., Rab and soluble $N$ ethylmaleimide-sensitive factor attachment protein receptor (SNARE), among the cell types studied, indicating tissue-specificity of the subcellular trafficking machinery $[125,126]$. Accordingly, a therapy aimed at the CD36-associated trafficking proteins in cardiomyocytes is expected to be cardiospecific and could be a more valuable therapeutic approach to inhibit CD36. We recently started to investigate the role of proteins involved in the trafficking machinery in the regulation of cardiac LCFA uptake (see chapter 6), and in the near future other SNARE proteins [like vesicle-associated membrane proteins (VAMPs)] are interesting to investigate in regard to CD36 internalization and externalization.

\section{Future perspectives}

The majority of cardiac LCFA uptake is CD36-dependent. However, the potential importance of other cardiac LCFA transporters has not been excluded (see chapter 5). CD36 could function in series or in parallel with the other proteins implicated in the LCFA transport process, especially since CD36 colocalizes with plasma membrane fatty acid-binding protein (FABPpm) [127], fatty acid-transport protein (FATP)1 [128] and FATP6 [129] at the sarcolemma. Future gain-of function and loss-of function studies aimed at each of the other cellular transport proteins alone and in combination with CD36 deficiency or overexpression will be helpful to 
further define the physiological roles and relevant interactions among the LCFA transporters. CD36 not only colocalizes with other LCFA transporters but also with caveolin-3, the major component of caveolae in muscle [130]. Caveolae are invaginations of the sarcolemma consisting of caveolin, cholesterol, and glycosphingolipids, and are enriched membrane receptors and signaling molecules [131]. It has been observed that caveolae are involved in the CD36-mediated LCFA uptake process in adipocytes $[132,133]$. These findings have not yet been extended to muscle tissue. Together, these findings suggest that the translocation of LCFA transporters to the sarcolemma is not the only regulatory step in LCFA uptake and that possibly also their interaction with other LCFA transporters and their targeting to caveolae could provide additional levels of regulation for LCFA transport. The molecular mechanism involved in the lateral movement of CD36 in and out of caveolae is not completely known. It appears that a dual palmitoylation of proteins is a targeting signal to caveolae [134]. CD36 contains at least four palmitoylation sites, two near the C-terminus and two close to the $\mathrm{N}$-terminus [135]. It is interesting for future studies to investigate whether palmitoylation sites are involved in the movement of CD36 in and out of caveolae and whether this subsequently influences LCFA uptake.

Another interesting finding in regard to the homeostasis of cardiac energy metabolism is that LCFA and glucose uptake can be selectively increased. These changes in substrate uptake are paralleled by concomitant changes in sarcolemmal abundance of substrate transporters. While insulin and contraction lead to the simultaneous recruitment of CD36 and GLUT4, treatment of cardiomyocytes with
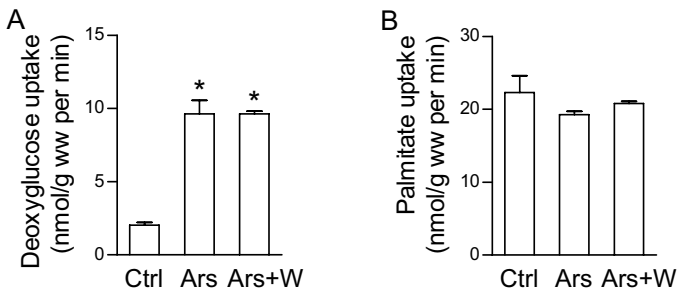

Fig. 7.5 Effect of arsenite on deoxyglucose and palmitate uptake into cardiomyocytes

Isolated rat cardiomyocytes were pre-incubated for $20 \mathrm{~min}$ at $37^{\circ} \mathrm{C}$ without additions (Ctrl) or with 200 $\mathrm{nmol} / 1$ wortmannin $(\mathrm{W})$, which inhibits phosphatidylinositol-3-kinase of the insulin signaling cascade. Thereafter, cardiomyocytes were treated for $20 \mathrm{~min}$ at $37^{\circ} \mathrm{C}$ without or with $100 \mu \mathrm{mol} / 1$ arsenite (Ars). Finally, initial uptake rates of ${ }^{3} \mathrm{H}$-deoxyglucose (panel A) and ${ }^{14} \mathrm{C}$-palmitate (panel B) were measured. Data are means \pm S.E.M. for 4-6 experiments carried out with different cardiomyocyte preparations.

*Significantly different from Ctrl $(\mathrm{P}<0.05)$. Taken from [136]. 
dipyridamole (see chapter 3) and arsenite (see Fig. 7.5) [136] specifically recruit one of these transporters leading to selectively increased LCFA and glucose uptake, respectively. The stimulatory action of dipyridamole activation is due to a yet unidentified protein kinase but it has been established to be situated in the contraction signaling cascade downstream of AMPK beyond the signaling branch between separate CD36 and GLUT4 translocation, specifically leading to CD36 translocation. The molecular mechanism behind the selective action on GLUT4 translocation by arsenite appears unrelated to its insulin signaling action (Fig. 7.5A), and might occur via a specific protein target of arsenite within insulinresponsive GLUT4-containing stores. In general, the possibility to translocate selectively either one transporter suggests that CD36 and GLUT4 are recruited by distinct signaling and/or trafficking mechanisms. These targets could be of interest in metabolic diseases in which a shift in substrate balance in the use of either glucose or LCFA elicits cardiac malfunctioning. Further unraveling downstream targets either involved in CD36 or GLUT4 trafficking are of interest for novel therapies in metabolic diseases. 


\section{References}

1 Belke DD, Larsen TS, Lopaschuk GD and Severson DL 1999 Glucose and fatty acid metabolism in the isolated working mouse heart. Am J Physiol 277: R1210-1217

2 Stanley WC, Recchia FA and Lopaschuk GD 2005 Myocardial substrate metabolism in the normal and failing heart. Physiol Rev 85: 1093-1129

3 Barr RL and Lopaschuk GD 2000 Methodology for measuring in vitro/ex vivo cardiac energy metabolism. J Pharmacol Toxicol Methods 43: 141-152

4 Luiken JJ, van Nieuwenhoven FA, America G, van der Vusse GJ and Glatz JF 1997 Uptake and metabolism of palmitate by isolated cardiac myocytes from adult rats: involvement of sarcolemmal proteins. J Lipid Res 38: 745-758

$5 \quad$ Neely JR and Morgan HE 1974 Relation between carbohydrate and lipid metabolism and the energy balance of the heart muscle. Annu Rev Biochem 36: 413-459

6 Luiken JJ, Coort SL, Koonen DP, Bonen A and Glatz JF 2004 Signalling components involved in contraction-inducible substrate uptake into cardiac myocytes. Proc Nutr Soc 63: 251-258

7 Luiken JJ, Willems J, van der Vusse GJ and Glatz JF 2001 Electrostimulation enhances FAT/CD36mediated long-chain fatty acid uptake by isolated rat cardiac myocytes. Am J Physiol Endocrinol Metab 281: E704-712

8 Awan MM and Saggerson ED 1993 Malonyl-CoA metabolism in cardiac myocytes and its relevance to the control of fatty acid oxidation. Biochem J 295: 61-66

9 Saddik M, Gamble J, Witters LA and Lopaschuk GD 1993 Acetyl-CoA carboxylase regulation of fatty acid oxidation in the heart. $J$ Biol Chem 268: 25836-25845

10 King KL, Okere IC, Sharma N, Dyck JR, Reszko AE, McElfresh TA, Kerner J, Chandler MP, Lopaschuk GD and Stanley WC 2005 Regulation of cardiac malonyl-CoA content and fatty acid oxidation during increased cardiac power. Am J Physiol Heart Circ Physiol 289: H1033-1037

11 Zhou L, Cabrera ME, Huang H, Yuan CL, Monika DK, Sharma N, Bian F and Stanley WC 2007 Parallel activation of mitochondrial oxidative metabolism with increased cardiac energy expenditure is not dependent on fatty acid oxidation in pigs. J Physiol 579: 811-821

12 Goodwin GW and Taegtmeyer H 2000 Improved energy homeostasis of the heart in the metabolic state of exercise. Am J Physiol Heart Circ Physiol 279: H1490-1501

13 Colston VL and Wheeler TJ 2001 Stimulation of cardiac glucose transport by inhibitors of oxidative phosphorylation. Life Sci 69: 2383-2398

14 Luiken JJ, Coort SL, Willems J, Coumans WA, Bonen A, van der Vusse GJ and Glatz JF 2003 Contraction-induced fatty acid translocase/CD36 translocation in rat cardiac myocytes is mediated through AMP-activated protein kinase signaling. Diabetes 52: 1627-1634

15 Wheeler TJ, Fell RD and Hauck MA 1994 Translocation of two glucose transporters in heart: effects of rotenone, uncouplers, workload, palmitate, insulin and anoxia. Biochim Biophys Acta 1196: 191-200

16 Luiken JJ, Coort SL, Koonen DP, van der Horst DJ, Bonen A, Zorzano A and Glatz JF 2004 Regulation of cardiac long-chain fatty acid and glucose uptake by translocation of substrate transporters. Pflugers Arch 448: 1-15

17 Marsin AS, Bertrand L, Rider MH, Deprez J, Beauloye C, Vincent MF, Van den Berghe G, Carling D and Hue L 2000 Phosphorylation and activation of heart PFK-2 by AMPK has a role in the stimulation of glycolysis during ischaemia. Curr Biol 10: 1247-1255

18 Hawley SA, Gadalla AE, Olsen GS and Hardie DG 2002 The antidiabetic drug metformin activates the AMP-activated protein kinase cascade via an adenine nucleotide-independent mechanism. Diabetes 51: 2420-2425

19 Smith RM, Peterson WH and McCoy E 1954 Oligomycin, a new antifungal antibiotic. Antibiotics and Chemotherapy 4: 962-970

20 Masamune S, Sehgal JM, Van Tamelen EE, Strong FM and Peterson WH 1958 Seperation and preliminary characterization of oligomycins A, B, and C. J Am Chem Soc 80

21 Lardy HA, Witonsky P and Johnson D 1965 Antibiotics as Tools for Metabolic Studies. Iv. Comparative Effectiveness of Oligomycins a, B, C, and Rutamycin as Inhibitors of Phosphoryl Transfer Reactions in Mitochondria. Biochemistry 4: 552-554 
22 Chappell JB and Greville GD 1961 Effects of oligomycin on respiration and swelling of isolated liver mitochondria. Nature 190: 502-504

23 Lardy HA, Johnson D and Mc MW 1958 Antibiotics as tools for metabolic studies. I. A survey of toxic antibiotics in respiratory, phosphorylative and glycolytic systems. Arch Biochem Biophys 78: 587-597

24 Gaballo A, Zanotti F and Papa S 2002 Structures and interactions of proteins involved in the coupling function of the protonmotive F(o)F(1)-ATP synthase. Curr Protein Pept Sci 3: 451-460

25 Walker JE and Dickson VK 2006 The peripheral stalk of the mitochondrial ATP synthase. Biochim Biophys Acta 1757: 286-296

26 Kim SB and Berdanier CD 1999 Oligomycin sensitivity of mitochondrial F(1)F(0)-ATPase in diabetesprone BHE/Cdb rats. Am J Physiol 277: E702-707

27 Penefsky HS 1985 Mechanism of inhibition of mitochondrial adenosine triphosphatase by dicyclohexylcarbodiimide and oligomycin: relationship to ATP synthesis. Proc Natl Acad Sci U S A 82: 1589-1593

28 Nadanaciva S, Bernal A, Aggeler R, Capaldi R and Will Y 2007 Target identification of drug induced mitochondrial toxicity using immunocapture based OXPHOS activity assays. Toxicol In Vitro 21: $902-$ 911

29 Grover GJ, Atwal KS, Sleph PG, Wang FL, Monshizadegan H, Monticello T and Green DW 2004 Excessive ATP hydrolysis in ischemic myocardium by mitochondrial F1F0-ATPase: effect of selective pharmacological inhibition of mitochondrial ATPase hydrolase activity. Am J Physiol Heart Circ Physiol 287: H1747-1755

30 Ylitalo K, Ala-Rami A, Vuorinen K, Peuhkurinen K, Lepojarvi M, Kaukoranta P, Kiviluoma K and Hassinen I 2001 Reversible ischemic inhibition of $\mathrm{F}(1) \mathrm{F}(0)$-ATPase in rat and human myocardium. Biochim Biophys Acta 1504: 329-339

31 Cho JH, Balasubramanyam M, Chernaya G, Gardner JP, Aviv A, Reeves JP, Dargis PG and Christian EP 1997 Oligomycin inhibits store-operated channels by a mechanism independent of its effects on mitochondrial ATP. Biochem J 324: 971-980

32 Tatsumi T, Shiraishi J, Keira N, Akashi K, Mano A, Yamanaka S, Matoba S, Fushiki S, Fliss H and Nakagawa M 2003 Intracellular ATP is required for mitochondrial apoptotic pathways in isolated hypoxic rat cardiac myocytes. Cardiovasc Res 59: 428-440

33 Lim JH, Lee JI, Suh YH, Kim W, Song JH and Jung MH 2006 Mitochondrial dysfunction induces aberrant insulin signalling and glucose utilisation in murine C2C12 myotube cells. Diabetologia 49: 1924-1936

34 Barth E, Stammler G, Speiser B and Schaper J 1992 Ultrastructural quantitation of mitochondria and myofilaments in cardiac muscle from 10 different animal species including man. J Mol Cell Cardiol 24: 669-681

35 Hoppeler H, Lindstedt SL, Claassen H, Taylor CR, Mathieu O and Weibel ER 1984 Scaling mitochondrial volume in heart to body mass. Respir Physiol 55: 131-137

36 Oron U and Mandelberg M 1985 Comparative morphometry of the mitochondria and activity of some enzymes in the myocardium of small mammals. J Mol Cell Cardiol 17: 627-632

37 Pan DA and Hardie DG 2002 A homologue of AMP-activated protein kinase in Drosophila melanogaster is sensitive to AMP and is activated by ATP depletion. Biochem J 367: 179-186

38 van Oort MM, van Doorn JM, Bonen A, Glatz JF, van der Horst DJ, Rodenburg KW and Luiken JJ 2008 Insulin-induced translocation of CD36 to the plasma membrane is reversible and shows similarity to that of GLUT4. Biochim Biophys Acta 1781: 61-71

39 Saddik M and Lopaschuk GD 1991 Myocardial triglyceride turnover and contribution to energy substrate utilization in isolated working rat hearts. J Biol Chem 266: 8162-8170

40 Beauloye C, Marsin AS, Bertrand L, Vanoverschelde JL, Rider MH and Hue L 2002 The stimulation of heart glycolysis by increased workload does not require AMP-activated protein kinase but a wortmannin-sensitive mechanism. FEBS Lett 531: 324-328

41 Marsin AS, Bouzin C, Bertrand L and Hue L 2002 The stimulation of glycolysis by hypoxia in activated monocytes is mediated by AMP-activated protein kinase and inducible 6-phosphofructo-2-kinase. $J$ Biol Chem 277: 30778-30783 
42 Kreisberg RA 1966 Effect of epinephrine on myocardial triglyceride and free fatty acid utilization. Am J Physiol 210: 385-389

43 Williamson JR 1964 Metabolic Effects of Epinephrine in the Isolated, Perfused Rat Heart. I. Dissociation of the Glycogenolytic from the Metabolic Stimulatory Effect. J Biol Chem 239: 2721-2729

44 Alousi AA and Mallow S 1964 Effects of Hyperthyroidism, Epinephrine, and Diet on Heart Lipoprotein Lipase Activity. Am J Physiol 206: 603-609

45 Gold M, Attar HJ, Spitzer JJ and Scott JC 1965 Effect of Norepinephrine on Myocardial Free Fatty Acid Uptake and Oxidation. Proc Soc Exp Biol Med 118: 876-879

46 Collins-Nakai RL, Noseworthy D and Lopaschuk GD 1994 Epinephrine increases ATP production in hearts by preferentially increasing glucose metabolism. Am J Physiol 267: H1862-1871

47 Zhou L, Huang H, Yuan CL, Keung W, Lopaschuk GD and Stanley WC 2008 Metabolic response to an acute jump in cardiac workload: effects on malonyl-CoA, mechanical efficiency, and fatty acid oxidation. Am J Physiol Heart Circ Physiol 294: H954-960

48 Gertz EW, Wisneski JA, Stanley WC and Neese RA 1988 Myocardial substrate utilization during exercise in humans. Dual carbon-labeled carbohydrate isotope experiments. J Clin Invest 82: 2017-2025

49 Johnson RH, Walton JL, Krebs HA and Williamson DH 1969 Metabolic fuels during and after severe exercise in athletes and non-athletes. Lancet 2: 452-455

50 Kolter T, Uphues I, Wichelhaus A, Reinauer H and Eckel J 1992 Contraction-induced translocation of the glucose transporter Glut4 in isolated ventricular cardiomyocytes. Biochem Biophys Res Commun 189: $1207-1214$

51 Zaninetti D, Greco-Perotto R and Jeanrenaud B 1988 Heart glucose transport and transporters in rat heart: regulation by insulin, workload and glucose. Diabetologia 31: 108-113

52 Yang J and Holman GD 2005 Insulin and contraction stimulate exocytosis, but increased AMP-activated protein kinase activity resulting from oxidative metabolism stress slows endocytosis of GLUT4 in cardiomyocytes. J Biol Chem 280: 4070-4078

53 Bergemann C, Loken C, Becker C, Graf B, Hamidizadeh M and Fischer Y 2001 Inhibition of glucose transport by cyclic GMP in cardiomyocytes. Life Sci 69: 1391-1406

54 Bertrand L, Ginion A, Beauloye C, Hebert AD, Guigas B, Hue L and Vanoverschelde JL 2006 AMPK activation restores the stimulation of glucose uptake in an in vitro model of insulin-resistant cardiomyocytes via the activation of protein kinase B. Am J Physiol Heart Circ Physiol 291: H239-250

55 Habets DD, Coumans WA, Voshol PJ, den Boer MA, Febbraio M, Bonen A, Glatz JF and Luiken JJ 2007 AMPK-mediated increase in myocardial long-chain fatty acid uptake critically depends on sarcolemmal CD36. Biochem Biophys Res Commun 355: 204-210

56 Bonen A, Han XX, Habets DD, Febbraio M, Glatz JF and Luiken JJ 2007 A null mutation in skeletal muscle FAT/CD36 reveals its essential role in insulin- and AICAR-stimulated fatty acid metabolism. Am J Physiol Endocrinol Metab 292: E1740-1749

57 Stapleton D, Mitchelhill KI, Gao G, Widmer J, Michell BJ, Teh T, House CM, Fernandez CS, Cox T, Witters LA and Kemp BE 1996 Mammalian AMP-activated protein kinase subfamily. J Biol Chem 271: 611-614

58 Dyck JR, Kudo N, Barr AJ, Davies SP, Hardie DG and Lopaschuk GD 1999 Phosphorylation control of cardiac acetyl-CoA carboxylase by cAMP-dependent protein kinase and 5'-AMP activated protein kinase. Eur J Biochem 262: 184-190

59 Abu-Elheiga L, Matzuk MM, Abo-Hashema KA and Wakil SJ 2001 Continuous fatty acid oxidation and reduced fat storage in mice lacking acetyl-CoA carboxylase 2. Science 291: 2613-2616

60 Rider MH, Bertrand L, Vertommen D, Michels PA, Rousseau GG and Hue L 2004 6-phosphofructo-2kinase/fructose-2,6-bisphosphatase: head-to-head with a bifunctional enzyme that controls glycolysis. Biochem J 381: 561-579

61 Depre C, Rider MH and Hue L 1998 Mechanisms of control of heart glycolysis. Eur J Biochem 258: 277-290

62 Musi N, Fujii N, Hirshman MF, Ekberg I, Froberg S, Ljungqvist O, Thorell A and Goodyear LJ 2001 AMP-activated protein kinase (AMPK) is activated in muscle of subjects with type 2 diabetes during exercise. Diabetes 50: 921-927 
63 Roepstorff C, Donsmark M, Thiele M, Vistisen B, Stewart G, Vissing K, Schjerling P, Hardie DG, Galbo H and Kiens B 2006 Sex differences in hormone-sensitive lipase expression, activity, and phosphorylation in skeletal muscle at rest and during exercise. Am J Physiol Endocrinol Metab 291: E1106-1114

64 Coven DL, Hu X, Cong L, Bergeron R, Shulman GI, Hardie DG and Young LH 2003 Physiological role of AMP-activated protein kinase in the heart: graded activation during exercise. Am J Physiol Endocrinol Metab 285: E629-636

65 Hawley SA, Boudeau J, Reid JL, Mustard KJ, Udd L, Makela TP, Alessi DR and Hardie DG 2003 Complexes between the LKB1 tumor suppressor, STRAD alpha/beta and MO25 alpha/beta are upstream kinases in the AMP-activated protein kinase cascade. $J$ Biol 2: 28

66 Hurley RL, Anderson KA, Franzone JM, Kemp BE, Means AR and Witters LA 2005 The $\mathrm{Ca} 2+/$ calmodulin-dependent protein kinase kinases are AMP-activated protein kinase kinases. $J$ Biol Chem 280: 29060-29066

67 Woods A, Vertommen D, Neumann D, Turk R, Bayliss J, Schlattner U, Wallimann T, Carling D and Rider MH 2003 Identification of phosphorylation sites in AMP-activated protein kinase (AMPK) for upstream AMPK kinases and study of their roles by site-directed mutagenesis. J Biol Chem 278: 2843428442

68 Hawley SA, Pan DA, Mustard KJ, Ross L, Bain J, Edelman AM, Frenguelli BG and Hardie DG 2005 Calmodulin-dependent protein kinase kinase-beta is an alternative upstream kinase for AMP-activated protein kinase. Cell Metab 2: 9-19

69 Jensen TE, Rose AJ, Jorgensen SB, Brandt N, Schjerling P, Wojtaszewski JF and Richter EA 2007 Possible CaMKK-dependent regulation of AMPK phosphorylation and glucose uptake at the onset of mild tetanic skeletal muscle contraction. Am J Physiol Endocrinol Metab 292: E1308-1317

70 Luiken JJ, Vertommen D, Coort SL, Habets DD, El Hasnaoui M, Pelsers MM, Viollet B, Bonen A, Hue L, Rider MH and Glatz JF 2008 Identification of protein kinase D as a novel contraction-activated kinase linked to GLUT4-mediated glucose uptake, independent of AMPK. Cell Signal 20: 543-556

71 Sakamoto K, Goransson O, Hardie DG and Alessi DR 2004 Activity of LKB1 and AMPK-related kinases in skeletal muscle: effects of contraction, phenformin, and AICAR. Am J Physiol Endocrinol Metab 287: E310-317

72 Sakamoto K, McCarthy A, Smith D, Green KA, Grahame Hardie D, Ashworth A and Alessi DR 2005 Deficiency of LKB1 in skeletal muscle prevents AMPK activation and glucose uptake during contraction. Embo J 24: 1810-1820

73 Rozengurt E, Sinnett-Smith J, Van Lint J and Valverde AM 1995 Protein kinase D (PKD): a novel target for diacylglycerol and phorbol esters. Mutat Res 333: 153-160

74 Cortassa S, Aon MA, Winslow RL and O'Rourke B 2004 A mitochondrial oscillator dependent on reactive oxygen species. Biophys $J$ 87: 2060-2073

75 Katz A 2007 Modulation of glucose transport in skeletal muscle by reactive oxygen species. $J$ Appl Physiol 102: 1671-1676

76 Storz P, Doppler H, Johannes FJ and Toker A 2003 Tyrosine phosphorylation of protein kinase D in the pleckstrin homology domain leads to activation. J Biol Chem 278: 17969-17976

77 Derave W, Straumann N, Olek RA and Hespel P 2006 Electrolysis stimulates creatine transport and transporter cell surface expression in incubated mouse skeletal muscle: potential role of ROS. $\mathrm{Am} \mathrm{J}$ Physiol Endocrinol Metab 291: E1250-1257

78 Higaki Y, Hirshman MF, Fujii N and Goodyear LJ 2001 Nitric oxide increases glucose uptake through a mechanism that is distinct from the insulin and contraction pathways in rat skeletal muscle. Diabetes 50: 241-247

79 Sandstrom ME, Zhang SJ, Bruton J, Silva JP, Reid MB, Westerblad H and Katz A 2006 Role of reactive oxygen species in contraction-mediated glucose transport in mouse skeletal muscle. J Physiol 575: 251262

80 Cuello F, Bardswell SC, Haworth RS, Yin X, Lutz S, Wieland T, Mayr M, Kentish JC and Avkiran M 2007 Protein kinase D selectively targets cardiac troponin I and regulates myofilament $\mathrm{Ca} 2+$ sensitivity in ventricular myocytes. Circ Res 100: 864-873 
81 Haworth RS, Cuello F, Herron TJ, Franzen G, Kentish JC, Gautel M and Avkiran M 2004 Protein kinase $\mathrm{D}$ is a novel mediator of cardiac troponin I phosphorylation and regulates myofilament function. Circ Res 95: 1091-1099

82 Schaub MC and Kunz B 1986 Regulation of contraction in cardiac and smooth muscles. J Cardiovasc Pharmacol 8 Suppl 8: S117-123

83 Layland J, Solaro RJ and Shah AM 2005 Regulation of cardiac contractile function by troponin I phosphorylation. Cardiovasc Res 66: 12-21

84 Glatz JF, Bonen A, Ouwens DM and Luiken JJ 2006 Regulation of sarcolemmal transport of substrates in the healthy and diseased heart. Cardiovasc Drugs Ther 20: 471-476

85 Ouwens DM, Diamant M, Fodor M, Habets DD, Pelsers MM, El Hasnaoui M, Dang ZC, van den Brom CE, Vlasblom R, Rietdijk A, Boer C, Coort SL, Glatz JF and Luiken JJ 2007 Cardiac contractile dysfunction in insulin-resistant rats fed a high-fat diet is associated with elevated CD36-mediated fatty acid uptake and esterification. Diabetologia 50: 1938-1948

86 Rose AJ and Richter EA 2005 Skeletal muscle glucose uptake during exercise: how is it regulated? Physiology (Bethesda) 20: 260-270

87 Hardie DG, Hawley SA and Scott JW 2006 AMP-activated protein kinase--development of the energy sensor concept. $J$ Physiol 574: 7-15

88 Hawley SA, Selbert MA, Goldstein EG, Edelman AM, Carling D and Hardie DG 1995 5'-AMP activates the AMP-activated protein kinase cascade, and $\mathrm{Ca} 2+$ /calmodulin activates the calmodulin-dependent protein kinase I cascade, via three independent mechanisms. J Biol Chem 270: 27186-27191

89 Momcilovic M, Hong SP and Carlson M 2006 Mammalian TAK1 activates Snf1 protein kinase in yeast and phosphorylates AMP-activated protein kinase in vitro. J Biol Chem 281: 25336-25343

90 Fujii N, Hirshman MF, Kane EM, Ho RC, Peter LE, Seifert MM and Goodyear LJ 2005 AMP-activated protein kinase alpha2 activity is not essential for contraction- and hyperosmolarity-induced glucose transport in skeletal muscle. J Biol Chem 280: 39033-39041

91 Jorgensen SB, Viollet B, Andreelli F, Frosig C, Birk JB, Schjerling P, Vaulont S, Richter EA and Wojtaszewski JF 2004 Knockout of the alpha2 but not alpha1 5'-AMP-activated protein kinase isoform abolishes 5-aminoimidazole-4-carboxamide-1-beta-4-ribofuranosidebut not contraction-induced glucose uptake in skeletal muscle. J Biol Chem 279: 1070-1079

92 Mu J, Brozinick JT, Jr., Valladares O, Bucan M and Birnbaum MJ 2001 A role for AMP-activated protein kinase in contraction- and hypoxia-regulated glucose transport in skeletal muscle. Mol Cell 7: 1085-1094

93 Witczak CA, Fujii N, Hirshman MF and Goodyear LJ 2007 Ca2+/calmodulin-dependent protein kinase kinase-alpha regulates skeletal muscle glucose uptake independent of AMP-activated protein kinase and Akt activation. Diabetes 56: 1403-1409

94 Thomson DM, Brown JD, Fillmore N, Condon BM, Kim HJ, Barrow JR and Winder WW 2007 LKB1 and the Regulation of Malonyl-CoA and Fatty Acid Oxidation in Muscle. Am J Physiol Endocrinol Metab

95 Kramer HF, Witczak CA, Taylor EB, Fujii N, Hirshman MF and Goodyear LJ 2006 AS160 regulates insulin- and contraction-stimulated glucose uptake in mouse skeletal muscle. J Biol Chem 281: 31478 31485

96 Dugani CB and Klip A 2005 Glucose transporter 4: cycling, compartments and controversies. EMBO Rep 6: 1137-1142

97 Montessuit C, Papageorgiou I and Lerch R 2008 Nuclear receptor agonists improve insulin responsiveness in cultured cardiomyocytes through enhanced signaling and preserved cytoskeletal architecture. Endocrinology 149: 1064-1074

98 Kramer HF, Witczak CA, Fujii N, Jessen N, Taylor EB, Arnolds DE, Sakamoto K, Hirshman MF and Goodyear LJ 2006 Distinct signals regulate AS160 phosphorylation in response to insulin, AICAR, and contraction in mouse skeletal muscle. Diabetes 55: 2067-2076

99 Chen HC, Bandyopadhyay G, Sajan MP, Kanoh Y, Standaert M, Farese RV, Jr. and Farese RV 2002 Activation of the ERK pathway and atypical protein kinase $\mathrm{C}$ isoforms in exercise- and aminoimidazole4-carboxamide-1-beta-D-riboside (AICAR)-stimulated glucose transport. J Biol Chem 277: 2355423562 
100 Braiman L, Alt A, Kuroki T, Ohba M, Bak A, Tennenbaum T and Sampson SR 2001 Activation of protein kinase $\mathrm{C}$ zeta induces serine phosphorylation of VAMP2 in the GLUT4 compartment and increases glucose transport in skeletal muscle. Mol Cell Biol 21: 7852-7861

101 Standaert ML, Bandyopadhyay G, Perez L, Price D, Galloway L, Poklepovic A, Sajan MP, Cenni V, Sirri A, Moscat J, Toker A and Farese RV 1999 Insulin activates protein kinases C-zeta and C-lambda by an autophosphorylation-dependent mechanism and stimulates their translocation to GLUT4 vesicles and other membrane fractions in rat adipocytes. J Biol Chem 274: 25308-25316

102 Fielitz J, Kim MS, Shelton JM, Qi X, Hill JA, Richardson JA, Bassel-Duby R and Olson EN 2008 Requirement of protein kinase D1 for pathological cardiac remodeling. Proc Natl Acad Sci U S A 105: 3059-3063

103 Saltiel AR and Pessin JE 2002 Insulin signaling pathways in time and space. Trends Cell Biol 12: 65-71

104 Del Vecchio RL and Pilch PF 1991 Phosphatidylinositol 4-kinase is a component of glucose transporter (GLUT 4)-containing vesicles. J Biol Chem 266: 13278-13283

105 Kristiansen S, Ramlal T and Klip A 1998 Phosphatidylinositol 4-kinase, but not phosphatidylinositol 3kinase, is present in GLUT4-containing vesicles isolated from rat skeletal muscle. Biochem J 335: 351 356

106 Hausser A, Storz P, Martens S, Link G, Toker A and Pfizenmaier K 2005 Protein kinase D regulates vesicular transport by phosphorylating and activating phosphatidylinositol-4 kinase IIIbeta at the Golgi complex. Nat Cell Biol 7: 880-886

107 Sriwijitkamol A, Coletta DK, Wajcberg E, Balbontin GB, Reyna SM, Barrientes J, Eagan PA, Jenkinson CP, Cersosimo E, DeFronzo RA, Sakamoto K and Musi N 2007 Effect of acute exercise on AMPK signaling in skeletal muscle of subjects with type 2 diabetes: a time-course and dose-response study. Diabetes 56: 836-848

108 Hardie DG 2008 Role of AMP-activated protein kinase in the metabolic syndrome and in heart disease. FEBS Lett 582: 81-89

109 Musi N and Goodyear LJ 2006 Insulin resistance and improvements in signal transduction. Endocrine 29: 73-80

110 Park TS, Yamashita H, Blaner WS and Goldberg IJ 2007 Lipids in the heart: a source of fuel and a source of toxins. Curr Opin Lipidol 18: 277-282

111 Iglesias MA, Furler SM, Cooney GJ, Kraegen EW and Ye JM 2004 AMP-activated protein kinase activation by AICAR increases both muscle fatty acid and glucose uptake in white muscle of insulinresistant rats in vivo. Diabetes 53: 1649-1654

112 Krook A, Wallberg-Henriksson H and Zierath JR 2004 Sending the signal: molecular mechanisms regulating glucose uptake. Med Sci Sports Exerc 36: 1212-1217

113 Belke DD, Larsen TS, Gibbs EM and Severson DL 2000 Altered metabolism causes cardiac dysfunction in perfused hearts from diabetic (db/db) mice. Am J Physiol Endocrinol Metab 279: E1104-1113

114 Goransson O, McBride A, Hawley SA, Ross FA, Shpiro N, Foretz M, Viollet B, Hardie DG and Sakamoto K 2007 Mechanism of action of A-769662, a valuable tool for activation of AMP-activated protein kinase. J Biol Chem 282: 32549-32560

115 Sanders MJ, Ali ZS, Hegarty BD, Heath R, Snowden MA and Carling D 2007 Defining the mechanism of activation of AMP-activated protein kinase by the small molecule A-769662, a member of the thienopyridone family. J Biol Chem 282: 32539-32548

116 Cool B, Zinker B, Chiou W, Kifle L, Cao N, Perham M, Dickinson R, Adler A, Gagne G, Iyengar R, Zhao G, Marsh K, Kym P, Jung P, Camp HS and Frevert E 2006 Identification and characterization of a small molecule AMPK activator that treats key components of type 2 diabetes and the metabolic syndrome. Cell Metab 3: 403-416

117 An D and Rodrigues B 2006 Role of changes in cardiac metabolism in development of diabetic cardiomyopathy. Am J Physiol Heart Circ Physiol 291: H1489-1506

118 Christoffersen C, Bollano E, Lindegaard ML, Bartels ED, Goetze JP, Andersen CB and Nielsen LB 2003 Cardiac lipid accumulation associated with diastolic dysfunction in obese mice. Endocrinology 144: 3483-3490 
119 Coort SL, Luiken JJ, van der Vusse GJ, Bonen A and Glatz JF 2004 Increased FAT (fatty acid translocase)/CD36-mediated long-chain fatty acid uptake in cardiac myocytes from obese Zucker rats. Biochem Soc Trans 32: 83-85

120 Carley AN, Atkinson LL, Bonen A, Harper ME, Kunnathu S, Lopaschuk GD and Severson DL 2007 Mechanisms responsible for enhanced fatty acid utilization by perfused hearts from type 2 diabetic $\mathrm{db} / \mathrm{db}$ mice. Arch Physiol Biochem 113: 65-75

121 Bonen A, Parolin ML, Steinberg GR, Calles-Escandon J, Tandon NN, Glatz JF, Luiken JJ, Heigenhauser GJ and Dyck DJ 2004 Triacylglycerol accumulation in human obesity and type 2 diabetes is associated with increased rates of skeletal muscle fatty acid transport and increased sarcolemmal FAT/CD36. Faseb J 18: 1144-1146

122 Yang J, Sambandam N, Han X, Gross RW, Courtois M, Kovacs A, Febbraio M, Finck BN and Kelly DP 2007 CD36 deficiency rescues lipotoxic cardiomyopathy. Circ Res 100: 1208-1217

123 Koonen DP, Febbraio M, Bonnet S, Nagendran J, Young ME, Michelakis ED and Dyck JR 2007 CD36 expression contributes to age-induced cardiomyopathy in mice. Circulation 116: 2139-2147

124 Rac ME, Safranow K and Poncyljusz W 2007 Molecular basis of human CD36 gene mutations. Mol Med 13: 288-296

125 Cushman SW, Goodyear LJ, Pilch PF, Ralston E, Galbo H, Ploug T, Kristiansen S and Klip A 1998 Molecular mechanisms involved in GLUT4 translocation in muscle during insulin and contraction stimulation. Adv Exp Med Biol 441: 63-71

126 Wu G, Yussman MG, Barrett TJ, Hahn HS, Osinska H, Hilliard GM, Wang X, Toyokawa T, Yatani A, Lynch RA, Robbins J and Dorn GW, 2nd 2001 Increased myocardial Rab GTPase expression: a consequence and cause of cardiomyopathy. Circ Res 89: 1130-1137

127 Chabowski A, Gorski J, Luiken JJ, Glatz JF and Bonen A 2007 Evidence for concerted action of FAT/CD36 and FABPpm to increase fatty acid transport across the plasma membrane. Prostaglandins Leukot Essent Fatty Acids 77: 345-353

128 Pohl J, Fitscher BA, Ring A, Ihl-Vahl R, Strasser RH and Stremmel W 2000 Fatty acid transporters in plasma membranes of cardiomyocytes in patients with dilated cardiomyopathy. Eur J Med Res 5: 438442

129 Gimeno RE, Ortegon AM, Patel S, Punreddy S, Ge P, Sun Y, Lodish HF and Stahl A 2003 Characterization of a heart-specific fatty acid transport protein. J Biol Chem 278: 16039-16044

130 Vistisen B, Roepstorff K, Roepstorff C, Bonen A, van Deurs B and Kiens B 2004 Sarcolemmal FAT/CD36 in human skeletal muscle colocalizes with caveolin-3 and is more abundant in type 1 than in type 2 fibers. J Lipid Res 45: 603-609

131 Pohl J, Ring A, Ehehalt R, Herrmann T and Stremmel W 2004 New concepts of cellular fatty acid uptake: role of fatty acid transport proteins and of caveolae. Proc Nutr Soc 63: 259-262

132 Pohl J, Ring A, Ehehalt R, Schulze-Bergkamen H, Schad A, Verkade P and Stremmel W 2004 Longchain fatty acid uptake into adipocytes depends on lipid raft function. Biochemistry 43: 4179-4187

133 Pohl J, Ring A, Korkmaz U, Ehehalt R and Stremmel W 2005 FAT/CD36-mediated long-chain fatty acid uptake in adipocytes requires plasma membrane rafts. Mol Biol Cell 16: 24-31

134 Feron O, Zhao YY and Kelly RA 1999 The ins and outs of caveolar signaling. m2 muscarinic cholinergic receptors and eNOS activation versus neuregulin and ErbB4 signaling in cardiac myocytes. Ann N Y Acad Sci 874: 11-19.

135 Tao N, Wagner SJ and Lublin DM 1996 CD36 is palmitoylated on both N- and C-terminal cytoplasmic tails. J Biol Chem 271: 22315-22320.

136 Luiken JJ, Momken I, Habets DD, El Hasnaoui M, Coumans WA, Koonen DP, Glatz JF and Bonen A 2006 Arsenite modulates cardiac substrate preference by translocation of GLUT4, but not CD36, independent of mitogen-activated protein kinase signaling. Endocrinology 147: 5205-5216 